\title{
Cytoplasmic dynein-1 cargo diversity is mediated by the combinatorial assembly of FTS-Hook-FHIP complexes
}

\author{
Jenna R. Christensen ${ }^{1^{*}}$, Agnieszka A. Kendrick ${ }^{1^{*}}$, Joey B. Truong ${ }^{1}$, Adriana Aguilar-Maldonado ${ }^{1}$, Vinit \\ Adani $^{1}$, Monika Dzieciatkowska ${ }^{2}$, and Samara L. Reck-Peterson ${ }^{1,3,4 \#}$ \\ ${ }^{1}$ Department of Cellular and Molecular Medicine, University of California, San Diego, La Jolla, CA 92093 \\ ${ }^{2}$ Department of Biochemistry and Molecular Genetics, University of Colorado Denver, Aurora, CO 80045 \\ ${ }^{3}$ Division of Biological Sciences, Cell and Developmental Biology Section, University of California, San Diego, La Jolla, CA \\ 92093 \\ ${ }^{4}$ Howard Hughes Medical Institute, Chevy Chase, MD 20815 \\ * These authors contributed equally \\ \# Correspondence: sreckpeterson@health.ucsd.edu, 9500 Gilman Drive, mail code 0694, University of California San Diego, \\ La Jolla, CA 92093, (858) 246-1265
}

\begin{abstract}
In eukaryotic cells, intracellular components are organized by the microtubule motors cytoplasmic dynein-1 (dynein) and kinesins, which are linked to cargos via adaptor proteins. While 40 kinesins transport cargo toward the plus end of microtubules, a single dynein moves cargo in the opposite direction. How dynein transports a wide variety of cargos remains an open question. The FTSHook-FHIP ("FHF") cargo adaptor complex links dynein to cargo in mammals and fungi. As human cells have three Hooks and four FHIP proteins, we hypothesized that the combinatorial assembly of different Hook and FHIP proteins could underlie dynein cargo diversity. Using proteomic approaches, we determine the protein 'interactome' of each FHIP protein. Live-cell imaging and biochemical approaches show that different FHF complexes associate with distinct motile cargos. These complexes also move with dynein and its cofactor dynactin in single-molecule in vitro reconstitution assays. Complexes composed of FTS, FHIP1B, and Hook1/Hook3 co-localize with Rab5-tagged early endosomes via a direct interaction between FHIP1B and GTP-bound Rab5. In contrast, complexes composed of FTS, FHIP2A and Hook2 colocalize with Rab1A-tagged ER-to-Golgi cargos and FHIP2A is involved in the motility of Rab1A tubules. Our findings suggest that combinatorial assembly of different FTS-Hook-FHIP complexes is one mechanism dynein uses to achieve cargo specificity.
\end{abstract}

Keywords: dynein, cargo adaptors, FHF complex

\section{Introduction}

Proper positioning of intracellular material in space and time is crucial for many cellular processes including cell division, cell signaling, and vesicle trafficking (Burute and Kapitein, 2019). Long distance transport occurs primarily on polarized microtubule tracks by the motors, dynein and kinesin. While kinesin motors transport cargo predominantly towards the 'plus' end of microtubules, cytoplasmic dynein-1 ("dynein" here) transports cargo towards the 'minus' end of microtubules. In mammalian cells, kinesin and dynein are responsible for transporting many diverse cargos including membrane-bound organelles, mRNAs, and protein complexes (Hirokawa et al., 2009; Reck-Peterson et al., 2018). The expansion of the kinesin family of motors within the animal kingdom itself reflects this necessity-the presence of many distinct motors promotes the specialized delivery of many different cargos (Kollmar and Mühlhausen, 2017; Miki et al., 2005; Welburn, 2013). Similarly, dynein adaptors have expanded in animal cells. In many organisms, processive dynein motility requires the dynactin complex and a coiled-coil activating adaptor (McKenney et al., 2014; Schlager et al., 2014a). There are $\sim 20$ known or candidate activating adaptors in human cells, several of which have been implicated in linking dynein to different cargos (Reck-Peterson et al., 2018; Wang et al., 2019). However, how activating adaptors link dynein to its cargo is only known in a few cases (Hoogenraad et al., 2001; Matanis et al., 2002; Schlager et al., 2010). The Hook family of activating adaptors is one of the most conserved families of dynein adaptors. Hook proteins make up one component of the "FHF" complex consisting of FTS/AKTIP ("FTS" here), Hook, and FHIP (FHF complex subunit Hook Interacting Protein) (Figure 1A).

The FHF complex has been implicated in linking dynein to cargo in the filamentous fungus Aspergillus nidulans and human cells (Bielska et al., 2014; Guo et al., 2016; Mattera et al., 2020; Xu et al., 2008; Yao et al., 2014; Zhang et al., 2014). A. nidulans has one FTS (FtsA), one Hook (HookA), and one FHIP (FhipA), which together link dynein to early endosomes (Yao et al., 2014). Both the A. nidulans HookA and FtsA proteins require FhipA to associate with early endosomes (Yao et al., 2014), suggesting that the FHIP protein mediates cargo recognition and binding. FTS is a member of the family of inactive E2 ubiquitin-conjugating enzyme variants with varying biological functions (Xu et al. 2008), whose role in the FHF complex remains unclear. Human cells have one FTS, three Hooks (Hook1, Hook2, Hook3), and four FHIPs (FHIP1A, FHIP1B, FHIP2A, FHIP2B) (Figure 1B). We hypothesize that gene expansion and functional divergence of the Hook and FHIP families of proteins may result in the formation of different FHF complexes, allowing dynein to bind multiple cargos in human cells.

The exact composition of the FHF complex and whether multiple distinct FHF complexes form remains unclear. FHIP1A (also known as FHIP-L and FAM160A1) and FHIP1B (also known as FHIP, p107 ${ }^{\mathrm{FHIP}}$, and FAM160A2) are the most well-characterized FHIP proteins. The initially described "FHF" complex was identified by immunoprecipitation-mass spectrometry of FTS in HeLa cells (Xu et al., 2008), and was found to contain FHIP1B, FTS, Hook1, Hook2, and 
bioRxiv preprint doi: https://doi.org/10.1101/2021.10.07.463551; this version posted October 8, 2021. The copyright holder for this preprint (which was not certified by peer review) is the author/funder, who has granted bioRxiv a license to display the preprint in perpetuity. It is made available under aCC-BY-NC-ND 4.0 International license.

Christensen, Kendrick et al., 10/06/2021

Hook3. Further studies confirmed a similar FHF complex composition (Guo et al., 2016) and found that FHIP1A binds FTS (Mattera et al., 2020), suggesting that it may also be an FHF complex component. However, very little is known about FHIP2A (also known as FAM160B1) and FHIP2B (also FAM160B2), and whether they also associate with FTS and/or Hook proteins. FHIP2A and FHIP2B were identified in Hook1 and Hook3 in proteomic datasets previously generated in our lab (Redwine et al., 2017), suggesting they may also be FHF complex components.

Several studies have provided insight into the cellular roles of the FHF complex. In Aspergillus nidulans, the sole FHF complex links dynein to early endosomes (Yao et al., 2014). In human cells, the only characterized FHF complex (FTS, Hook1/2/3, FHIP1B) has several proposed functions. This FHF complex has been shown to associate with homotypic fusion and protein sorting (HOPS) complex components and may be involved in late endosome/lysosome clustering and epidermal growth factor trafficking (Xu et al., 2008). In rat hippocampal neurons, an FHF complex of similar composition has been demonstrated to bind Rab5A and is involved in the retrograde axonal transport of transferrin receptor (Guo et al., 2016). Finally, a similar FHF complex has also been demonstrated to link dynein to the AP-4 adaptor complex (Mattera et al., 2020). However, very little is known about the roles of FHIP2A and FHIP2B, whether they are associated with distinct FHF complexes, and whether they are also involved in linking dynein to specific intracellular cargos.

Here we use the FHF complex as a model cargo adaptor system to understand how dynein achieves cargo specificity. We identify and characterize the different FHF complexes using proximity-dependent biotinylation, mass spectrometry, and immunoprecipitations, and show in single-molecule motility assays using purified components that moving dynein/dynactin complexes associate with different FHF complexes. We also show that in cells FHF complexes containing Hook1 and/or Hook3 and FHIP1B associate with Rab5B-endosomes, while complexes containing Hook2 and FHIP2A associate with Rab1A-tagged ER-to-Golgi cargos. Furthermore, FHIP1B and FHIP2A are important for the formation and movement of their corresponding cargos. Taken together, our data provides a mechanistic understanding of how a single dynein complex transports numerous cellular components.

\section{Results}

\section{FHIP BioID protein interactomes}

To elucidate the cellular roles of the FHIP proteins, we first identified the 'interactome' of each FHIP in 293 T cells. To do this, we used a proximity biotinylation (BioID) approach in which the carboxy-terminus of each of the four FHIP proteins was tagged with a promiscuous biotin ligase BioID2 (Kim et al., 2016; Redwine et al., 2017; Roux et al., 2012). We then generated stable doxycycline-inducible 293T cell lines expressing each BioID2-tagged protein or cytoplasmic BioID2 control (Figure $1-$ figure supplement 1A). For each BioID experiment, we grew the FHIPBioID2-expressing cell line in doxycycline and biotin-containing media for 16 hours. We then collected cells and performed a streptavidin immunoprecipitation of the biotinylated proteins and identified protein interactomes via mass spectrometry. Significant protein 'hits' were determined using a label-free proteomics approach by comparison to the cytoplasmic BioID2 control (Redwine et al., 2017; Zhang et al., 2010). Proteins present in 3 out of 4 technical replicates, with 3-fold enrichment over the BioID2 control or not present in the BioID2 control, and with pvalue of less than 0.05 were considered significant.

Comparative analysis of the significant hits in each FHIP BioID dataset showed some overlapping hits between the different FHIP proteins, as well as numerous unique hits present in each FHIP dataset
(Figure 1C, Figure 1 - figure supplement 1B, Supplementary File 1). Certain components of the FHF complex (Hook1, Hook3, and FTS) were present in all four FHIP datasets (Figure 1C), consistent with our lab's previous Hook1 and Hook3 BioID datasets (Redwine et al., 2017) and previous reports for FHIP1A and FHIP1B protein interactions (Mattera et al., 2020; Xu et al., 2008). Gene ontology (GO) analysis of significant hits in each FHIP dataset showed that different FHIP datasets had an enrichment of diverse cellular processes, functions, and components (Figure 1C, Supplementary File 2, (Eden et al., 2009, 2007). For example, endosome-associated proteins were enriched in the FHIP1A and FHIP1B datasets (Figure 1C - blue circles), consistent with their previouslyidentified endosomal functions (Guo et al., 2016; Xu et al., 2008; Yao et al., 2014). FHIP1B was previously proposed to interact with Rab5 (Guo et al., 2016) and HOPS complex components (Xu et al., 2008). Though we identified Rab5B as a significant hit in the FHIP1B dataset, we found no HOPS complex components in any of our FHIP datasets.

In contrast, the interactomes of FHIP2A and FHIP2B were highly enriched for Golgi-associated proteins (Figure 1C-green circles). Additionally, multiple proteins involved in endosome-to-trans-Golgi network (TGN) transport (TBC1D23, FAM91A1, GOLGA4, GOLGA5, WDR11) and endoplasmic reticulum (ER)-Golgi transport (SCFD1, SEC22B, SEC24B, BET1, BET1L, STX5, GOSR1, GOSR2) were found in either the FHIP2A or both the FHIP2A and FHIP2B datasets, but not in the FHIP1A or FHIP1B datasets. Although there was some overlap between the FHIP2A and FHIP2B datasets, we also observed a high level of enrichment for mitochondria-associated proteins specifically in FHIP2B interactome (Figure 1C - orange circles).

We also found certain cytoskeletal components enriched in the different FHIP BioID datasets. The FHIP1B dataset had multiple actomyosin-associated proteins, while the FHIP1A, FHIP2A, and FHIP2B datasets had many kinesin hits (Figure 1 - figure supplement 1C). Taken together, our BioID data show that different FHIP proteins associate with diverse cellular interactomes, suggesting that these proteins may link to different cellular cargos.

\section{Different FHIP proteins interact with different Hooks}

The FHIP BioID datasets demonstrate that the FHIP proteins associate with different Hook proteins. Only Hook1 and Hook3 are present in the FHIP1A and FHIP1B BioID datasets, while all three Hooks are present in the FHIP2A and FHIP2B datasets (Figure 1C, Figure 2A). Our lab previously performed BioID experiments for Hook1 and Hook3 and all four FHIPs were present as significant hits in those datasets (Redwine et al., 2017). We performed a similar BioID experiment for Hook2 and found only FHIP2A and FHIP2B in the Hook2 BioID dataset (Figure 2A, Supplementary File 1). We confirmed these BioID findings by coimmunoprecipitations and western blotting. Our co-immunoprecipitation experiments suggest the formation of several different FHF complexes (Figure 2C). The first FHF complex is similar to the complex described previously (Guo et al., 2016; Mattera et al., 2020; Xu et al., 2008) and consists of FHIP1A/FHIP1B and Hook1/3. Supporting this, 3XFLAGtagged FHIP1A and FHIP1B expressed in 293T cells coimmunoprecipitated Hook1 and Hook3, but not Hook2 (Figure 2B). In the converse experiment, Hook1 and Hook3 correspondingly coimmunoprecipitated FHIP1B (Figure 2 - figure supplement 1A). We were unable to test which Hooks co-immunoprecipitate with FHIP1A as none of the commercially available antibodies worked well in western blots.

Our data also suggest the formation of a second FHF complex consisting of FHIP2A and Hook2. 3XFLAG-tagged FHIP2A coimmunoprecipitated Hook2 and Hook3, with FHIP2A coimmunoprecipitating Hook2 to a much greater extent than Hook3 (Figure 
bioRxiv preprint doi: https://doi.org/10.1101/2021.10.07.463551; this version posted October 8, 2021. The copyright holder for this preprint (which was not certified by peer review) is the author/funder, who has granted bioRxiv a license to display the preprint in perpetuity. It is made available under aCC-BY-NC-ND 4.0 International license.

Christensen, Kendrick et al., 10/06/2021
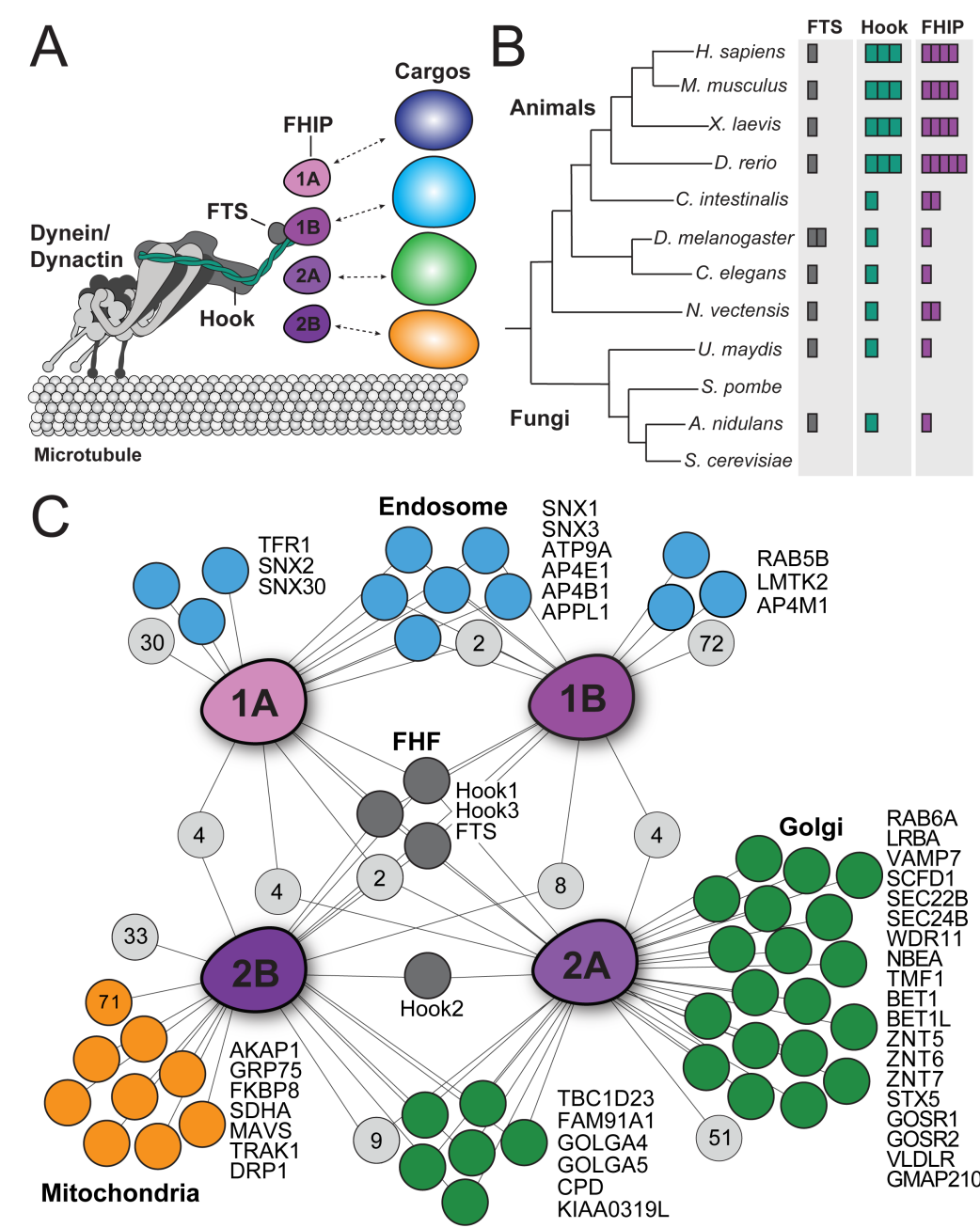

Figure 1. Proximity biotinylation reveals different FHIP protein interactomes.

(A) Schematic of the dynein complex and interactions with potential cargo adaptor complexes. (B) Phylogenetic tree showing the number of FTS (gray), Hook (green) and FHIP (purple) protein homologs present in each animal or fungal species listed. Each colored box denotes a putative homolog identified by reciprocal protein BLAST search. H. sapiens, Homo sapiens; $M$. musculus, Mus musculus; X. laevis, Xenopus laevis; D. rerio, Danio rerio; C. intestinalis, Ciona intestinalis; D. melanogaster, Drosophila melanogaster; C. elegans, Caenorhabditis elegans; N. vectensis, Nematostella vectensis; U. maydis, Ustilago maydis; S. pombe, Schizosaccharomyces pombe; A. nidulans, Aspergillus nidulans; S. cerevisiae, Saccharomyces cerevisiae. (C) Interaction diagram for FHIP carboxy-terminal BiolD datasets. Oblong purple shapes represent FHIP1A ('1A'), FHIP1B ('1B'), FHIP2A ('2A'), and FHIP2B ('2B') datasets. Significant protein hits present in a FHIP BiolD dataset that are known to be associated with specific organelles (based on gene ontology analysis) are indicated by colored circles connected by lines. Light gray circles with numbers inside represent the number of other significant protein hits in that dataset or combination of datasets. Significant hits displayed in the diagram showed a $\geq 3$-fold enrichment over the cytoplasmic BiolD2 control or absence in the cytoplasmic BiolD2 control, significance of $p<0.05$ by Student's two-tailed t-test, and presence in 3 out of 4 technical replicates. is an example of a double column figure.

2B). In the converse experiment, Hook2 preferentially coimmunoprecipitated FHIP2A (Figure 2 - figure supplement 1A). Finally, FHIP2B appears to associate with all three Hook proteins. Though 3XFLAG-tagged FHIP2B only co-immunoprecipitated Hook2 and Hook3 (Figure 2B), all three Hook proteins co-immunoprecipitated FHIP2B (Figure 2 - figure supplement 1A). Together, these data demonstrate the preferential formation of different FHF complexes: FHIP1A and FHIP1B form a complex with Hook1 and Hook3, while FHIP2A appears to preferentially associate with Hook2, and FHIP2B is potentially capable of forming a complex with Hook1, Hook2, and Hook3 (Figure 2C).

\section{Different FHF complexes associate with motile dynein/dynactin complexes}

Based on our BioID and co-immunoprecipitation experiments showing preferential formation of different FHF complexes (Figure 2), we next sought to determine if these FHF complexes associate with moving dynein/dynactin using in vitro reconstitution and single-molecule motility assays (Figure $3 \mathrm{~A}$ ). While Hook 2 activates organelle motility in cells (Dwivedi et al., 2019), Hook2 has not been shown to activate dynein motility in vitro. Thus, we first aimed to characterize the dynein activation properties of purified full-length Hook2. We performed in vitro motility assays with purified dynein labeled with Alexa-TMR, unlabeled dynactin and unlabeled full-length Hook2 in the presence of 

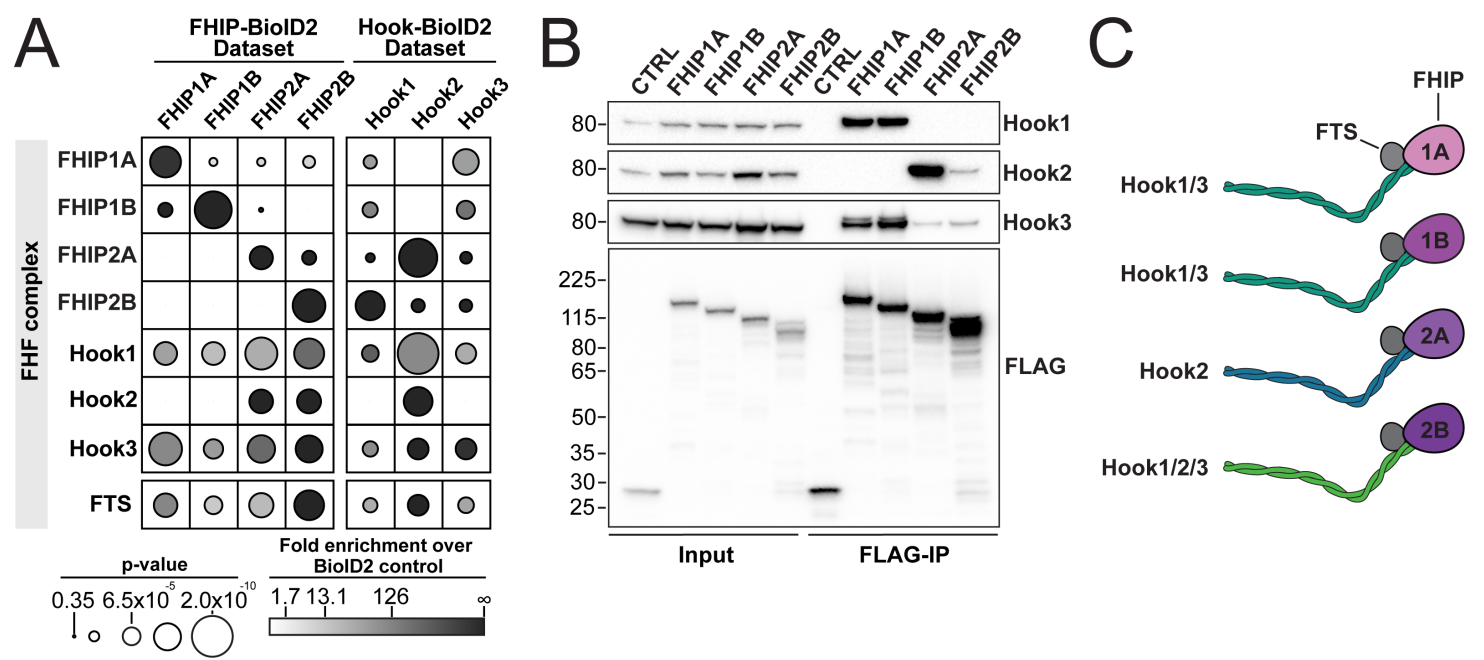

Figure 2. FHIP proteins preferentially interact with different Hook proteins to form different FHF complexes.

(A) Fold-enrichment over cytoplasmic BiolD2 control (grayscale intensity) and p-value (circle size) for FHF complex proteins identified in carboxy-terminal FHIP and carboxy-terminal Hook BiolD datasets. Hook1 and Hook3 datasets are from Redwine et al., 2017. (B) Human FHIP1A, FHIP1B, FHIP2A, and FHIP2B tagged at their carboxy termini with BioID2 and 3xFLAG were immunoprecipitated with FLAG affinity resin (FLAG-IP) from stable 293T cell lines. Immunoblots were probed with anti-Hook1, anti-Hook2, anti-Hook3, anti-p150, and anti-FLAG antibodies. Protein molecular weight markers are shown in kilo-Daltons to the left of each immunoblot. BiolD2-3xFLAG provided a control (CTRL). (C) Cartoon representation of the possible FHF complexes formed.

Lis1 (Figure 3 - figure supplement 1A). Lis1 was included in the reaction mixture to aid in the formation of activated dynein/dynactin/Hook2 complexes (Elshenawy et al., 2020; Htet et al., 2020). Purified full-length Hook 2 activated dynein/dynactin in single-molecule motility assays to a greater extent when Lis1 was present (Figure 3B - top panel), as opposed to a buffer control (Figure 3 - figure supplement $1 \mathrm{~B}$ and $\mathrm{C}$ ). Thus, we included Lis1 in all further single-molecule experiments that involved Hook2. Dynein/dynactin complexes activated by full-length Hook2 moved with a velocity comparable to complexes activated by full-length Hook3 in the presence of Lis1 (Figure 3 - figure supplement 1D - F). This shows that purified full-length Hook2 is a bona fide dynein activating adaptor.

We next determined if moving dynein/dynactin complexes can associate with different FHF complexes. We expressed and purified FTSSNAP, FHIP2A-HaloTag, and co-expressed and co-purified FTS and FHIP1B-HaloTag from insect cells. We then labeled FHIP proteins with Alexa-660 via the HaloTag to monitor the colocalization of these proteins with the moving TMR-dynein/dynactin complexes. Reconstitution of FTS, Hook2 and FHIP2A-Alexa 660, as well as FTS, Hook3, and FHIP1B-Alexa 660 complexes in the presence of TMR-labeled dynein and unlabeled dynactin (Figure 3A and Figure 3 - figure supplement 1A) led to colocalization of TMR-dynein with FHIP2A-Alexa 660 (Figure 3B - bottom panel, yellow arrows; top panel - controls) and FHIP1B-660 (Figure 3C - bottom panel, yellow arrows; top panel - controls) in singlemolecule assays. Consistent with the role of Hook proteins in simultaneous activation of dynein/dynactin complexes and linking it to FHIP/FTS, we did not observe any colocalization or motile events when Hook 2 or Hook 3 were omitted from the reaction mixtures (Figure 3 figure supplement $2 \mathrm{~A}$ and B). The colocalization of these FHF complexes with moving dynein/dynactin had no effect or only minimal effects on dynein's motile properties including velocity, landing rates, and pausing frequencies (Figure $3 \mathrm{D}-\mathrm{G}$ and Figure 3 - figure supplement $2 \mathrm{C}-\mathrm{D}$ ). Although run lengths increased slightly for FTS, Hook2, FHIP2A complexes (Figure 3 - figure supplement 2E), run lengths for FTS, Hook3, FHIP1B complexes remained unchanged (Figure 3 - figure supplement 3F). In addition, the FTS, Hook2, FHIP2A complexes colocalized with moving dynein/dynactin more frequently $(50 \%)$, as compared to the FTS, Hook3, FHIP1B complexes (20\%). These data show that the different FHF complexes activate and move with dynein/dynactin complexes and that no other proteins are required for their assembly.

As our BioID and co-immunoprecipitation data suggest that different FHIP proteins might associate with more than one Hook protein (Figure 2), we also tested if the purified FHIP proteins interact with different Hooks in single-molecule motility assays. Replacing FHIP1B with FHIP2A in the FTS/Hook2 mixture led to the appearance of very rare non-motile colocalization events (Figure 3 - figure supplement $3 \mathrm{~A}$, yellow arrows). Furthermore, replacement of FHIP2A with FHIP1B in the FTS/Hook3 mixture led to occasional colocalization between motile TMR-dynein and FHIP2A-Alexa-660, but similarly to the FTS, Hook2, FHIP2A complexes, these events were very rare. Taken together these data show that FHIP2A preferentially interacts with Hook2 and FHIP1B with Hook3 to form FHF complexes that associate with motile dynein/dynactin.

\section{FHIP1B and FHIP2A colocalize with microtubule-associated cargos with different morphologies}

Our BioID data demonstrates that FHIP proteins have different protein interactomes, which suggests they may link dynein to different cargos. For example, the FHIP1A and FHIP1B datasets have many endosomeassociated proteins, while there are many Golgi-associated proteins in the FHIP2A and FHIP2B datasets (Figure 1C). We chose to focus on FHIP1B and FHIP2A as representatives of these two groups of proteins (Figure 4A) because of their higher expression in mammalian cell lines (Thul et al., 2017, Human Protein Atlas, available from http://www.proteinatlas.org) and the availability of reliable antibodies for these proteins. We used CRISPR/Cas9 to generate FHIP1B and FHIP2A knockout cell lines (FHIP1B KO, FHIP2A KO) in human U2OS cells using two different CRISPR/Cas9-gRNAs. In each case, the appropriate FHIP was successfully knocked out without major effects on the expression of the other FHIP or the three Hook proteins (Figure 4B, Figure 4 - figure supplement 1A). We then used lentiviral expression vectors to re-introduce a fluorescently-tagged version of FHIP1B or FHIP2A (FHIP1B- or FHIP2A-TagRFP-T-V5) in the corresponding 
bioRxiv preprint doi: https://doi.org/10.1101/2021.10.07.463551; this version posted October 8, 2021. The copyright holder for this preprint (which was not certified by peer review) is the author/funder, who has granted bioRxiv a license to display the preprint in perpetuity. It is made available under aCC-BY-NC-ND 4.0 International license.

Christensen, Kendrick et al., 10/06/2021
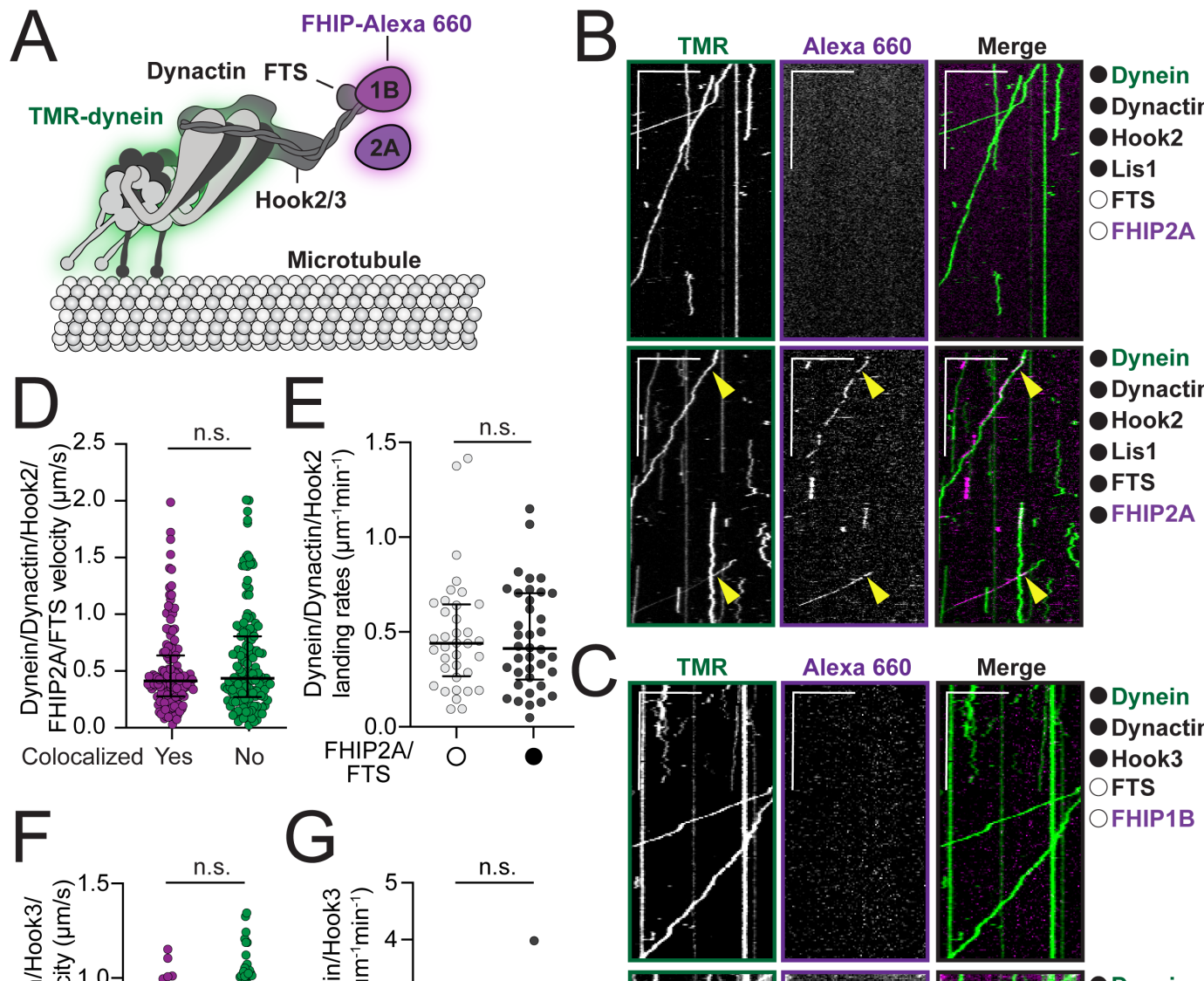

\section{- Dynein}

- Dynactin

Hook2

- Lis1

OFTS

OFHIP2A
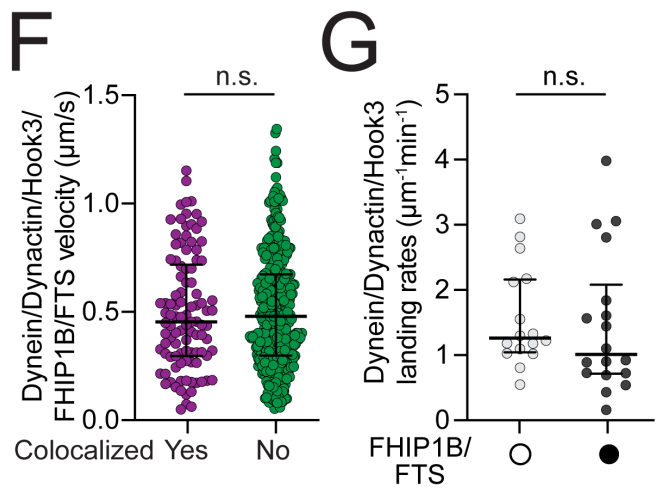

Alexa 660
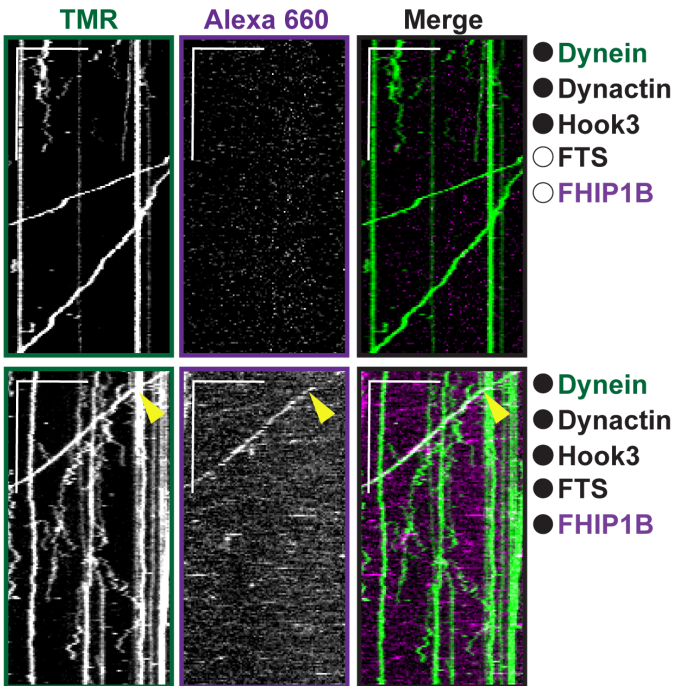

Figure 3. FHF complexes co-migrate with moving dynein/ dynactin on microtubules.

(A) Schematic of the dynein, dynactin, and FHF (FTS, Hook2 or Hook3, and FHIP1B or FHIP2A) complexes used in reconstitution experiments. Proteins labeled with fluorophores in motility assay are highlighted (dynein - green and FHIP1B and FHIP2A - magenta). (B) Representative kymographs from single-molecule motility assays with purified TMR-labeled dynein (green), unlabeled dynactin, unlabeled full-length Hook2, and unlabeled Lis1 in the absence (top panel, white circle) or presence (bottom panel, black circle) of unlabeled FTS and Alexa-660-labeled FHIP1B (magenta). Two-color colocalized runs are marked with yellow arrows on each single-channel image and in the merge. Scale bars, $10 \mu \mathrm{m}(\mathrm{x})$ and $40 \mathrm{~s}(\mathrm{y})$. (C) Representative kymographs from single-molecule motility assays with purified TMR-labeled dynein (green), unlabeled dynactin, and unlabeled full-length Hook3 in the absence (top panel, white circle) or presence (bottom panel, black circle) of unlabeled FTS and Alexa-660-labeled FHIP2A (magenta). A two-color colocalized run is marked with yellow arrows on each single-channel image and in the merge. Scale bars, $10 \mu \mathrm{m}(\mathrm{x})$ and $40 \mathrm{~s}$ (y). (D) Single-molecule velocity (median \pm interquartile range) of TMR-dynein/dynactin/Hook2 runs in the presence of Alexa-660 FHIP2A and FTS, either colocalized with FHIP2AAlexa-660 (yes, $n=140$ ) or not (no, $n=150$ ). n.s., no significance, $P=0.1193$, t-test with Welch's correction. ( $E$ ) Landing rates (median \pm interquartile range) from TMR-dynein/dynactin/Hook2 experiments performed in the absence (white circle, $n=36$ ) or in the presence of FHIP2A-Alexa-660 and FTS (black circle, $n=38$ ). n.s., no significance, $P=0.9272$, Mann-Whitney test. $(F)$ Single-molecule velocity (median \pm interquartile range) of TMRdynein/dynactin/Hook3 runs in the presence of FHIP1B-Alexa-660 and FTS, either colocalized with FHIP1B-Alexa-660 (yes, $n=102)$ or not (no, $n=430$ ). n.s., no significance, $P=0.8328$, t-test with Welch's correction. $(G)$ Landing rates (median \pm interquartile range) from TMR-dynein/dynactin/Hook3 experiments performed in the absence (white circle, $n=16$ ) or in the presence of FHIP1B-Alexa-660 and FTS (black circle, $n=18$ ). $n . s .$, no significance, $P=0.3653$, Mann-Whitney test.

knockout cell line (Figure 4C-D, Figure 4 - figure supplement 1B, Video 1). Via spinning-disk confocal imaging, fluorescently-tagged FHIP1B and FHIP2A both associated with motile cargos that move on microtubules (Figure 4E-F, Video 2). However, the morphologies of these cargos were distinct. FHIP1B associated almost exclusively with punctate structures (Figure 4C, Video 1), while FHIP2A associated with both punctate and tubular structures (Figure 4D, Video 1). These different morphologies together with our BioID results suggest that FHIP1B and FHIP2A may associate with different motile cargos. 

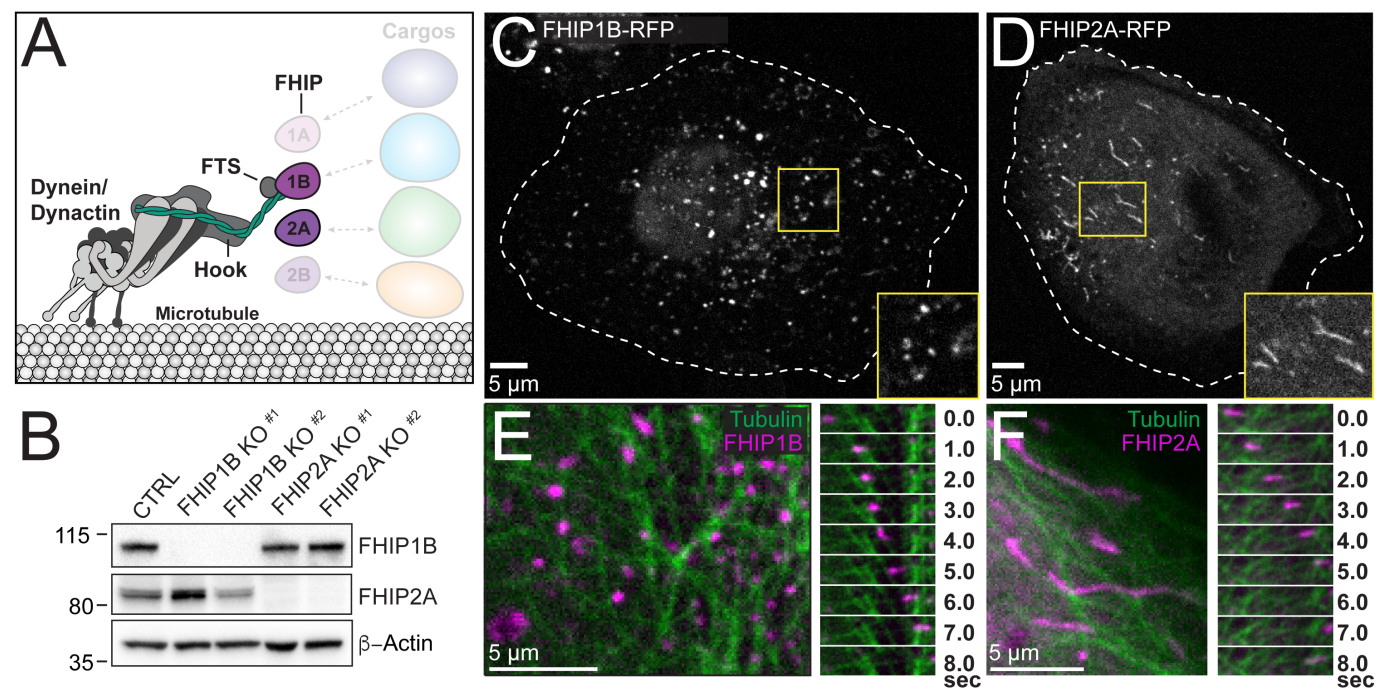

Figure 4. FHIP1B and FHIP2A localize to motile cargos with different morphologies.

(A) Schematic of FHIP proteins (FHIP1B and FHIP2A) further examined in this study. (B) U2OS cells were transfected with control CRISPR/Cas9 (CTRL) or with two different CRISPR/Cas9-gRNA specific for FHIP1B and FHIP2A. Knockouts were confirmed by immunoblotting with anti-FHIP1B and antiFHIP2A antibodies. $\beta$-actin provided a loading control. (C-D) Single-plane confocal micrograph of FHIP1B KO U2OS cells expressing FHIP1B-TagRFPT-V5 (FHIP1B-RFP) (C) or FHIP2A KO U2OS cells expressing FHIP2A-TagRFP-T-V5 (FHIP2A-RFP) (D). Yellow rectangles denote region of cropped inset. Dotted lines denote cell outline. (E-F) Single-plane confocal micrograph crop (left panels) and corresponding time-lapse montage (right panels) of FHIP1B KO U2OS cells expressing FHIP1B-TagRFP-T-V5 (FHIP1B) and mEmerald-tubulin (E) or FHIP2A KO U2OS cells expressing FHIP2A-TagRFPT-V5 (FHIP2A) and mEmerald-tubulin (F).

\section{FHIP1B associates with early endosomes via a direct interaction with GTP-bound Rab5B}

As our FHIP1B BioID dataset had many endosome-associated proteins (Figure 1C, Figure 5A), we tested whether FHIP1B was associated with early endosomes by co-expressing the early endosome marker GFPRab5B in our knockout cells expressing FHIP1B-TagRFP-T. We found that FHIP1B strongly colocalized with motile and non-motile Rab5B early endosomes via live-cell imaging (Figure 5B-C, Video 3). FHIP1B also colocalized with Rab5A via immunofluorescence (Figure 5 - figure supplement 1A). Furthermore, the overexpression of FHIP1B present in our FHIP1BKO lines expressing FHIP1B-TagRFPT resulted in an accumulation of endosomes near the centrosome (Figure 5D), suggesting that FHIP1B may link dynein to early endosomes, resulting in their transport to the minus ends of microtubules located near the centrosome. As FHIP1B associates with Hook1 and Hook3 via coimmunoprecipitation (Figure 2) and dynein/dynactin/Hook3 complexes in single-molecule motility assays (Figure 3C - bottom panel), we examined colocalization of all three Hook proteins with Rab5B. Using spinning-disk confocal imaging with triggered acquisition, we found that Hook 1 and Hook3 colocalized with Rab5B early endosomes, while Hook2 did not (Figure 5E, Video 4-6, Figure 5 - figure supplement 1B), suggesting that an FHF complex containing FHIP1B and Hook1 or Hook3 links dynein to Rab5B early endosomes.

Rab proteins are a family of small GTPases that undergo cycles of GTP binding and hydrolysis to regulate their cellular localization and function (Homma et al., 2021). GDP-bound Rabs are present in the cytosol in an inactive form, while GTP-bound Rabs associate with membranous structures and "effector" proteins that in some cases link Rabs to motors (Pylypenko et al., 2018). In mammalian cells there are 3 different Rab5 isoforms (Rab5A, Rab5B and Rab5C). FHIP1B has previously been proposed to be an effector protein for Rab5A (Guo et al., 2016). Thus, we tested if purified FHIP1B directly interacts with purified Rab5B, as Rab5B was detected in our BioID FHIP1B dataset. To do this we mixed purified Rab5B tagged at the amino-terminus with 6xHis and carboxy-terminus with SNAP-tag with purified FHIP1B in the presence of GDP or the non-hydrolyzable GTP analog GMPPNP and performed pull-down experiments with Ni-NTA beads. We found that GMPPNPbound Rab5B bound FHIP1B to a higher extent as compared to GDPbound Rab5B (Figure 5F), consistent with the hypothesis that FHIP1B binds to membrane-bound Rab5B.

We also tested if FHIP1B associates with other Rab GTPases. We expressed 13 GFP-tagged Rab proteins (Rab1A, 2, 3A, 4A, 5B, 6A, $7,8,9,10,11,14$ and 18) in $293 \mathrm{~T}$ cells and performed coimmunoprecipitation experiments in the presence of the nonhydrolyzable GTP analog, GTPyS. FHIP1B co-immunoprecipitated with Rab5B, as expected, but we did not detect an interaction with any of the 12 other Rab GTPases tested (Figure 5G). Taken together, these data show that FHIP1B is a Rab5B-specific effector.

\section{FHIP2A associates with Rab1A-bound ER-to-Golgi tubular intermediates}

Both the FHIP2A and FHIP2B BioID datasets had many protein hits corresponding to Golgi-related processes (Figure 1C). Several proteins involved in endosome-to-TGN trafficking were found in both the FHIP2A and FHIP2B BioID datasets (Figure 6 - figure supplement 1A). We therefore sought to determine whether FHIP2A was involved in endosome-to-TGN transport by expressing known GFP-tagged endosome-to-TGN transport proteins in our FHIP2A KO cells expressing FHIP2A-TagRFP-T. We found that the GFP-tagged golgin GOLGA4 colocalized with a population of FHIP2A at the Golgi apparatus (Figure 6 - figure supplement 1B). Endosome-to-TGN transport protein TBC1D23 (Shin et al., 2017) colocalized with FHIP2A at the Golgi apparatus as well, but neither GOLGA4 nor TBC1D23 colocalized with motile FHIP2A tubules (Figure 6 - figure supplement 1B), suggesting that FHIP2A was not involved in endosome-to-Golgi transport.

Many proteins known to be involved in ER-to-Golgi transport were found exclusively in the FHIP2A, but not the FHIP2B BioID dataset (Figure 6A). Therefore, we tested whether FHIP2A was associated with ER-to-Golgi transport. To do this, we expressed a GFP-tagged 
bioRxiv preprint doi: https://doi.org/10.1101/2021.10.07.463551; this version posted October 8, 2021. The copyright holder for this preprint (which was not certified by peer review) is the author/funder, who has granted bioRxiv a license to display the preprint in perpetuity. It is made available under aCC-BY-NC-ND 4.0 International license.

Christensen, Kendrick et al., 10/06/2021

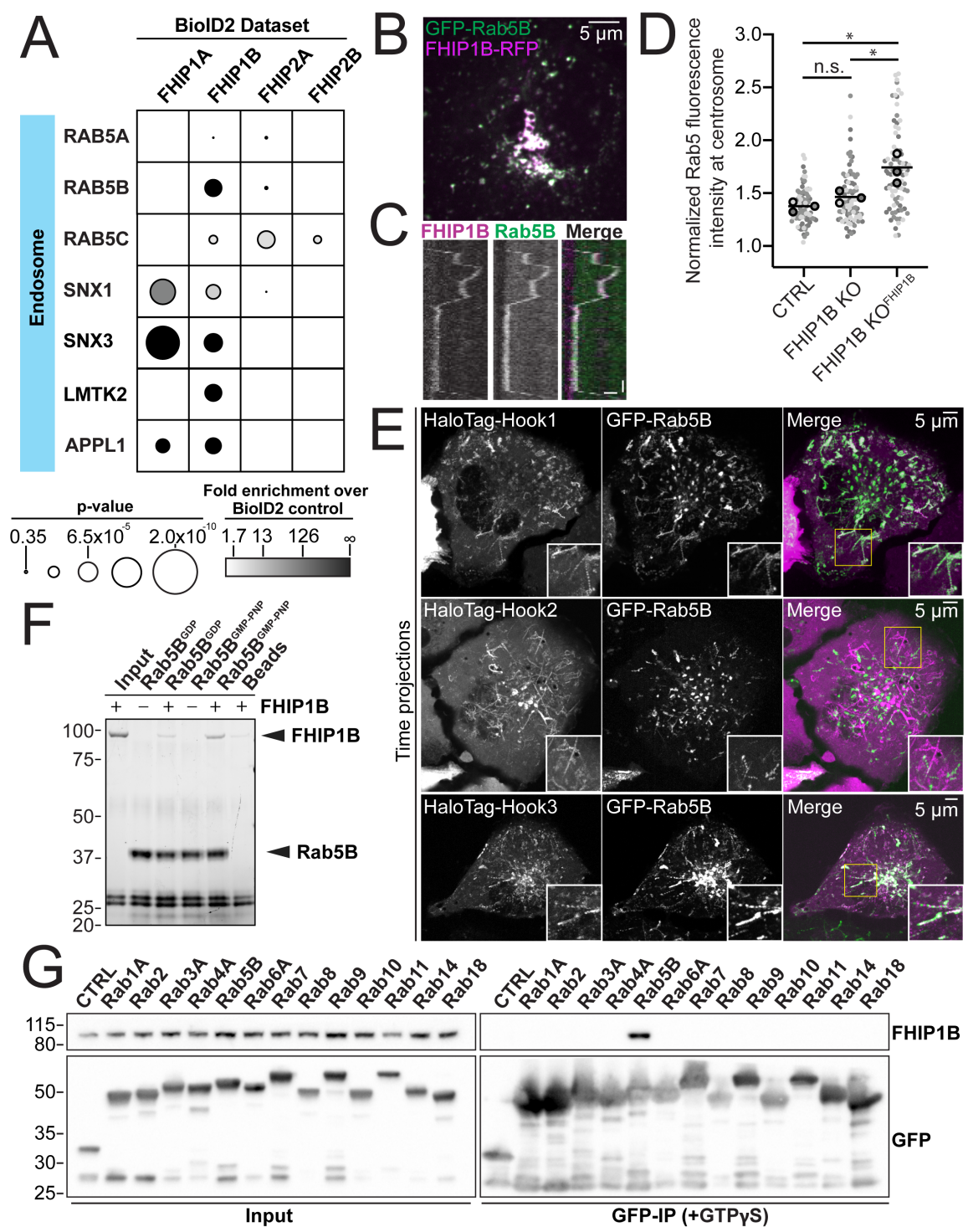

Figure 5. FHIP1B and Hook1/3 colocalize with early endosomes via a direct interaction between FHIP1B and GTP-bound Rab5.

(A) Fold-enrichment over cytoplasmic BiolD2 control (grayscale intensity) and p-value (circle size) for selected known endosome-associated proteins identified in the indicated FHIP BiolD2 datasets. (B) Single plane confocal micrograph of FHIP1B KO U2OS cell expressing FHIP1B-TagRFP-T-V5 (FHIP1B-RFP) and GFP-Rab5B. (C) Representative kymograph of moving Rab5B puncta colocalized with FHIP1B. Scale bar, $1 \mu$ m. Time bar, 2 sec. (D) Quantification of Rab5 fluorescent at the centrosome in Cas9 control cells expressing cytoplasmic TagRFP-T (CTRL), FHIP1B KO cells expressing cytoplasmic TagRFP-T (FHIP1B KO), or FHIP1B KO cells expressing FHIP1B-TagRFP-T-V5 (FHIP1B KOFHIA). Fluorescence intensity at the centrosome was normalized to the whole cell fluorescence, and to the areas of the regions of interest used to quantify centrosome versus whole cell fluorescence. Bold line denotes mean. Bolded circles denote means for each biological replicate. Differently shaded circles correspond to individual datapoints for cells from different biological replicates. $\mathrm{N}=77$ Cas9 control, $81 \mathrm{FHIP} 1 \mathrm{~B} \mathrm{KO}$, and 88 FHIP1B KO FHIP1B . Cells from 3 biological replicates. n.s., no significance, $P=0.1,{ }^{*} P<0.0001$, Kruskal-Wallis with Dunn's post hoc test for multiple comparisons. (E) Single plane timelapse projections of U2OS cells expressing GFP-Rab5B and Halo-Hook1 tagged with Janelia Fluor (JF) 646 (top), HaloTag(JF646)-Hook2 (middle), or HaloTag(JF646)-Hook3. Timelapse movies obtained by triggered acquisition. Yellow rectangle denotes region of cropped inset shown. $(F)$ Purified 6His-Rab5B-SNAP preloaded with GDP or GMPPNP was bound to Co-NTA beads and incubated with purified FHIP1B. Elutions were resolved on an SDS-PAGE gel. (G) Indicated human Rab proteins tagged at the amino termini with EGFP were transiently expressed in 293T cells and immunoprecipitated with GFP nanonbody affinity resin (GFPIP) in the presence of GTPyS. Immunoblots were probed with anti-FHIP1B and anti-GFP antibodies. Protein molecular weight markers are shown in kilodaltons to the left of each immunoblot. 3xHA-sfGFP provided a control (CTRL).

glycoprotein of vesicular stomatitis virus (VSV-G) in FHIP2A KO cells expressing FHIP2A-TagRFP-T to determine if VSV-G colocalized with FHIP2A (Presley et al., 1997). VSV-G is a temperature-sensitive cargo that becomes trapped in the ER when cells are grown at $40^{\circ} \mathrm{C}$. Upon a temperature shift to $32^{\circ} \mathrm{C}$, VSV-G is transported from the ER to the Golgi and from the Golgi to the plasma membrane. We incubated cells at $40^{\circ} \mathrm{C}$ and after 12 hours, shifted the cells to $32^{\circ} \mathrm{C}$ and began imaging. We observed two primary subsets of GFP-VSV-G cargo. The first subset of cargo consisted of tubules that moved in both the anterograde and retrograde direction, and likely represent ER-to-Golgi transport intermediates (Ben-Tekaya et al., 2005a; Marra et al., 2001; Presley et al., 1997; Sannerud et al., 2006a). These tubules were colocalized with 
bioRxiv preprint doi: https://doi.org/10.1101/2021.10.07.463551; this version posted October 8, 2021. The copyright holder for this preprint (which was not certified by peer review) is the author/funder, who has granted bioRxiv a license to display the preprint in perpetuity. It is made available under aCC-BY-NC-ND 4.0 International license.

Christensen, Kendrick et al., 10/06/2021

FHIP2A (Figure 6B \#1, Video 7). The second subset of VSV-G cargo were very bright, long tubules that moved directly from the Golgi to the cell periphery (Hirschberg et al., 1998). These tubules represent transport from the Golgi to the plasma membrane and were not colocalized with FHIP2A (Figure 6B \#2, Video 7). Therefore, our results suggest that FHIP2A is specifically associated with the ER-to-Golgi stage of VSV-G transport. We further tested whether FHIP2A was associated with ER-toGolgi transport by expressing GFP-tagged ER-to-Golgi proteins identified in our BioID dataset in FHIP2A KO cells expressing FHIP2ATagRFP-T. We found that FHIP2A colocalized with GMAP210, SCFD1, and BET1 (Figure 6 - figure supplement 1C), further confirming that FHIP2A is involved in ER-to-Golgi transport.

ER-to-Golgi transport is mediated by a number of small GTPases including members of the Rab, Arf, and Arl families (Schwaninger et al., 1992; Suda et al., 2018). As FHIP1B was associated with Rab5-bound early endosomes, we sought to determine whether FHIP2A was also connected to a cargo associated via a specific small GTPase. We expressed several GFP-tagged GTPases known to be associated with the ER, Golgi, or ER-Golgi transport (Rab1A, Rab2, Rab18, Arf1 and Sar1) in our FHIP2A KO cells expressing FHIP2ATagRFP-T to determine if FHIP2A colocalized with any of these GTPases. We found that FHIP2A strongly colocalized with GFP-Rab1A, which is crucial for several steps in ER-to-Golgi trafficking (Saraste et al., 1995; Tisdale et al., 1992; Westrate et al., 2020; Yan et al., 2021), but none of the other small GTPases tested (Figure 6C, Figure 6 - figure supplement 2A). However, FHIP2A did not immunoprecipitate with Rab1A or any of the other 12 Rabs (Rab2, 3A, 4A, 5B, 6A, 7, 8, 9, 10, 11,14 and 18 ) we tested (Figure 6 - figure supplement 3A-B), suggesting that this interaction may be indirect or require additional molecular interactions between FHIP2A and ER-to-Golgi transport intermediates.

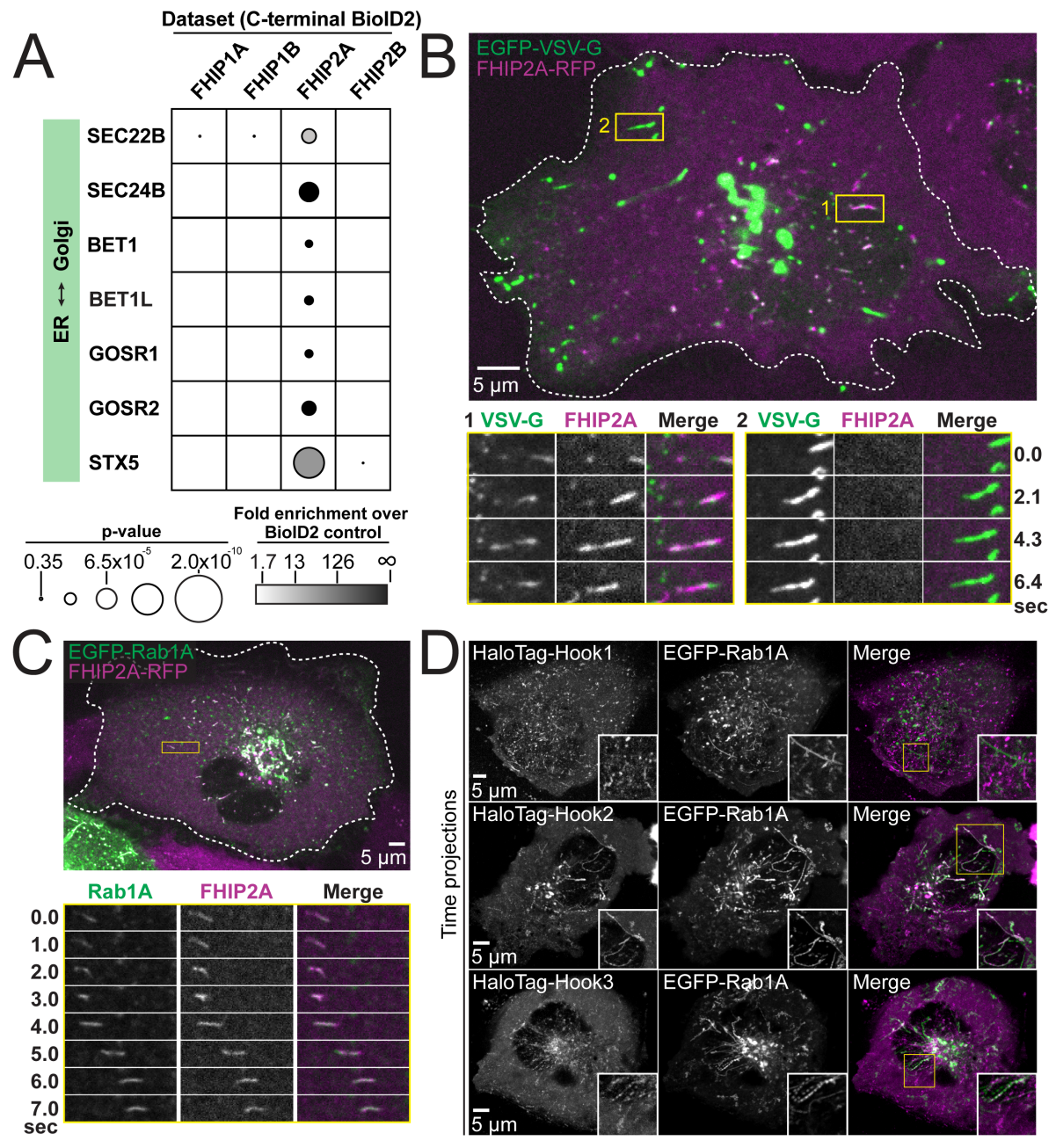

Figure 6. FHIP2A and Hook2 colocalize with Rab1A-associated ER-to-Golgi tubular intermediates.

(A) Fold-enrichment over cytoplasmic BiolD2 control (grayscale intensity) and p-value (circle size) for selected known ER-to-Golgi proteins identified in the indicated FHIP BiolD2 datasets. (B) Single-plane confocal micrograph of FHIP2A KO U2OS cell expressing FHIP2A-TagRFP-T-V5 (FHIP2A-RFP) and temperature-sensitive EGFP-VSV-G following temperature shift from $40^{\circ} \mathrm{C}$ to $32^{\circ} \mathrm{C}$. Yellow rectangle (1) and corresponding time-lapse montages denote EGFP-VSV-G tubule moving from the ER to the Golgi, while (2) denotes EGFP-VSV-G tubule moving from the Golgi to the plasma membrane. (C) Singleplane confocal micrograph of FHIP2A KO U2OS cell expressing FHIP2A-TagRFP-T-V5 (FHIP2A-RFP) and EGFP-Rab1A. Dotted line denotes cell edge and yellow rectangle denotes region of time-lapse montage below. (D) Single plane time-lapse projections of U2OS cells expressing EGFP-Rab1A and HaloTag-Hook1 tagged with Janelia Fluor (JF) 646 (top), HaloTag(JF646)-Hook2 (middle), or HaloTag(JF646)-Hook3. Time-lapse movies obtained by triggered acquisition. Yellow rectangle denotes region of cropped inset shown. 
bioRxiv preprint doi: https://doi.org/10.1101/2021.10.07.463551; this version posted October 8, 2021. The copyright holder for this preprint (which was not certified by peer review) is the author/funder, who has granted bioRxiv a license to display the preprint in perpetuity. It is made available under aCC-BY-NC-ND 4.0 International license.

Christensen, Kendrick et al., 10/06/2021
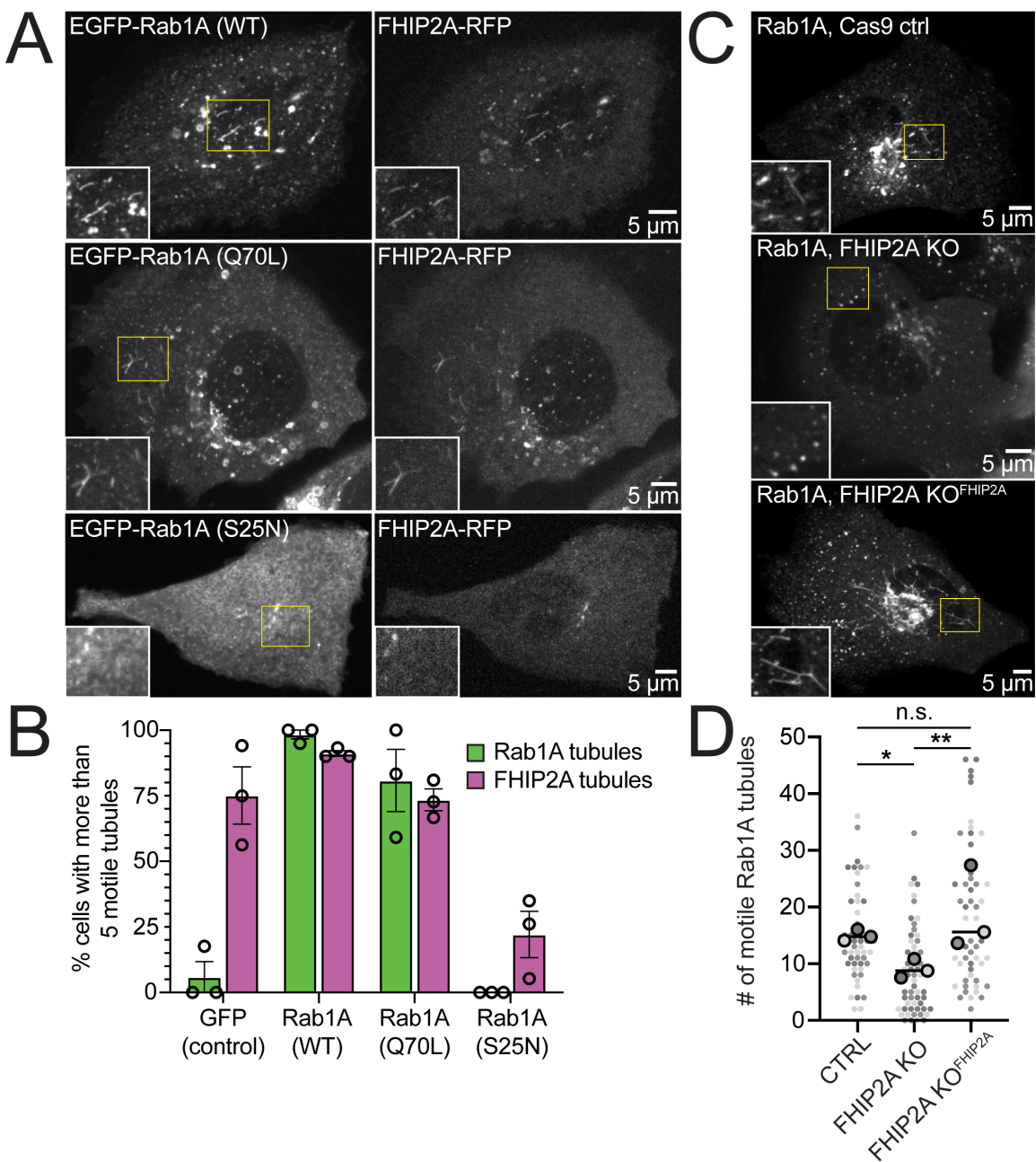

Figure 7. FHIP2A affects Rab1A-associated tubule formation.

(A) Single-plane confocal micrographs of FHIP2A KO U2OS cells expressing FHIP2A-TagRFP-T-V5 (FHIP2A-RFP, right panels) and EGFP-Rab1A (WT) (top), EGFP-Rab1A (Q70L) (middle), or EGFP-Rab1A (S25N) (bottom, left panels). Yellow rectangles denote region of cropped inset. (B) Quantification of percentage of cells expressing more than five motile GFP/EGFP-Rab1A-positive (green) or FHIP2A-RFP positive (magenta) tubules. Error bars $=$ mean \pm S.E.M. $n=53$ GFP (control), 55 EGFP-Rab1A (WT), 61 EGFP-Rab1A (Q70L), and 62 EGFP-Rab1A (S25N)-expressing cells from 3 biological replicates. Open circles denote mean of each biological replicate. (C) Single-plane confocal micrographs of EGFP-Rab1A(WT) (Rab1A) in Cas9 control cells expressing cytoplasmic TagRFP-T (top), FHIP2A KO cells expressing cytoplasmic TagRFP-T (middle), or FHIP2A KO cells expressing FHIP2A-TagRFPT-V5 (bottom). TagRFP-T panels not shown. (D) Quantification of the number of motile Rab1A tubules in Cas9 control cells expressing cytoplasmic TagRFP-T (Ctrl), FHIP2A KO cells expressing cytoplasmic TagRFP-T (FHIP2A KO), or FHIP2A KO cells expressing FHIP2A-TagRFP-T-V5 (FHIP2A $\mathrm{KO}^{\mathrm{FH}}{ }^{\mathrm{P} 2 \mathrm{~A}}$ ). Bold line denotes median. Bolded circles denote means for each biological replicate. Differently shaded circles correspond to individual datapoints for cells from different biological replicates. $\mathrm{N}=55$ Cas9 control, 59 FHIP2A KO, and 54 FHIP2A KO ${ }^{\text {FHIP2A }}$. Cells from 3 biological replicates. ${ }^{* * *} P=0.0001$, Kruskal-Wallis with Dunn's post hoc test for multiple comparisons.

As FHIP2A forms a complex predominantly with Hook2, but also weakly interacted with other Hook proteins (Figure 2 and Figure 3 figure supplement $3 \mathrm{~B}$ ), we tested whether different Hook proteins also colocalize with Rab1A. We found that Hook2 showed strong colocalization with Rab1A (Video 9). Hook3 also showed some colocalization with Rab1A (Video 10), while Hook1 showed very little colocalization with Rab1A (Figure 6D, Video 8, controls in Figure 5 figure supplement 1B).

To test the functional relationship between Rab1A and FHIP2A, we examined the presence of motile FHIP2A tubules in cells expressing wild-type, GTP-locked (Q70L), or GDP-locked (S25N) Rab1A. In cells expressing either wild-type or GTP-locked Rab1A, FHIP2A strongly colocalized with Rab1A tubules (Figure 7A, Video 11), and at least $73 \%$ of cells had more than 5 motile Rab1A and FHIP2A tubules (Figure 7B). On the other hand, in cells expressing GDP-locked
Rab1A, $0 \%$ of cells had more than 5 motile Rab1A tubules, and only $22 \%$ of cells had more than 5 motile FHIP2A tubules. These data suggest a link between the presence of membrane-bound Rab1A on an ER-to-Golgi tubule and the recruitment of FHIP2A.

Finally, we tested whether FHIP2A affects the formation or motility of Rab1A tubules by expressing GFP-Rab1A in CRISPR/Cas9 control, FHIP2A KO, or FHIP2A KO cells expressing FHIP2A-TagRFPT. We found a $39 \%$ decrease in the number of motile Rab1A tubules in FHIP2A KO cells compared to control cells (Figure 7C-D, Video 12). The number of motile Rab1A tubules was rescued in FHIP2A KO cells expressing FHIP2A-TagRFP-T, suggesting that FHIP2A KO is involved in the formation and/or motility of Rab1A tubules. We found that tubule length was slightly, but significantly, decreased in FHIP2A KO cells compared to the rescue cells (Figure 7 - figure supplement 1A), suggesting that FHIP2A likely plays a larger role in tubule motility rather 
bioRxiv preprint doi: https://doi.org/10.1101/2021.10.07.463551; this version posted October 8, 2021. The copyright holder for this preprint (which was not certified by peer review) is the author/funder, who has granted bioRxiv a license to display the preprint in perpetuity. It is made available under aCC-BY-NC-ND 4.0 International license.

Christensen, Kendrick et al., 10/06/2021

than formation. Thus, our data suggest that an FHF complex containing FHIP2A and Hook2 links dynein to Rab1A ER-to-Golgi tubular intermediates.

\section{Discussion}

In this study, we found that functional divergence in two families of adaptor proteins, the Hook and FHIP families, allows for the formation of distinct cargo adaptor complexes that link dynein to different cellular cargos. We identified the preferential formation of specific FHF complexes (FTS/Hook1 or Hook3/FHIP1B and FTS/Hook2/FHIP2A), and found that these FHF complexes associate with moving dynein/dynactin complexes. We found that FHIP1B, Hook1, and Hook3 associate with early endosomes via a direct interaction between FHIP1B and Rab5B, while FHIP2A and Hook2 mediate transport of Rab1Aassociated ER-to-Golgi transport intermediates. Together, our data demonstrate that gene expansion and functional divergence of the Hook and FHIP families of proteins provide a unique mechanism of regulating dynein's cellular cargo specificity (Figure 8).

\section{Distinct FHF complexes link dynein to its cargos via Rab GTPases}

For dynein to move processively, it requires the protein complex dynactin and a coiled-coil activating adaptor (McKenney et al. 2014, Schlager et al. 2014). There are currently $\sim 20$ known or putative activating adaptors in human cells, but it is not known how most activating adaptors link to cargo (Reck-Peterson et al. 2018). Rab GTPases present appealing targets for cargo-specific recognition by activating adaptors, as they are frequently the most upstream proteins denoting membrane identity (Pfeffer, 2017). Several activating adaptors have been implicated in linking dynein/dynactin directly or indirectly to cargo-bound Rab GTPases (Horgan et al., 2010; Lee et al., 2018; Matanis et al., 2002; Schlager et al., 2010). In this study and studies from other labs, we found that the activating adaptors Hook1 and Hook3 link dynein to Rab5 via the intermediate protein FHIP1B (Guo et al. 2016). Working with pure recombinant proteins, we showed that the interaction between Rab5 and FHIP1B is direct (Figure 5F). We also found that Hook2 links to Rab1A via FHIP2A. However, the Rab1A-FHIP2A interaction is likely indirect, as Rab1A was not present in our FHIP2A BioID dataset (Supplementary Table 1) and we were unable to co-immunoprecipitation FHIP2A with Rab1A (Figure 7 - figure supplement $1 \mathrm{~A}$ and $\mathrm{B}$ ). Therefore, there are likely other intermediate protein(s) between FHIP2A and Rab1A that will be of interest for future studies.

\section{Combinatorial assembly leads to the formation of distinct FHF complexes}

Although the initial discovery of the FHF complex suggested formation of a single complex composed of Hook proteins, FTS, and FHIP1B (Xu et al., 2008), our work shows that different FHF complexes exist in cells and in vitro (Figure 2 and 3). Specifically, we find that Hook1 and Hook3 are found in complexes containing FHIP1B, while Hook2 predominantly interacts with complexes containing FHIP2A. Our findings are further supported by studies showing that distinct Hook proteins exhibit different cellular localizations and functions, possibly due to their interactions with different FHIP proteins (Herrmann et al., 2015; Olenick et al., 2019; Xu et al., 2008). We reconstituted these dynein/dynactin/FHF complexes, showing that no other proteins are required for their formation or movement on microtubules. Although the formation of these complexes did not significantly affect dynein's motile properties, FHIP colocalization with moving dynein/dynactin in single-molecule motility assays suggests that FHF complexes form functional linkages that may bridge dynein to cargo in cells. An interesting area of future work will be to determine if the addition of cargo to moving dynein/dynactin/FHF complexes affects dynein's motile properties.

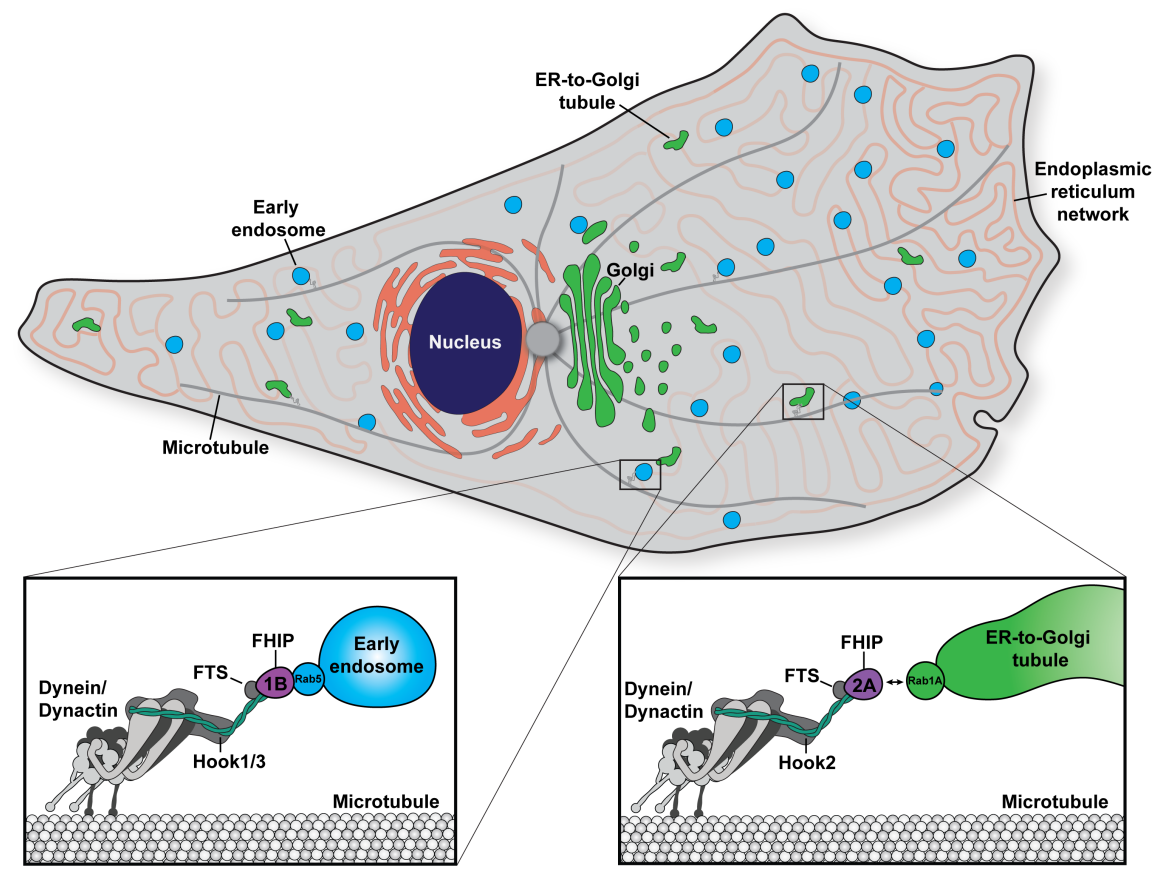

Figure 8. Model of the biological functions of distinct FHF complexes. Dynein/dynactin associates with each FHF complex via a direct interaction with a Hook protein. The FHF complex composed of FTS, Hook1 and/or Hook3, and FHIP1B links dynein/dynactin with early endosomes via a direct interaction between FHIP1B and Rab5. The FHF complex composed of FTS, Hook2, and FHIP2A links dynein/dynactin to Rab1A-associated ER-to-Golgi tubular transport intermediates. 
bioRxiv preprint doi: https://doi.org/10.1101/2021.10.07.463551; this version posted October 8, 2021. The copyright holder for this preprint (which was not certified by peer review) is the author/funder, who has granted bioRxiv a license to display the preprint in perpetuity. It is made available under aCC-BY-NC-ND 4.0 International license.

Christensen, Kendrick et al., 10/06/2021

FHIP proteins are likely the most cargo-proximal adaptors in the FHF complex. Here we showed that FHIP1B directly interacts with Rab5B (Figure 5F), which is consistent with work in Aspergillus nidulans where FhipA associates with RabA/Rab5- marked early endosomes in the absence of FtsA and HookA in vivo (Yao et al., 2014). In humans, FHIP proteins and FTS likely interact with each other in the absence of Hook proteins as yeast two-hybrid studies indicate that human FTS and FHIP1B can bind to each other independently of association with Hook (Mattera et al., 2020). In further support of this, mutations in a conserved carboxy-terminal $\alpha$-helix in Hook1 (also conserved in Hook2 and Hook3) prevent Hook1 association with FTS and FHIP, but do not affect FTS binding to FHIP (Xu et al., 2008). An important area for future work will be to determine the order of assembly of Hook proteins with dynein/dynactin complexes and FHIP/FTS complexes.

\section{FHIP1B-containing FHF complexes link dynein to early endosomes}

We demonstrate that FHIP1B is involved in dynein-mediated transport of Rab5 early endosomes. Specifically, we find that FHIP1B colocalizes with Rab5B-tagged early endosomes (Figure 5B) by directly interacting with GTP-bound Rab5B (Figure 5F). Furthermore, FHIP1B overexpression results in an accumulation of early endosomes at the centrosome (Figure 5D). FHIP1B has been previously shown to associate with GTP-locked Rab5A via co-immunoprecipitation and yeast two-hybrid system (Guo et al., 2016). We also find that Hook1 and Hook3 colocalize with Rab5B-tagged early endosomes (Figure 5E), consistent with previous data for Hook1 and Hook3, and Rab5A-tagged endosomes in rat hippocampal neurons (Olenick et al., 2019). Though we see FHIP1B association with nearly every Rab5B-tagged early endosome, it is possible that FHF complexes containing FHIP1B/Hook1 may interact with a different subpopulation of endosomes from FHF complexes containing FHIP1B/Hook3. In agreement with this hypothesis, Hook1, but not Hook3 was previously shown to colocalize with a subpopulation of Rab5-tagged endosomes and regulate TrkBbrain-derived neurotrophic factor (BDNF)-signaling endosomes in primary hippocampal neurons (Olenick et al., 2019). Together, these data suggest that FHIP1B recruits dynein to early endosomes in a Rab5 and Hook $1 / 3$ dependent manner, ultimately driving endosome movement towards the minus end of microtubules.

\section{FHIP2A-containing FHF complexes link dynein to ER-to-Golgi transport intermediates}

Prior to this work, the role of FHIP2A in dynein-mediated cargo transport had not been investigated. We discovered that FHIP2A is important for the motility, but likely not the formation, of Rab1A-associated tubular ER-to-Golgi transport intermediates (Figures 6 and 7). Rab1 A is involved in several steps of ER-to-Golgi transport (Yan et al., 2021). We show that FHIP2A colocalizes with a Rab1A-associated subset of motile VSV$\mathrm{G}$ tubules (Figure 6B), a cargo that uses microtubules and the dynein complex to move bidirectionally between the ER and Golgi (Ben-Tekaya et al., 2005a; Marra et al., 2001; Sannerud et al., 2006b; Weigel et al., 2021; Yan et al., 2021). Consistent with our data, previous work has implicated dynactin in regulating movement of ER-to-Golgi transport intermediates, as the dynactin subunit $\mathrm{p} 150^{\text {Glued }}$ colocalizes with tubular ER-to-Golgi intermediates (Weigel et al., 2021) and disruption of the dynactin complex via overexpression of its p50 subunit inhibits VSV-G transport (Presley et al., 1997). Together our findings suggest that FTS/Hook2/FHIP2A complexes link dynein/dynactin to Rab1A-marked tubular ER-to-Golgi transport intermediates.

\section{The protein interactomes of the different FHIP proteins suggest other candidate cargos}

FHIP1A and FHIP1B share many hits in their BioID protein interactomes, suggesting partial redundancy between these proteins. For example, both FHIP1A and FHIP1B have been previously shown to associate with the AP-4 adaptor complex (Mattera et al., 2020), and we also found multiple AP-4 adaptor proteins in our FHIP1A and FHIP1B BioID datasets (Figure 1C, Supplemental File 1). On the other hand, FHIP1A may also have a slightly different role from FHIP1B. For example, transferrin receptor (TFR) and two sorting nexins (SNX2, SNX30) were found in the FHIP1A but not FHIP1B dataset (Figure 1C, Supplemental File 2), suggesting that FHIP1A may be involved in TFR recycling or another endosome-adjacent biological function using sorting nexins. A final possibility is that FHIP1A plays an important role in other cell types, since it's expression is significantly lower in the $293 \mathrm{~T}$ and U2OS cells used in this study, as compared to other FHIP proteins (Thul et al., 2017, Human Protein Atlas, available from http://www.proteinatlas.org).

While ER-to-Golgi transport proteins were generally found exclusively in the FHIP2A BioID datasets, FHIP2B also shared some BioID hits with FHIP2A, including several proteins known to be involved in (TBC1D23, FAM91A1, GOLGA4, GOLGA5) or cargos of (KIAA0319L, carboxypeptidase D) endosome-to-Golgi transport (Figure 1C, Figure 6 - figure supplement 1A) (Hirst et al., 2015; Shin et al., 2017). Therefore, FHIP2B may play a role in endosome-to-Golgi transport. Additionally, a large number of mitochondria-associated proteins were found in the FHIP2B dataset, including several outer membrane proteins (AKAP1, GRP75, TRAK1, DRP1). Thus, another possibility is that FHIP2B is involved in dynein-mediated transport of mitochondria, or another mitochondria-related function.

Finally, our FHIP1A, FHIP1B, FHIP2A, and FHIP2B protein interactomes, along with the protein interactomes of Hook1, Hook2, and Hook3 will be a powerful resource to identify additional dynein/ dynactin cargos and regulatory proteins (Supplementary Table 1 and Redwine et al., 2017). Further mining of this data is likely to shed additional light on how combinatorial assembly of cargo adaptor complexes can regulate dynein's cargo specificity.

\section{Materials and Methods}

\section{Molecular cloning}

Plasmid design was performed using SnapGene software (from Insightful Science; available at snapgene.com). All plasmids used in this study, unless otherwise stated, were constructed by PCR and Gibson isothermal assembly, and are included in Table 1. Hook3 (clone ID: 5106726), FHIP1A (FAM160A1, clone ID: 3921921), FHIP1B (FAM160A2, clone ID: 4811942), FHIP2A (FAM160B1, clone ID: 4828347), FHIP2B (FAM160B2 clone ID: 8327615), and FTS (AKTIP, clone ID: 2967019) were obtained from Dharmacon. Hook1 (clone ID: HsCD00044030), and Hook2 isoform 2 (clone ID: HsCD00326811) cDNAs were from PlasmidID (Harvard Medical School). The His-Rab5B(A15-G191) plasmid was mutagenized in the Reck-Peterson lab to add amino acids 2-14 of human Rab5B.

\section{Cell lines and transfections}

Human 293T and human U2OS (U-2 OS) cells were obtained from ATCC and maintained at $37^{\circ} \mathrm{C}$ with $5 \% \mathrm{CO} 2$ in Dulbecco's Modified Eagle Medium (DMEM, Corning) supplemented with $10 \%$ fetal bovine serum (FBS, Gibco) and 1\% Penicillin Streptomycin (PenStrep, Corning). Sf9 cells were obtained from Thermo Fisher Scientific and grown in Sf-900 II SFM media (Thermo Fisher Scientific). All cells were routinely tested for mycoplasma contamination and were not authenticated after purchase.

\section{FLP/FRT stable cell line generation}

All BiolD stable cell lines were created with the FLP/FRT system and TRex 293T cells with constitutively expressed Tet repressor (Thermo Fisher Scientific). Stable cell lines expressing BiolD tagged genes of interest were 
bioRxiv preprint doi: https://doi.org/10.1101/2021.10.07.463551; this version posted October 8, 2021. The copyright holder for this preprint (which was not certified by peer review) is the author/funder, who has granted bioRxiv a license to display the preprint in perpetuity. It is made available under aCC-BY-NC-ND 4.0 International license.

Christensen, Kendrick et al., 10/06/2021

generated by transfection with Lipofectamine 2000 (Thermo Fisher Scientific) and a combination of the appropriate pcDNA5/FRT/TO construct and Flipase expressing pOG44 plasmid. After recovery, cells were grown in DMEM containing $10 \%$ FBS, $1 \%$ PenStrep, and $50 \mu \mathrm{g} / \mathrm{mL}$ Hygromycin B. Gene expression was induced with $2 \mu \mathrm{g} / \mathrm{ml}$ doxycycline treatment for $\sim 16 \mathrm{hrs}$ before cell harvest. Colonies were isolated, expanded, and screened for expression of the fusion proteins by western blotting with an anti-FLAG M2-HRP antibody (Sigma, mouse monoclonal, cat\#: A8592)

\section{CRISPR/Cas9-mediated genome-editing}

Gene-editing for creation of FHIP1B and FHIP2A-depleted U2OS cells was performed as described previously (Kendrick et al., 2019) with slight modifications. Briefly, in vitro transcribed 20-nulceotide Alt-R crRNA along with Alt-R CRISPR-Cas9 tracrRNA were purchased from Integrated DNA Technologies (IDT). The exon 3 FHIP1B CrRNA (Hs.Cas9.FAM160A2.1.AB) sequence was 5'ACTGGACCATGCCGCAACAGTGG -3 ' and the exon 2 FHIP1B crRNA (Hs.Cas9.FAM160A2.1.AA) sequence was 5'CTGGGCACCGTATACCTCAAGGG -3'. The exon 3 FHIP2A crRNA (Hs.Cas9.FAM160B1.1.AA) (Hs.Cas9.FAM160B1.AC) ACGTTAATGTGTGGAAGTAGTGG -3'. To prepare the Alt-R crRNA and Alt-R tracrRNA duplex, reconstituted oligos $(100 \mu \mathrm{M})$ were mixed at equimolar concentrations in sterile PCR water and annealed at $95^{\circ} \mathrm{C}$ for 5 mins, followed by slow cooling to room temperature. To generate knockouts $70-80 \%$ confluent U2OS cells were reverse co-transfected with $200 \mathrm{ng}$ of pX459 vector and gene specific crRNA-tracrRNA duplexes (10 nM) diluted in OptiMEM (Gibco) and combined with RNAimax reagent (Thermo Fisher Scientific). Briefly, cells were dislodged with $0.25 \%$ trypsinEDTA and resuspended in DMEM medium. Cells were mixed with transfection complexes and plated into a 6-well plate to a final concertation of 0.64 million cells/well. 48 hours post-transfection, the cells were pulsed with $1 \mu \mathrm{g} / \mathrm{mL}$ puromycin for 24 hours to allow selection of pX459transfected cells. Following puromycin selection and recovery in DMEM without puromycin, single cell clones were plated in 96-well format by limiting dilution and cultured to allow single colonies to grow out. Clones were expanded to 12-well plates, and samples of resulting clones were screened via immunoblotting with gene-specific antibodies for FHIP1B (Abcam, FAM160A2 rabbit monoclonal, Cat \#: EPR13604) and FHIP2A (Thermo Fisher Scientific, FAM160B1 rabbit polyclonal, Cat \#: PA560442). A SURVEYOR mutation detection kit (IDT, \#706020) was used to detect gene edited clones.

\section{Stable cell lines with near-endogenous protein expression generation}

FHIP1B KO and FHIP2A KO clones were transfected with nearendogenous TagRFP-T-V5 under a mutated CMV promoter (Ferreira et al., 2011) using a retroviral infection/MSCV-driven expression system as described previously (Sowa et al., 2009). Briefly, plasmid DNA (retroviral pMSCV with FHIP1B-TagRFPT-V5, FHIP2A-TagRFPT-V5 or TagRFPTV5 genes inserted) along with viral helper constructs (retroviral MSCVvsvg, MSCV-gag/pol) were diluted in OptiMEM (Gibco) and combined with $1 \mu \mathrm{g} / \mu \mathrm{L}$ polyethylenimine (PEI; Polysciences Inc.) in a 3:1 ratio of PEI:DNA concentration. The transfection mixture was added to 293T cells, followed by incubation for 12-16 hours. Fresh DMEM was added to the cells, followed by a 24-hour incubation to allow virus production. Viral supernatant was collected, filtered, and added to recipient U2OS cells along with $1 \mu \mathrm{g} / \mathrm{mL}$ polybrene for infection. Stable cell lines were established by hygromycin selection $(400 \mu \mathrm{g} / \mathrm{mL})$ for $48-72 \mathrm{~h}$. Expression of ectopic proteins was confirmed via western blotting with FHIP1B and FHIP2A-specific antibodies as well as anti-V5-HRP antibody (Thermo Fisher Scientific, mouse monoclonal, cat\#: R96025). After recovery, stable cell lines were grown in DMEM containing 10\% FBS, $1 \%$ PenStrep, and $200 \mu \mathrm{g} / \mathrm{mL}$ hygromycin.

\section{Transient transfections}

For immunoprecipitations from transiently transfected $293 \mathrm{~T}$ cells, $1.5 \times 10^{6}$ cells were plated onto one $10 \mathrm{~cm}$ dish per transfection in DMEM containing $10 \%$ FBS. Transfections were performed with PEI and 2-5 $\mu \mathrm{g}$ of transfection grade DNA (ZymoPure Plasmid MaxiPrep Kit, Zymo) per dish as described in above. Cells were harvested 48 hours after transfection. Transfection conditions for immunofluorescence and live-cell imaging are described in the Microscopy section below.

\section{Immunoprecipitations and Immunoblotting}

\section{Immunoprecipitations}

Transiently transfected cells (see above) were collected by decanting the media and washing the cells off the dish with ice cold PBS. Cells were collected by centrifugation at $1000 \times \mathrm{g}$ for 3 minutes, washed again with PBS, and then transferred with PBS to Eppendorf tubes for lysis. Cells were flash frozen for storage or immediately lysed in $500 \mu \mathrm{L}$ of lysis buffer: $50 \mathrm{mM}$ HEPES, pH 7.4; $50 \mathrm{mM}$ KOAc; $2 \mathrm{mM} \mathrm{MgOAc} ; 1 \mathrm{mM}$ EGTA; $1 \%(\mathrm{v} / \mathrm{v})$ TritonX-100, $1 \mathrm{mM}$ DTT; and protease inhibitors (cOmplete Protease Inhibitor Cocktail, Roche) with gentle mixing at $4^{\circ} \mathrm{C}$ for 20 minutes. When indicated $2 \mathrm{mM}$ GTPyS (Abcam) was included in the lysis buffer. Lysates were then centrifuged at maximum speed in a $4^{\circ} \mathrm{C}$ microcentrifuge for 15 minutes. For each immunoprecipitation, $420 \mu \mathrm{L}$ clarified lysate was retrieved and added to $40 \mu \mathrm{L}$ packed volume of anti-FLAG M2 agarose slurry (Sigma), Pierce anti-HA agarose slurry (Thermo Fisher Scientific) or in-house prepared anti-GFP-nanobody Sepharose slurry and incubated for $\sim 20-24$ hours at $4^{\circ} \mathrm{C}$. Cells were washed four times with $1 \mathrm{~mL}$ of lysis buffer, and elutions were carried out by incubating beads with $60 \mu \mathrm{L}$ of lysis buffer supplemented with NuPage LDS sample buffer (Thermo Fisher Scientific) and NuPage reducing agent (Thermo Fisher Scientific), and 10 min heat denaturation at $95^{\circ} \mathrm{C}$. For $3 X$ FLAG immunoprecipitations elutions were performed with $50 \mu \mathrm{L}$ of lysis buffer supplemented with $1 \mathrm{mg} / \mathrm{mL} 3 X$ FLAG peptide (ApexBio).

\section{GFP-nanobody coupling to the beads}

Purified GFP-nanobody-6His was diluted to $3 \mathrm{mg} / \mathrm{ml}$ in coupling buffer (200 $\mathrm{mM} \mathrm{NaHCO}, \mathrm{pH} \mathrm{7.9;500} \mathrm{mM} \mathrm{NaCl}$ ) and incubated overnight at $4^{\circ} \mathrm{C}$ with NHS-activated Sepharose Fast Flow resin (Cytvia) pre-equilibrated with coupling buffer. The next day the coupling reaction was quenched by the addition of $1 \mathrm{M}$ Tris- $\mathrm{HCl} \mathrm{pH} 7.4$ (final concentration $50 \mathrm{mM}$ Tris- $\mathrm{HCl}, \mathrm{pH}$ 7.4 ) followed by a 15 minute incubation in room temperature. Beads were washed with quenching buffer $(50 \mathrm{mM}$ Tris- $\mathrm{HCl}, \mathrm{pH} 7.4 ; 150 \mathrm{mM} \mathrm{NaCl})$ and stored in $4^{\circ} \mathrm{C}$ in $20 \%$ Ethanol until further use.

\section{BioID sample preparation and mass spectrometry}

\section{Cell growth and streptavidin purification}

Growth of cells and sample preparation for BiolD experiments were performed as previously described (Kendrick et al., 2019) with slight modifications. Briefly, different BiolD cell lines were plated at $\sim 20 \%$ confluence in $15 \mathrm{~cm}$ dishes as four replicates, with each replicate consisting of $4 \times 15 \mathrm{~cm}$ plates. After 24 hours, biotin was added to the media to a final concentration of $50 \mu \mathrm{M}$, and the cells were grown for another 16 hours. After decanting the media, cells were dislodged from each plate by pipetting with ice-cold 1X PBS. Cells were centrifuged at $1000 \times \mathrm{g}$ for $2 \mathrm{~min}$, washed with ice cold 1X PBS and the cell pellets were resuspended and lysed in $16 \mathrm{~mL}$ RIPA buffer (50 mM Tris-HCl, pH 8.0; 150 $\mathrm{mM} \mathrm{NaCl} ; 1 \%(\mathrm{v} / \mathrm{v}) \mathrm{NP}-40,0.5 \%$ (w/v) sodium deoxycholate; $0.1 \%(\mathrm{w} / \mathrm{v})$ SDS; $1 \mathrm{mM}$ DTT; and protease inhibitors (cOmplete Protease Inhibitor Cocktail, Roche) by gentle rocking for 15 mins at $4^{\circ} \mathrm{C}$. The cell lysate was clarified via centrifugation at $66,000 \times \mathrm{g}$ for $30 \mathrm{~min}$ in a Type $70 \mathrm{Ti}$ rotor (Beckman Coulter) at $4^{\circ} \mathrm{C}$. The clarified lysate was retrieved and combined with pre-washed $0.5 \mathrm{~mL}$ streptavidin-conjugated beads (Pierce Streptavidin magnetic beads) and incubated overnight at $4^{\circ} \mathrm{C}$ with gentle rocking. Bead/lysate mixtures were collected on a magnetic stand into a single $2 \mathrm{~mL}$ round-bottom microcentrifuge tube. The beads were washed 3 times with $2 \mathrm{~mL}$ RIPA buffer and once with 1X PBS with immobilization and solution removal performed on a magnetic stand.

\section{On-bead digestion}

Samples were prepared for mass spectrometry (MS) as previously described (Kendrick et al., 2019). After the final wash the beads were resuspended in $100 \mu \mathrm{L}$ of $50 \mathrm{mM}$ ammonium bicarbonate (Thermo Fisher Scientific) and the proteins on the beads were reduced with $10 \mathrm{mM}$ DTT for 30 minutes at room temperature and alkylated with $55 \mathrm{mM}$ iodoacetamide (Sigma) for 30 minutes in the dark. Protein digestion was carried out with sequencing grade modified Trypsin (Promega) at 1/50 protease/protein (wt/wt) at $37^{\circ} \mathrm{C}$ overnight. After trypsin digestion, the beads were washed twice with $100 \mu \mathrm{L}$ of $80 \%$ acetonitrile (Thermo Fisher Scientific) in $1 \%$ formic acid (Thermo Fisher Scientific) and the supernatants were collected. Samples were dried in Speed-Vac (Thermo Fisher Scientific) and desalted and concentrated on Thermo Fisher Scientific Pierce C18 Tip.

\section{MS data acquisition}

On bead digested samples were analyzed on an Orbitrap Fusion mass spectrometer (Thermo Fisher Scientific) coupled to an Easy-nLC 1200 
bioRxiv preprint doi: https://doi.org/10.1101/2021.10.07.463551; this version posted October 8, 2021. The copyright holder for this preprint (which was not certified by peer review) is the author/funder, who has granted bioRxiv a license to display the preprint in perpetuity. It is made available under aCC-BY-NC-ND 4.0 International license.

Christensen, Kendrick et al., 10/06/2021

system (Thermo Fisher Scientific) through a nanoelectrospray ion source. Peptides were separated on a self-made C18 analytical column (100 $\mu \mathrm{m}$ internal diameter, x $20 \mathrm{~cm}$ length) packed with $2.7 \mu \mathrm{m}$ Cortecs particles. After equilibration with $3 \mu \mathrm{L} 5 \%$ acetonitrile and $0.1 \%$ formic acid mixture, the peptides were separated by a 120 min linear gradient from $6 \%$ to $42 \%$ acetonitrile with $0.1 \%$ formic acid at $400 \mathrm{~nL} / \mathrm{min}$. LC (Optima ${ }^{\mathrm{TM}} \mathrm{LC} / \mathrm{MS}$, Thermo Fisher Scientific) mobile phase solvents and sample dilutions were all made in $0.1 \%$ formic acid diluted in water (Buffer $A$ ) and $0.1 \%$ formic acid in $80 \%$ acetonitrile (Buffer B). Data acquisition was performed using the instrument supplied Xcalibur ${ }^{\mathrm{TM}}$ (version 4.1) software. Survey scans covering the mass range of 350-1800 were performed in the Orbitrap by scanning from $\mathrm{m} / \mathrm{z} 300-1800$ with a resolution of 120,000 (at $\mathrm{m} / \mathrm{z} 200$ ), an S-Lens RF Level of $30 \%$, a maximum injection time of 50 milliseconds, and an automatic gain control (AGC) target value of 4e5. For MS2 scan triggering, monoisotopic precursor selection was enabled, charge state filtering was limited to $2-7$, an intensity threshold of 2e4 was employed, and dynamic exclusion of previously selected masses was enabled for 45 seconds with a tolerance of $10 \mathrm{ppm}$. MS2 scans were acquired in the Orbitrap mode with a maximum injection time of $35 \mathrm{~ms}$, quadrupole isolation, an isolation window of $1.6 \mathrm{~m} / \mathrm{z}, \mathrm{HCD}$ collision energy of $30 \%$, and an AGC target value of $5 \mathrm{e} 4$

\section{MS data analysis}

MS/MS spectra were extracted from raw data files and converted into .mgf files using a Proteome Discoverer Software (ver. 2.1.0.62). These .mgf files were then independently searched against human database using an inhouse Mascot server (Version 2.6, Matrix Science). Mass tolerances were $+/-10 \mathrm{ppm}$ for MS peaks, and +/- $25 \mathrm{ppm}$ for MS/MS fragment ions. Trypsin specificity was used allowing for 1 missed cleavage. Methionine oxidation, protein amino-terminal acetylation, amino-terminal biotinylation, lysine biotinylation, and peptide amino-terminal pyroglutamic acid formation, were all allowed as variable modifications, while carbamidomethyl of Cysteine was set as a fixed modification. Scaffold (version 4.8, Proteome Software, Portland, OR, USA) was used to validate MS/MS based peptide and protein identifications. Peptide identifications were accepted if they could be established at greater than $95.0 \%$ probability as specified by the Peptide Prophet algorithm. Protein identifications were accepted if they could be established at greater than $99.0 \%$ probability and contained at least two identified unique peptides.

To estimate relative protein levels, Normalized Spectral Abundance Factor dNSAFs were calculated for each non- redundant protein, as described (Redwine et al., 2017). Average dNSAFs were calculated for each protein using replicates with non-zero dNSAF values. Enrichment of proteins in streptavidin affinity purifications from BiolDtagged stable cell lines relative to a control BiolD stable cell line were calculated as the ratio of average dNSAF (ratio = avg. dNSAFORF-BiolD: avg. dNSAFBiolD).

BiolD grayscale circle plots (Figure 2A, Figure 5A, Figure $6 \mathrm{~A}$, Figure 6 - figure supplement $1 A$ ) were generated by calculating the log2(fold enrichment) against the -log10(p-value), where the p-value (2tailed Student's T-test) was generated by comparing the replicate dNSAF values of target-BiolD dataset to the BiolD control. Potential interactions were considered statistically significant if they were $>3$-fold enriched in each dataset over BiolD-3X-FLAG control dataset and had $p$-values < 0.05 . The $\log 2$ (fold enrichment) and $-\log 10$ ( $p$-value) values were plotted for each protein in Cytoscape (Shannon et al., 2003). BiolD interaction diagrams (Figure $1 \mathrm{C}$ and Extended Data 1d-e) were also created using Cytoscape.

\section{Microscopy}

All immunofluorescence and live-cell imaging was performed using a Yokogawa W1 confocal scanhead mounted to a Nikon Ti2 microscope with an Apo TIRF 100x 1.49 NA objective. The microscope was run with NIS Elements using the $488 \mathrm{~nm}$ and $561 \mathrm{~nm}$ lines of a six-line $(405 \mathrm{~nm}, 445 \mathrm{~nm}$, $488 \mathrm{~nm}, 515 \mathrm{~nm}, 561 \mathrm{~nm}$, and $640 \mathrm{~nm}$ ) LUN-F-XL laser engine and a Prime95B camera (Photometrics). Cells were imaged in an Okolab Bold Line stage top incubator that was designed to fit in the piezo Z-stage (MadCity Labs).

\section{FHIP1B and FHIP2A imaging}

For imaging of FHIP1B-TagRFPT/FHIP2A-TagRFPT alone or with coexpression of GFP-tagged microtubules (mEmerald-Tubulin-6), putative cargos (GFP-Rab5B, EGFP-Rab1A, EGFP-Rab1A(Q70L), EGFPRab1A(S25N), EGFP-GOLGA4, TBC1D23-GFP, GMAP210-GFP, BET1GFP, SCFD1-GFP, EGFP-Rab2, EGFP-Rab18, EGFP-Rab30, Arf1-GFP, Sar1-GFP) or GFP control (pMX-GFP), $0.04 \times 10^{6}$ FHIP1B KO U2OS cells stably expressing FHIP1B-TagRFPT-V5 or FHIP2A KO U2OS cells stably expressing FHIP2A-TagRFPT-V5 were plated into a 6 -well glass bottom plate with \#1.5H coverglass (Cellvis) and grown for 24 hours. The next day, transfections were performed with Lipofectamine 2000 and $0.25-1 \mathrm{\mu g}$ of the appropriate DNA per well. The Lipofectamine/DNA mixture was added to wells containing fresh DMEM $+10 \%$ FBS (no antibiotics) and incubated overnight. Cells were imaged 24 hours after transfection on Fluorobrite DMEM (Thermo Fisher Scientific). Single-plane images were taken from each channel every $500 \mathrm{~ms}$ for 1 minute. Separate image channels were acquired with sequential acquisition, triggered acquisition, or simultaneous acquisition, as denoted in figure legends. For sequential acquisition, separate image channels of 488-561 were acquired using bandpass filters for each channel (525/50 and 595/50). For triggered acquisition of 488561 , firing of the $488 \mathrm{~nm}$ and $561 \mathrm{~nm}$ lasers was synchronized by the Prime95B trigger signal, which was integrated into a Nikon BB that itself was connected to a National Instruments 6723 DAQ board housed in an external Pxi chassis. A quad bandpass filter (Chroma ZET405/488/561/640mv2) was placed in the emission path of the W1 scanhead.

\section{Quantification of motile Rab1A tubules}

Quantification of the number of motile Rab1A tubules was performed in FIJI (Schindelin et al., 2012). The 488 (EGFP-Rab1A) and 561 (TagRFPT or FHIP2A-TagRFPT-V5) channels were split and individual cells identified and isolated from the EGFP-Rab1A channel. Slice label information was removed, cells were saved as separate files, and file names were blinded using the Blind Analysis Tools macro. For each cell, the number of motile tubules present during the one minute movie was then quantified manually using the multi-point tool. In order for a tubule to be counted, it had to move from its initial location and be more than $1 \mu \mathrm{m}$ long at some point during its motility. Tubules that did not move from their original location and puncta shorter than $1 \mu \mathrm{m}$ were not counted. Quantification of the percentage of cells with 5 or more motile tubules was performed similarly, except that cells were selected and blinded and quantifications tallied from both 488 (GFP or EGFP-Rab1A) and 561 (FHIP2A-TagRFPT) channels. Tubule length was quantified by measuring the length of each motile tubule identified in the above analysis at its longest point using FIJI. KruskalWallis with Dunn's post hoc test for multiple comparisons was performed using GraphPad Prism version 9.1.2 for Mac, GraphPad Software, San Diego, CA USA.

\section{HaloTag-Hook/Rab imaging}

For imaging colocalization of Hook proteins with Rab1A or Rab5B, $0.02 \times$ $10^{6} \mathrm{U} 2 \mathrm{OS}$ cells were plated into a 24-well glass bottom plate with \#1.5H coverglass (Cellvis) and grown for 24 hours. The next day, transfections were performed with Lipofectamine 2000 and $0.25 \mu \mathrm{g}$ of HaloTag3XFLAG, HaloTag-Hook1, HaloTag-Hook2, or HaloTag-Hook3 and 0.25 $\mu \mathrm{g}$ of pMX-GFP (Cell Biolabs), EGFP-Rab5B, or EGFP-Rab1A DNA per well ( $0.5 \mathrm{ug}$ total DNA in each well). The Lipofectamine/DNA mixture was added to wells containing fresh DMEM $+10 \%$ FBS (no antibiotics) and incubated overnight. The next day, Fluorobrite DMEM with $25 \mathrm{nM}$ HaloTagJF646 ligand in DMSO was added to the wells for 15 minutes under norma incubation conditions. Following incubation with dye, cells were rinsed once with warm Fluorobrite DMEM and imaged in fresh Fluorobrite DMEM Single plane images were taken every $500 \mathrm{~ms}$ for 30 seconds. Separate image channels were acquired with triggered acquisition of 488-640, firing of the $488 \mathrm{~nm}$ and $640 \mathrm{~nm}$ lasers was synchronized and filtered as described in 'FHIP1B and FHIP2A imaging'. Timelapse projections were generated by taking maximum intensity projections of the timelapse movie in FIJI.

\section{VSV-G imaging}

For imaging of FHIP2A/VSV-G colocalization, $0.075 \times 10^{6}$ FHIP2A KO U2OS cells stably expressing FHIP2A-TagRFPT-V5 were plated into a $35 \mathrm{~mm}$ glass bottom FluoroDish with $23 \mathrm{~mm}$ well (World Precision Instruments) and grown for 24 hours. The next day, transfections were performed with Lipofectamine 2000 and $0.5 \mu \mathrm{g}$ EGFP-VSV-G DNA per well. The Lipofectamine/DNA mixture was added to wells containing fresh DMEM $+10 \%$ FBS (no antibiotics). After 12 hours, cells were shifted to $40^{\circ} \mathrm{C}$ for 12 hours to retain EGFP-VSVG in the ER. Following incubation, cells were switched to Fluorobrite media. Immediately before imaging, cells were transferred to the microscope with Okolab chamber mounted and set to $40^{\circ} \mathrm{C}$. The temperature was then reduced to $32^{\circ} \mathrm{C}$ to induce transport of EGFP-VSVG from the ER and imaging was initiated. Separate image channels were acquired sequentially using bandpass filters for each channel (525/50 and 595/50). Single-plane images were taken from each channel approximately every second for 1 minute. 
bioRxiv preprint doi: https://doi.org/10.1101/2021.10.07.463551; this version posted October 8, 2021. The copyright holder for this preprint (which was not certified by peer review) is the author/funder, who has granted bioRxiv a license to display the preprint in perpetuity. It is made available under aCC-BY-NC-ND 4.0 International license.

Christensen, Kendrick et al., 10/06/2021

\section{Immunofluorescence}

\section{FHIP1B/Rab5B immunofluorescence}

For imaging of Rab5B accumulation surrounding the centrosome, $0.015 \times 10^{6} \mathrm{U} 20 \mathrm{~S}$ cells (Cas9 ctrl, FHIP1B KO, or FHIP1B KO stably expressing FHIP1B-TagRFPT-V5) were grown on fibronectin coated glass coverslips and fixed with a solution of $3.7 \%$ formaldehyde (Electron Microscopy Sciences), 90\% Methanol (VWR), and $5 \mathrm{mM}$ Sodium Bicarbonate (VWR Chemicals) in 1X PBS. Cells were washed with PBS then permeabilized and blocked with $5 \%$ normal goat serum (Cell Signaling Technology) and $1 \%$ BSA in PBS containing $0.3 \%$ Triton X-100 (Sigma). Cells were immunostained for 1 hour at room temperature with mouse monoclonal anti- - -tubulin (Abcam, Cat \#27074) and rabbit monoclonal anti-Rab5 (Cell Signaling, Cat \# 3547) diluted in PBS with $1 \%$ bovine serum albumin (BSA, Sigma) and $0.1 \%$ Triton $X-100$. Cells were washed with PBS and stained with goat anti-mouse IgG $(\mathrm{H}+\mathrm{L})$ Alexa Fluor-488 (Thermo Fisher Scientific cat. No. A11001, 1:500 dilution) and goat antirabbit IgG $(\mathrm{H}+\mathrm{L})$ Alexa Fluor-568 (Thermo Fisher cat. No. A11036, 1:500 dilution). Cells were then washed with PBS with calcium and magnesium (Thermo Fisher Scientific) and stained with iFluor ${ }^{T M} 647$ Wheat Germ Agglutinin Conjugate (AAT Bioquest) and DAPI. Cells and coverslips were mounted on glass slides with Prolong ${ }^{\text {TM }}$ Glass Antifade Mountant (Thermo Scientific Scientific). Z-stacks were acquired using a piezo $Z$ stage (Mad City Labs). Separate image channels were acquired sequentially using bandpass filters for each channel (405: 455/50, 488: 525/50, 561: 595/50, 640: 705/75)

To quantify early endosome accumulation at the centrosome, sum projections of Z-stacks were created in FIJI for each separate channel. Channels were separated and the brightest $\gamma$-tubulin puncta was identified in the 488 channel as the centrosome and a 60 pixel-wide circle was drawn around it, creating a region of interest (ROI). A whole cell $\mathrm{ROI}$ was then created from the 640 channel using wheat germ agglutinin as a cell membrane marker. Each ROI was then applied to the Rab5/561 channel to quantify the fluorescence intensity at the centrosome and of the whole cell. The fluorescence intensity at the centrosome divided by the whole cell fluorescence was then quantified to determine the percentage of total fluorescence present at the centrosome. Then, the area of the centrosome $\mathrm{ROI}$ was divided by the area of the whole cell ROI to determine the percentage of the area of the cell that the centrosome ROl included. The fluorescence intensity ratio was then divided by the area ratio and plotted using GraphPad Prism. Kruskal-Wallis with Dunn's post hoc test for multiple comparisons was performed using GraphPad Prism.

For imaging of colocalization between FHIP1B and Rab5, FHIP1B KO cells stably expressing FHIP1B-TagRFPT-V5 were grown, plated, fixed, and stained as described above, but with mouse monoclonal anti-V5 (Thermo Fisher Scientific, cat\# R960-25) and rabbit monoclonal anti-Rab5 (Cell Signaling, cat \# 3547) primary antibodies.

\section{Protein expression and purifications}

\section{Baculovirus generation from Sf9 insect cells}

Full-length SNAP-dynein, Lis1, Hook2-HaloTag, Hook3-HaloTag, HaloTag-FHIP1B-FTS, FHIP2A-HaloTag, and FTS-SNAP constructs were expressed in Sf9 cells as described previously (Baumbach et al., 2017; Htet et al., 2020; Schlager et al., 2014b). Briefly, the pDyn3 plasmid containing the human dynein genes, pFastBac, pLIB or pBIG plasmids containing the above indicated proteins (also listed in Table 1) were transformed into $\mathrm{DH} 10 \mathrm{EmBacY}$ chemically competent cells with heat shock at $42^{\circ} \mathrm{C}$ for 15 seconds followed by incubation at $37^{\circ} \mathrm{C}$ for 5 hours in S.O.C media (Thermo Fisher Scientific). The cells were then plated on LBagar plates containing kanamycin $(50 \mu \mathrm{g} / \mathrm{ml})$, gentamicin $(7 \mu \mathrm{g} / \mathrm{ml})$, tetracycline $(10 \mu \mathrm{g} / \mathrm{ml})$, BluoGal $(100 \mu \mathrm{g} / \mathrm{ml})$ and IPTG $(40 \mu \mathrm{g} / \mathrm{ml})$ and positive clones were identified by a blue/white color screen after 48 hours. For full-length human dynein constructs, white colonies were additionally tested for the presence of all six dynein genes using PCR. These colonies were then grown overnight in LB medium containing kanamycin $(50 \mu \mathrm{g} / \mathrm{ml})$, gentamicin $(7 \mu \mathrm{g} / \mathrm{ml})$ and tetracycline $(10 \mu \mathrm{g} / \mathrm{ml})$ at $37^{\circ} \mathrm{C}$. Bacmid DNA was extracted from overnight cultures using an isopropanol precipitation method as described previously (Zhang et al., 2017). $2 \mathrm{~mL}$ of Sf9 cells at $0.5 \times 10^{6}$ cells $/ \mathrm{mL}$ were transfected with $2 \mu \mathrm{g}$ of fresh bacmid DNA and FuGene HD transfection reagent (Promega) at a 3:1 transfection reagent to DNA ratio according to the manufacturer's instructions. After three days, the supernatant containing the "V0" virus was harvested by centrifugation at $200 \times \mathrm{g}$ for 5 minutes at $4^{\circ} \mathrm{C}$. To generate "V1", $1 \mathrm{~mL}$ of the $\mathrm{V} 0$ virus was used to transfect $50 \mathrm{~mL}$ of $S f 9$ cells at $1 \times 10^{6}$ cells $/ \mathrm{mL}$. After three days, the supernatant containing the $\mathrm{V} 1$ virus was harvested by centrifugation at 200 $\mathrm{x} \mathrm{g}$ for 5 minutes at $4^{\circ} \mathrm{C}$ and stored in the dark at $4^{\circ} \mathrm{C}$ until use. For protein expression, $4-6 \mathrm{~mL}$ of the $\mathrm{V} 1$ virus were used to transfect $400-600 \mathrm{~mL}$ of Sf9 cells at $1 \times 10^{6}$ cells $/ \mathrm{mL}$. After three days, the cells were harvested by centrifugation at $3000 \times \mathrm{g}$ for 10 minutes at $4^{\circ} \mathrm{C}$. The pellet was resuspended in $10 \mathrm{~mL}$ of ice-cold PBS and pelleted again. The pellet was flash frozen in liquid nitrogen and stored at $-80^{\circ} \mathrm{C}$ until further purification.

\section{Dynein}

Full-length dynein was purified as described previously (Schlager et al. $2014 \mathrm{~b})$. Frozen cell pellets from a $400 \mathrm{~mL}$ culture were resuspended in 40 $\mathrm{mL}$ of Dynein-lysis buffer (50 mM HEPES [pH 7.4], $100 \mathrm{mM}$ sodium chloride, $1 \mathrm{mM}$ DTT, $0.1 \mathrm{mM}$ Mg-ATP, $0.5 \mathrm{mM}$ Pefabloc, $10 \%$ (v/v) glycerol) supplemented with 1 cOmplete EDTA-free protease inhibitor cocktail tablet (Roche) per $50 \mathrm{~mL}$ and lysed using a Dounce homogenize (10 strokes with a loose plunger and 15 strokes with a tight plunger). The lysate was clarified by centrifuging at $183,960 \mathrm{x} \mathrm{g}$ for $88 \mathrm{~min}$ in Type $70 \mathrm{Ti}$ rotor (Beckman). The clarified supernatant was incubated with $4 \mathrm{~mL}$ of $\mathrm{IgG}$ Sepharose 6 Fast Flow beads (GE Healthcare Life Sciences) for 3-4 hours on a roller. The beads were transferred to a gravity flow column, washed with $200 \mathrm{~mL}$ of Dynein-lysis buffer and $300 \mathrm{~mL}$ of TEV buffer $(50 \mathrm{mM}$ Tris$\mathrm{HCl}[\mathrm{pH}$ 8.0], $250 \mathrm{mM}$ potassium acetate, $2 \mathrm{mM}$ magnesium acetate, $1 \mathrm{mM}$ EGTA, $1 \mathrm{mM}$ DTT, $0.1 \mathrm{mM}$ Mg-ATP, 10\% (v/v) glycerol). For fluorescent labeling of carboxy-terminal SNAPf tag, dynein-coated beads were labeled with 5 MM SNAP-Cell-TMR (New England Biolabs) in the column for $10 \mathrm{~min}$ at room temperature and unbound dye was removed with a $300 \mathrm{~mL}$ wash with TEV buffer at $4^{\circ} \mathrm{C}$. The beads were then resuspended and incubated in $15 \mathrm{~mL}$ of TEV buffer supplemented with $0.5 \mathrm{mM}$ Pefabloc and $0.2 \mathrm{mg} / \mathrm{mL}$ TEV protease (purified in the Reck-Peterson lab) overnight on a roller. The supernatant containing cleaved proteins was concentrated using a $100 \mathrm{~K}$ MWCO concentrator (EMD Millipore) to $500 \mu \mathrm{L}$ and purified via size exclusion chromatography on a TSKgel G4000SWXL column (TOSOH Bioscience) with GF150 buffer (25 mM HEPES [pH7 4], $150 \mathrm{mM}$ potassium chloride, $1 \mathrm{mM}$ magnesium chloride, $5 \mathrm{mM}$ DTT, $0.1 \mathrm{mM} \mathrm{Mg}$-ATP) at 1 $\mathrm{mL} / \mathrm{min}$. The peak fractions were collected, buffer exchanged into a GF150 buffer supplemented with $10 \%$ glycerol, concentrated to $0.1-0.5 \mathrm{mg} / \mathrm{mL}$ using a 100K MWCO concentrator (EMD Millipore). Purity was evaluated on SDS-PAGE gels and protein aliquots were snap frozen in liquid N2 and stored at $-80^{\circ} \mathrm{C}$.

\section{Lis1}

Lis 1 constructs were purified from frozen cell pellets from $400 \mathrm{~mL}$ culture as described previously (Baumbach et al., 2017). Lysis and clarification steps were similar to full-length dynein purification except lysis was performed in Lis1-lysis buffer ( $30 \mathrm{mM}$ HEPES [pH 7.4], $50 \mathrm{mM}$ potassium acetate, $2 \mathrm{mM}$ magnesium acetate, $1 \mathrm{mM}$ EGTA, $300 \mathrm{mM}$ potassium chloride, $1 \mathrm{mM}$ DTT, $0.5 \mathrm{mM}$ Pefabloc, 10\% (v/v) glycerol) supplemented with 1 cOmplete EDTA-free protease inhibitor cocktail tablet (Roche) per $50 \mathrm{~mL}$ was used. The clarified supernatant was incubated with $0.5 \mathrm{~mL}$ of IgG Sepharose 6 Fast Flow beads (GE Healthcare Life Sciences) for 2-3 hours on a roller. The beads were transferred to a gravity flow column, washed with $20 \mathrm{~mL}$ of Lis1-lysis buffer, $100 \mathrm{~mL}$ of modified TEV buffer (10 $\mathrm{mM}$ Tris- $\mathrm{HCl}[\mathrm{pH} 8.0$ ], $2 \mathrm{mM}$ magnesium acetate, $150 \mathrm{mM}$ potassium acetate, $1 \mathrm{mM}$ EGTA, $1 \mathrm{mM}$ DTT, $10 \%(\mathrm{v} / \mathrm{v})$ glycerol) supplemented with $100 \mathrm{mM}$ potassium acetate, and $50 \mathrm{~mL}$ of modified TEV buffer. Lis 1 was cleaved from IgG beads via incubation with $0.2 \mathrm{mg} / \mathrm{mL}$ TEV protease overnight on a roller. The cleaved Lis1 was filtered by centrifuging with an Ultrafree-MC VV filter (EMD Millipore) in a tabletop centrifuge. Purity was evaluated on SDS-PAGE gels and protein aliquots were snap frozen in liquid $\mathrm{N} 2$ and stored at $-80^{\circ} \mathrm{C}$.

\section{FHIP1B, FHIP2A, Hook2, and Hook3}

FHIP1B (FHIP1B-HaloTag-TEV-ZZ), FHIP2A (ZZ-TEV-HaloTag-FHIP2A) FHIP2A-FTS (ZZ-TEV-HaloTag-FHIP2A-3xFLAG-FTS), Hook2 (Hook2 HaloTag-Tev-ZZ) and Hook3 (Hook3-HaloTag-Tev-ZZ) were purified from Baculovirus-infected Sf9 insect cells as described for the dynein and Lis1 purifications with slight modifications. Cell pellets from $600 \mathrm{~mL}$ cultures were resuspended in lysis buffer $(50 \mathrm{mM}$ Tris- $\mathrm{HCl} \mathrm{pH} 7.4 ; 300 \mathrm{mM} \mathrm{NaCl})$ supplemented with 1X protease inhibitor cocktail (cOmplete Protease Inhibitor Cocktail, Roche), $1 \mathrm{mM}$ DTT and $0.5 \mathrm{mM}$ Pefabloc SC (SigmaAldrich). For fluorescent labeling of HaloTag, FHIP1B or FHIP2A-coated IgG beads were labeled with $5 \mu \mathrm{M}$ HaloTag-Alexa-660 (New England Biolabs) in the column for 10 minutes at room temperature and unbound dye was removed with a $300 \mathrm{~mL}$ wash with TEV buffer at $4^{\circ} \mathrm{C}$. After overnight protein cleavage from IgG beads with TEV protease the cleaved protein eluate was loaded onto a Mono Q 5/50 GL $1 \mathrm{~mL}$ column on an AKTA FPLC (Cytvia). The column was washed with $8 \mathrm{~mL}$ of Buffer A (50 $\mathrm{mM}$ Tris-HCl, $\mathrm{pH} 8.0 ; 1 \mathrm{mM}$ DTT) and then subjected to a $15 \mathrm{~mL}$ linear gradient from 10-55\% Buffer B mixed with Buffer A (Buffer B: 50 mM Tris$\mathrm{HCl}$, pH 8.0; $1 \mathrm{M} \mathrm{NaCl} ; 1 \mathrm{mM}$ DTT), followed by $5 \mathrm{~mL}$ additional $100 \%$ Buffer B. Fractions containing pure protein were pooled and buffer exchanged through iterative rounds of dilution and concentration on a 50 or $100 \mathrm{kDa}$ MWCO centrifugal filter (Amicon Ultra, Millipore) into fina storage buffer (25 mM HEPES pH 7.4; $50 \mathrm{mM} \mathrm{KCl,} 1 \mathrm{mM} \mathrm{MgCl}, 1 \mathrm{mM}$ 
bioRxiv preprint doi: https://doi.org/10.1101/2021.10.07.463551; this version posted October 8, 2021. The copyright holder for this preprint (which was not certified by peer review) is the author/funder, who has granted bioRxiv a license to display the preprint in perpetuity. It is made available under aCC-BY-NC-ND 4.0 International license.

Christensen, Kendrick et al., 10/06/2021

DTT, $10 \%$ glycerol). Purity was evaluated on SDS-PAGE gels and protein aliquots were snap frozen in liquid $\mathrm{N} 2$ and stored at $-80^{\circ} \mathrm{C}$.

\section{FTS}

FHIP1B (3XFLAG-SNAP-FTS) was purified from Baculovirus-infected Sf9 insect cells as described for the dynein and Lis1 purifications with slight modifications. Cell pellets from $400 \mathrm{~mL}$ cultures were resuspended in lysis buffer (50 mM Tris- $\mathrm{HCl}$ pH 7.4; $300 \mathrm{mM} \mathrm{NaCl}$ ) supplemented with 1X protease inhibitor cocktail (cOmplete Protease Inhibitor Cocktail, Roche), $1 \mathrm{mM}$ DTT and $0.5 \mathrm{mM}$ Pefabloc SC (Sigma-Aldrich). The clarified lysate was incubated with $1.5 \mathrm{~mL}$ packed anti-FLAG M2 agarose resin (Sigma) at $4^{\circ} \mathrm{C}$ for 16 hours. After incubation, the lysate/resin mixture was centrifuged at $1000 \times \mathrm{g}$ for 2 minutes at $4^{\circ} \mathrm{C}$ to pellet the resin and the supernatant was decanted. The resin was transferred to a column at $4^{\circ} \mathrm{C}$ and the column was washed with $100 \mathrm{~mL}$ low salt wash buffer $(50 \mathrm{mM}$ Tris- $\mathrm{HCl}, \mathrm{pH} 7.4: 50$ $\mathrm{mM} \mathrm{NaCl}$; $1 \mathrm{mM}$ DTT) $100 \mathrm{~mL}$ high salt wash buffer $(50 \mathrm{mM}$ Tris- $\mathrm{HCl}, \mathrm{pH}$ 7.4; $300 \mathrm{mM} \mathrm{NaCl} ; 1 \mathrm{mM} \mathrm{DTT} ; 0.02 \%$ Triton X-100), and finally with $50 \mathrm{~mL}$ of low salt wash buffer. The resin was resuspended in $800 \mu \mathrm{L}$ of low salt wash buffer containing $2 \mathrm{mg} / \mathrm{mL} 3 X-F L A G$ peptide (ApexBio) and incubated for $30 \mathrm{~min}$ at $4^{\circ} \mathrm{C}$. The mixture was retrieved and centrifuged through a small filter column to remove the resin. The eluate was next loaded onto a Mono Q $5 / 50 \mathrm{GL} 1 \mathrm{~mL}$ column on an AKTA FPLC (GE Healthcare). The column was washed with $5 \mathrm{~mL}$ of Buffer A (50 mM Tris$\mathrm{HCl}, \mathrm{pH} 8.0 ; 1 \mathrm{mM}$ DTT) and then subjected to a $15 \mathrm{~mL}$ linear gradient from $5-45 \%$ Buffer B mixed with Buffer A (Buffer $B=50 \mathrm{mM}$ Tris- $\mathrm{HCl}, \mathrm{pH} 8.0$; $1 \mathrm{M} \mathrm{NaCl} ; 1 \mathrm{mM}$ DTT), followed by $5 \mathrm{~mL}$ additional $100 \%$ Buffer $B$. Fractions containing pure FTS ( $35-40 \%$ Buffer B) were pooled and buffer exchanged through iterative rounds of dilution and concentration on a 30 kDa MWCO centrifugal filter (Amicon Ultra, Millipore) using GF150 buffer with $10 \%$ glycerol. For co-purification of FHIP1B and FTS, both proteins were co-expressed in Baculovirus-infected Sf9 insect cells as described above. After overnight protein cleavage from IgG beads with TEV protease the cleaved protein eluate was further purified via size exclusion chromatography on a Superdex 200 column (Cytvia) with modified GF150 buffer (25 mM HEPES [pH7.4], $150 \mathrm{mM}$ potassium chloride, $1 \mathrm{mM}$ DTT) at $1 \mathrm{~mL} / \mathrm{min}$. The peak fractions containing Alexa-660-HaloTag-FHIP1B coeluted with SNAP-FLAG were pooled and buffer exchanged through iterative rounds of dilution and concentration on a $100 \mathrm{kDa}$ MWCO centrifugal filter (Amicon Ultra, Millipore) into final storage buffer $(25 \mathrm{mM}$ HEPES pH 7.4; $150 \mathrm{mM}$ potassium chloride, $1 \mathrm{mM}$ DTT, $10 \%$ glycerol). Purity was evaluated on SDS-PAGE gels and protein aliquots were snap frozen in liquid $\mathrm{N} 2$ and stored at $-80^{\circ} \mathrm{C}$.

\section{Dynactin}

Dynactin (p62-HaloTag-3XFLAG) was purified from a stable 293T cell line as previously described (Redwine et al., 2017). Briefly, frozen pellets from $293 T$ cells $(160 \times 15 \mathrm{~cm}$ plates) were resuspended in DLB lysis buffer (30 mM HEPES, pH 7.4; 50 mM KOAc; 2 mM MgOAc; 1 mM EGTA, pH 7.5; $10 \%$ glycerol) supplemented with $0.5 \mathrm{mM}$ ATP, $0.2 \%$ Triton X-100 and $1 \mathrm{X}$ protease inhibitor cocktail (cOmplete Protease Inhibitor Cocktail, Roche) and gently mixed at $4^{\circ} \mathrm{C}$ for $15 \mathrm{~min}$. The lysed cells were then centrifuged at $66,000 \times \mathrm{g} \mathrm{rpm}$ in a Ti70 rotor (Beckman) at $4^{\circ} \mathrm{C}$ for $30 \mathrm{~min}$. The clarified lysate was retrieved and added to $3 \mathrm{~mL}$ packed anti-FLAG M2 agarose resin (Sigma) and incubated with gentle mixing at $4^{\circ} \mathrm{C}$ for 16 hours. After incubation, the lysate/resin mixture was centrifuged at $1000 \mathrm{xg}$ for 2 minutes at $4^{\circ} \mathrm{C}$ to pellet the resin and the supernatant was decanted. The resin was transferred to a column at $4^{\circ} \mathrm{C}$ and the column was washed with $100 \mathrm{~mL}$ low salt wash buffer (30 mM HEPES, pH 7.4; $50 \mathrm{mM} \mathrm{KOAc;} 2 \mathrm{mM}$ MgOAc; 1 mM EGTA, pH 7.5; $10 \%$ glycerol; 1 mM DTT; 0.5 mM ATP; 0.5 $\mathrm{mM}$ Pefabloc; $0.02 \%$ Triton X-100), $100 \mathrm{~mL}$ high salt wash buffer $(30 \mathrm{mM}$ HEPES, pH 7.4; 250 mM KOAc; 2 mM MgOAc; 1 mM EGTA, pH 7.5; $10 \%$ glycerol; $1 \mathrm{mM}$ DTT; $0.5 \mathrm{mM}$ ATP; $0.5 \mathrm{mM}$ Pefabloc; $0.02 \%$ Triton X-100), and finally with $50 \mathrm{~mL}$ of low salt wash buffer. The resin was resuspended in $800 \mu \mathrm{L}$ of low salt wash buffer containing $2 \mathrm{mg} / \mathrm{mL} 3 X-F L A G$ peptide (ApexBio) and incubated for $30 \mathrm{~min}$ at $4^{\circ} \mathrm{C}$. The mixture was retrieved and centrifuged through a small filter column to remove the resin. The eluate was then loaded onto a Mono Q 5/50 GL $1 \mathrm{~mL}$ column on an AKTA FPLC (GE Healthcare). The column was washed with $5 \mathrm{~mL}$ of Buffer $A$ ( $50 \mathrm{mM}$ Tris- $\mathrm{HCl}, \mathrm{pH}$ 8.0; $2 \mathrm{mM} \mathrm{MgOAc;} 1 \mathrm{mM}$ EGTA; $1 \mathrm{mM}$ DTT) and then subjected to a $26 \mathrm{~mL}$ linear gradient from $35-100 \%$ Buffer B mixed with Buffer A (Buffer B $=50 \mathrm{mM}$ Tris-HCl, $\mathrm{pH}$ 8.0; $1 \mathrm{M} \mathrm{KOAc;} 2 \mathrm{mM} \mathrm{MgOAc} ; 1$ $\mathrm{mM}$ EGTA; $1 \mathrm{mM}$ DTT), followed by $5 \mathrm{~mL}$ additional $100 \%$ Buffer $B$. Fractions containing pure dynactin $(\sim 75-80 \%$ Buffer $B)$ were pooled and buffer exchanged through iterative rounds of dilution and concentration on a $100 \mathrm{kDa}$ MWCO centrifugal filter (Amicon Ultra, Millipore) using GF150 buffer with $10 \%$ glycerol. Purity was evaluated on SDS-PAGE gels and protein aliquots were snap frozen in liquid $\mathrm{N} 2$ and stored at $-80^{\circ} \mathrm{C}$.

\section{Rab5B}

6xHis-SNAP-Rab5B(A2-G191) was transformed into BL21-CodonPlus (DE3)-RIPL cells (Agilent). $2 \mathrm{~L}$ of cells were grown at $37^{\circ} \mathrm{C}$ in $\mathrm{LB}$ media to a $600 \mathrm{~nm}$ optical density of $0.4-0.8$ before the temperature was reduced to $18^{\circ} \mathrm{C}$ and expression was induced with $0.5 \mathrm{mM}$ IPTG. After $16-18$ hours, the cells were harvested via centrifugation for $6 \mathrm{~min}$ at $4^{\circ} \mathrm{C}$ at $6,000 \times \mathrm{g}$ in a Beckman-Coulter JLA 8.1000 fixed angle rotor. Pellets were resuspended in $40 \mathrm{~mL}$ of Ni Buffer A (50 mM phosphate pH 7.4:500 mM $\mathrm{NaCl} ; 20 \mathrm{mM}$ Imidazole) supplemented with $0.5 \mathrm{mM}$ Pefabloc SC (SigmaAldrich) and $1 \mathrm{X}$ protease inhibitor cocktail (cOmplete Protease Inhibito Cocktail, Roche). Cells were lysed via sonication (Branson Digital Sonifier) and clarified via centrifugation at $66,000 \mathrm{x} \mathrm{g}$ for $30 \mathrm{~min}$ in a Type 70 Ti roto (Beckman) at $4^{\circ} \mathrm{C}$. The supernatant was loaded onto a HisTrap $5 / 501 \mathrm{~mL}$ column on an AKTA FPLC (Cytvia). The column was washed with $10 \mathrm{~mL}$ of Ni Buffer $A$ and then subjected to a $15 \mathrm{~mL}$ linear gradient from $10-55 \%$ Buffer B mixed with Buffer A (Buffer B: $50 \mathrm{mM}$ phosphate pH 7.4; $500 \mathrm{mM}$ $\mathrm{NaCl} ; 1 \mathrm{M}$ Imidazole), followed by $5 \mathrm{~mL}$ additional $100 \%$ Buffer $\mathrm{B}$. Fractions containing 6xHis-SNAP-Rab5B(A15-G191) were pooled, concentrated using a $10 \mathrm{kDa}$ MWCO centrifugal filter (Amicon Ultra, Millipore) and further purified using MonoQ Column as described for FHIP1B purification above. Fractions containing pure 6xHis-SNAP-Rab5B(A15-G191) ( 30\% Buffer $B$ ) were pooled and buffer exchanged through iterative rounds of dilution and concentration on a $10 \mathrm{kDa}$ MWCO centrifugal filter (Amicon Ultra, Millipore) into final storage buffer (50 mM Tris-HCl pH 7.4; $150 \mathrm{mM} \mathrm{NaCl}$ $5 \mathrm{mM} \mathrm{MgCl}_{2}, 1 \mathrm{mM}$ DTT, $10 \%$ glycerol). Purity was evaluated on SDSPAGE gels and protein aliquots were snap frozen in liquid N2 and stored at $-80^{\circ} \mathrm{C}$.

\section{GFP nanobody}

GFP-nanobody-6xHis was transformed into BL21-CodonPlus (DE3)-RIPL cells (Agilent) and protein expression and purification was performed as described above for Rab5B with slight modifications. His-Trap fractions containing GFP-nanobody-6xHis were pooled and concentrated using a 10 kDa MWCO centrifugal filter (Amicon Ultra, Millipore). Concentrated GFPnanobody-6xHis was applied to Superdex S75 Increase 10/300 GL Column connected to an AKTA FPLC (Cytvia) and run in a buffer containing $25 \mathrm{mM}$ HEPES pH 7.4; $50 \mathrm{mM} \mathrm{KCl} ; 1 \mathrm{mM} \mathrm{MgCl}_{2} ; 1 \mathrm{mM}$ DTT. Peak fractions containing pure GFP-nanobody-6xHis were pooled concentrated and buffer exchanged to the same buffer supplemented with $10 \%$ glycerol using a $10 \mathrm{kDa}$ MWCO centrifugal filter (Amicon Ultra, Millipore). Aliquots were snap frozen in LN2 and stored at $-80^{\circ} \mathrm{C}$. Protein purity was checked on a Sypro (Thermo Fisher Scientific) stained SDSPAGE gel.

\section{TIRF microscopy}

Imaging was performed with an inverted microscope (Nikon, Ti-E Eclipse) equipped with a $100 \times 1.49$ N.A. oil immersion objective (Nikon, Plano Apo) The xy position of the stage was controlled by ProScan linear motor stage controller (Prior). The microscope was equipped with an MLC400B lase launch (Agilent) equipped with $405 \mathrm{~nm}(30 \mathrm{~mW}), 488 \mathrm{~nm}(90 \mathrm{~mW}), 561 \mathrm{~nm}$ $(90 \mathrm{~mW})$, and $640 \mathrm{~nm}(170 \mathrm{~mW})$ laser lines. The excitation and emission paths were filtered using appropriate single bandpass filter cubes (Chroma). The emitted signals were detected with an electron multiplying CCD camera (Andor Technology, iXon Ultra 888). Illumination and image acquisition was controlled by NIS Elements Advanced Research software (Nikon).

\section{Single-molecule motility assays}

Single-molecule motility assays were performed in flow chambers assembled as described previously (Case et al., 1997) using the TIRF microscopy set up described above. Biotinylated and PEGylated coverslips (Microsurfaces) were used to reduce non-specific binding. Microtubules were polymerized from tubulin prepared from bovine brain as previously described (Waterman-Storer, 2001). Microtubules contained 10\% biotintubulin for attachment to streptavidin-coated cover slip and $\sim 10 \%$ Alexa Fluor 488 (Thermo Fisher Scientific) tubulin for visualization. Imaging buffer was DLB supplemented with $20 \mu \mathrm{M}$ taxol, $1 \mathrm{mg} / \mathrm{mL}$ casein, $1 \mathrm{mM}$ Mg-ATP, $71.5 \mathrm{mM}$ BME (beta mercaptoethanol) and an oxygen scavenger system, $0.4 \%$ glucose, $45 \mu \mathrm{g} / \mathrm{ml}$ glucose catalase (Sigma-Aldrich), and $1.15 \mathrm{mg} / \mathrm{ml}$ glucose oxidase (Sigma-Aldrich). Images were recorded every $0.4 \mathrm{sec}$ for 3 minutes. Movies showing significant drift were not analyzed.

All movies were collected in two-color set up with the following protein concentrations: $125 \mathrm{pM}$ TMR-dynein, $250 \mathrm{pM}$ unlabeled dynactin, 9 nM Hook3 or Hook2, 450 nM FTS, 450 nM FHIP1B (FHIP1B-HaloTagAlexa660) or $450 \mathrm{nM}$ FHIP2A (FHIP2A-HaloTag-Alexa660). All experiments performed with Hook2, unless otherwise stated, also included $15 \mathrm{nM}$ Lis1. For conditions missing one of the indicated protein components, corresponding matching buffers were used. The FHF 
bioRxiv preprint doi: https://doi.org/10.1101/2021.10.07.463551; this version posted October 8, 2021. The copyright holder for this preprint (which was not certified by peer review) is the author/funder, who has granted bioRxiv a license to display the preprint in perpetuity. It is made available under aCC-BY-NC-ND 4.0 International license.

Christensen, Kendrick et al., 10/06/2021

complexes composed of FTS, Hook2 or Hook3 and FHIP1B or FHIP2A samples were incubated on ice for 10 minutes prior to dynein and dynactin addition. Each protein mixture was then incubated on ice for an additional 5 minutes following Lis 1 addition and an additional 5 minutes incubation on ice prior to TIRF imaging.

\section{TIRF data analysis}

The velocity of moving particles was calculated form kymographs generated in ImageJ as described previously (Roberts et al., 2014). Velocities were only calculated from molecules that moved processively for greater than 5 frames. Non-motile or diffusive events were not considered in velocity calculations. Processive events were defined as events that move unidirectionally and do not exhibit directional changes greater than $600 \mathrm{~nm}$. Diffusive events were defined as events that exhibit at least one bidirectional movement greater than $600 \mathrm{~nm}$ in each direction. Singlemolecule movements that change apparent behavior (e.g., shift from nonmotile to processive) were considered as multi-velocity events and counted as multiple events. For run length analysis the length of each track in a multi-velocity event was combined to calculate the total run length. Landing rates were calculated by counting the number of processive events that start after the first frame and end before the last frame of each movie and dividing this number by the microtubule length and total movie time. Pausing frequencies were calculated by counting the total number of pauses in multi-velocity events and dividing this number by the total run length. Colocalization events were manually scored in kymographs. Twocolor partially colocalized processive events were counted as colocalized events.

Data visualization and statistical analyses were performed using GraphPad Prism (9.2; GraphPad Software), Excel (version 16.52; Microsoft), and ImageJ (2.0). Brightness and contrast were adjusted in Image $\mathrm{J}$ for all videos and kymographs. The exact value of $n$, evaluation of statistical significance, and the specific statistical analysis are described in the corresponding figures and figure legends. All experiments were analyzed from at least three independent replicates and cumulative data are shown in each figure, unless otherwise indicated.

\section{In vitro binding assay}

Direct binding between Rab5B and FHIP1B was assessed by incubating $15 \mu \mathrm{M}$ 6xHis-SNAP-Rab5B with 25-molar excess of GTPyS (Abcam) or GPD (Abcam) in nucleotide buffer $(50 \mathrm{mM}$ Tris- $\mathrm{HCl} \mathrm{pH} \mathrm{7.5,300} \mathrm{mM} \mathrm{NaCl,}$ $10 \mathrm{mM}$ EDTA) overnight at $4^{\circ} \mathrm{C}$. The next day, reactions were supplemented with $15 \mathrm{mM} \mathrm{MgCl} 2$ and nucleotide bound 6xHis-SNAPRab5B was diluted to $5 \mu \mathrm{M}$ in Ni-binding buffer ( $50 \mathrm{mM}$ Tris- $\mathrm{HCl} \mathrm{pH} 7.5$, $500 \mathrm{mM} \mathrm{NaCl}, 20 \mathrm{mM}$ Imidazole, $0.1 \%$ casein). 6xHis-SNAP-Rab5B was then captured onto $20 \mu \mathrm{L}$ Dynabeads His-Tag Magnetic Beads (Thermo Fisher Scientific) and washed three times in Ni-binding buffer in $2 \mathrm{~mL}$ Protein Lo Bind Tubes (Eppendorf). Bead conjugated 6xHis-SNAP-Rab5B was incubated for 15 minutes in room temperature with gentle agitation. The beads were then washed three times with Ni-binding buffer and 250 nM FHIP1B-HaloTag diluted in modified Ni-binding buffer $(25 \mathrm{mM}$ Tris- $\mathrm{HCl}$ $\mathrm{pH} 7.5,250 \mathrm{mM} \mathrm{NaCl}, 10 \mathrm{mM}$ Imidazole, $0.1 \%$ casein) was added to the beads. FHIP1B-HaloTag-conjugated bead complexes were gently shaken for 30 minutes at room temperature following three washes with $1 \mathrm{~mL} \mathrm{Ni-}$ binding buffer. FHIP1B-HaloTag was eluted of the beads by applying 30 $\mu \mathrm{L}$ of elution buffer $(50 \mathrm{mM}$ Tris- $\mathrm{HCl} \mathrm{pH} 7.5,150 \mathrm{mM} \mathrm{NaCl}, 300 \mathrm{mM}$ Imidazole, $0.01 \% \mathrm{NP}-40$ ) and 10 minutes incubation at room temperature. The elution was analyzed via SDS-PAGE on a gel stained with SYPRO TM Red (Thermo Fisher Scientific).

\section{Homolog identification}

FTS/AKTIP (FTS), Hook, and FHIP homologs in Figure 1B and Figure 1 figure supplement $1 \mathrm{~A}$ were identified by reciprocal protein BLAST (BLASTp) search (Altschul et al., 1990). FTS (Uniprot accession: Q9H8T0), Hook1 (UniProt accession: Q9UJC3), Hook2 (Q96ED9), Hook3 (Q86VS8), FHIP1A (Q05DH4), FHIP1B (Q8N612), FHIP2A (Q5W0V3), or FHIP2B (Q86V87) protein sequences from Homo sapiens were retrieved from UniProtKB. Each protein sequence was used as a BLASTp query using the following BLASTp algorithm parameters (BLOSUM 62 matrix, word size 3 , filtering low complexity regions) within the reference protein (refseq protein) organism databases for Mus musculus (BLAST taxid: 10090), Xenopus laevis (taxid: 8355), Danio rerio (taxid: 7955), Ciona intestinalis (taxid: 7719), Drosophila melanogaster (taxid: 7227), Caenorhabditis elegans (taxid: 6239), Nematostella vectensis (taxid: 45351), Ustilago maydis (taxid: 5270), Schizosaccharomyces pombe (taxid: 4896), Aspergillus nidulans (taxid: 162425), and Saccharomyces cerevisiae (taxid: 4932). A follow-up PSI-BLAST search using the same parameters and Drosophila melanogaster hook (Uniprot accession: $\mathrm{Q} 24185)$ as a query and three iterations of max 500 sequences was also performed. From each organism, identified proteins with an e-value of less than $1.0 \times 10^{-5}$ were identified. Each of these hits was then used as a BLASTp query against the Homo sapiens database (taxid: 9606) to determine if the corresponding Homo sapiens protein was the top reciprocal hit. Homologs found on both Xenopus laevis S- and Lsubgenomes were only counted as a single homolog. Any identified protein in which the corresponding Homo sapiens protein was also the top reciprocal hit was counted as a putative homolog on Figure $1 \mathrm{~B}$ and Figure 1 - figure supplement $1 \mathrm{~A}$. These searches did not identify Aspergillus nidulans FhipA (gene AN10801), but this protein has been previously identified and characterized as a FHIP homolog (Yao et al. 2014).

\section{Author Contributions}

JRC, AAK and SLRP designed research. JRC, AAK, JBT, AA-M, VA, and MD performed research. JRC, AAK and SLRP analyzed data and wrote the manuscript.

The authors declare no conflict of interest.

This article contains supporting information online.

\section{Acknowledgments}

We thank Eric Griffis, Hiroyuki Hakozaki, and the Nikon Imaging Center at UC San Diego for assistance with live-cell imaging and quantification. JRC is funded by a MOSAIC K99/R00 award from the National Institutes of Health (K99GM140269). AAK is supported by American Cancer Society PF-18-190-01-CCG. SLRP is supported by the Howard Hughes Medical Institute and NIH grants R01GM121772 and 1R35GM141825.

\section{References}

Altschul SF, Gish W, Miller W, Myers EW, Lipman DJ. 1990. Basic local alignment search tool. Journal of Molecular Biology 215:403-410. doi:10.1016/S0022-2836(05)80360-2

Baumbach J, Murthy A, McClintock MA, Dix Cl, Zalyte R, Hoang HT, Bullock SL. 2017. Lissencephaly-1 is a context-dependent regulator of the human dynein complex. eLife 6:711. doi:10.7554/eLife.21768

Ben-Tekaya H, Miura K, Pepperkok R, Hauri H-P. 2005a. Live imaging of bidirectional traffic from the ERGIC. Journal of Cell Science 118:357367. doi:10.1242/jcs.01615

Ben-Tekaya H, Miura K, Pepperkok R, Hauri H-P. 2005b. Live imaging of bidirectional traffic from the ERGIC. Journal of Cell Science 118:357367. doi:10.1242/jcs.01615

Bielska E, Schuster M, Roger Y, Berepiki A, Soanes DM, Talbot NJ, Steinberg G. 2014. Hook is an adapter that coordinates kinesin-3 and dynein cargo attachment on early endosomes. The Journal of cell biology 204:989-1007.

Burute M, Kapitein LC. 2019. Cellular Logistics: Unraveling the Interplay Between Microtubule Organization and Intracellular Transport. Annual Review of Cell and Developmental Biology 35:29-54. doi:10.1146/annurev-cellbio-100818-125149

Choudhury A, Dominguez M, Puri V, Sharma DK, Narita K, Wheatley CL, Marks DL, Pagano RE. 2002. Rab proteins mediate Golgi transport of caveola-internalized glycosphingolipids and correct lipid trafficking in Niemann-Pick C cells. J Clin Invest 109:1541-1550. doi:10.1172/JCl15420

Chun J, Shapovalova Z, Dejgaard SY, Presley JF, Melançon P. 2008. Characterization of class I and II ADP-ribosylation factors (Arfs) in live cells: GDP-bound class II Arfs associate with the ER-Golgi intermediate compartment independently of GBF1. Mol Biol Cell 19:3488-3500. doi:10.1091/mbc.e08-04-0373

Day RN, Davidson MW. 2009. The fluorescent protein palette: tools for cellular imaging. Chem Soc Rev 38:2887-2921. doi:10.1039/B901966A 
bioRxiv preprint doi: https://doi.org/10.1101/2021.10.07.463551; this version posted October 8, 2021. The copyright holder for this preprint (which was not certified by peer review) is the author/funder, who has granted bioRxiv a license to display the preprint in perpetuity. It is made available under aCC-BY-NC-ND 4.0 International license.

Christensen, Kendrick et al., 10/06/2021

Dwivedi D, Kumari A, Rathi S, Mylavarapu SVS, Sharma M. 2019. The dynein adaptor Hook2 plays essential roles in mitotic progression and cytokinesis. J Cell Biol 151:jcb.201804183.

Eden E, Lipson D, Yogev S, Yakhini Z. 2007. Discovering Motifs in Ranked Lists of DNA Sequences. PLoS Comput Biol 3:e39. doi:10.1371/journal.pcbi.0030039

Eden E, Navon R, Steinfeld I, Lipson D, Yakhini Z. 2009. GOrilla: a tool for discovery and visualization of enriched $\mathrm{GO}$ terms in ranked gene lists. BMC Bioinformatics 10:48. doi:10.1186/1471-2105-10-48

Elshenawy MM, Kusakci E, Volz S, Baumbach J, Bullock SL, Yildiz A. 2020. Lis1 activates dynein motility by modulating its pairing with dynactin. Nat Cell Biol 22:570-578. doi:10.1038/s41556-020-0501-4

Ferreira JP, Peacock RWS, Lawhorn IEB, Wang CL. 2011. Modulating ectopic gene expression levels by using retroviral vectors equipped with synthetic promoters. Systems and synthetic biology 5:131-138.

Guo X, Farías GG, Mattera R, Bonifacino JS. 2016. Rab5 and its effector FHF contribute to neuronal polarity through dynein-dependent retrieval of somatodendritic proteins from the axon. Proceedings of the National Academy of Sciences of the United States of America 113:E5318-27.

Herrmann L, Wiegmann C, Arsalan-Werner A, Hilbrich I, Jäger C, Flach K, Suttkus A, Lachmann I, Arendt T, Holzer M. 2015. Hook Proteins: Association with Alzheimer Pathology and Regulatory Role of Hook3 in Amyloid Beta Generation. PLoS ONE 10:e0119423. doi:10.1371/journal.pone.0119423

Hirokawa N, Noda Y, Tanaka Y, Niwa S. 2009. Kinesin superfamily motor proteins and intracellular transport. Nat Rev Mol Cell Biol 10:682-696. doi:10.1038/nrm2774

Hirschberg K, Miller CM, Ellenberg J, Presley JF, Siggia ED, Phair RD, Lippincott-Schwartz J. 1998. Kinetic Analysis of Secretory Protein Traffic and Characterization of Golgi to Plasma Membrane Transport Intermediates in Living Cells. Journal of Cell Biology 143:1485-1503. doi:10.1083/jcb.143.6.1485

Hirst J, Edgar JR, Borner GHH, Li S, Sahlender DA, Antrobus R, Robinson MS. 2015. Contributions of epsinR and gadkin to clathrin-mediated intracellular trafficking. Mol Biol Cell 26:3085-3103. doi:10.1091/mbc.E15-04-0245

Homma Y, Hiragi S, Fukuda M. 2021. Rab family of small GTPases: an updated view on their regulation and functions. The FEBS Journal 288:36-55. doi:10.1111/febs.15453

Hoogenraad CC, Akhmanova A, Howell SA, Dortland BR, De Zeeuw Cl, Willemsen R, Visser P, Grosveld F, Galjart N. 2001. Mammalian Golgi-associated Bicaudal-D2 functions in the dynein-dynactin pathway by interacting with these complexes. EMBO $J$ 20:40414054. doi:10.1093/emboj/20.15.4041

Horgan CP, Hanscom SR, Jolly RS, Futter CE, McCaffrey MW. 2010. Rab11-FIP3 links the Rab11 GTPase and cytoplasmic dynein to mediate transport to the endosomal-recycling compartment. J Cell Sci 123:181-191. doi:10.1242/jcs.052670

Htet ZM, Gillies JP, Baker RW, Leschziner AE, DeSantis ME, ReckPeterson SL. 2020. LIS1 promotes the formation of activated cytoplasmic dynein-1 complexes. Nat Cell Biol 22:518-525. doi:10.1038/s41556-020-0506-z

Huang B, Hubber A, McDonough JA, Roy CR, Scidmore MA, Carlyon JA. 2010. The Anaplasma phagocytophilum-occupied vacuole selectively recruits Rab-GTPases that are predominantly associated with recycling endosomes. Cell Microbiol 12:1292-1307. doi:10.1111/j.1462-5822.2010.01468.x

Kendrick AA, Dickey AM, Redwine WB, Tran PT, Vaites LP, Dzieciatkowska M, Harper JW, Reck-Peterson SL. 2019. Hook3 is a scaffold for the opposite-polarity microtubule-based motors cytoplasmic dynein-1 and KIF1C. J Cell Biol 218:2982-3001.

Kim DI, Jensen SC, Noble KA, Kc B, Roux KH, Motamedchaboki K, Roux KJ. 2016. An improved smaller biotin ligase for BiolD proximity labeling. Mol Biol Cell 27:1188-1196. doi:10.1091/mbc.E15-12-0844
Kollmar M, Mühlhausen S. 2017. Myosin repertoire expansion coincides with eukaryotic diversification in the Mesoproterozoic era. BMC Evolutionary Biology 17:211. doi:10.1186/s12862-017-1056-2

Lee I-G, Olenick MA, Boczkowska M, Franzini-Armstrong C, Holzbaur ELF, Dominguez R. 2018. A conserved interaction of the dynein light intermediate chain with dynein-dynactin effectors necessary for processivity. Nature communications 9:986.

Marra P, Maffucci T, Daniele T, Tullio GD, Ikehara Y, Chan EKL, Luini A, Beznoussenko G, Mironov A, De Matteis MA. 2001. The GM130 and GRASP65 Golgi proteins cycle through and define a subdomain of the intermediate compartment. Nat Cell Biol 3:1101-1113. doi:10.1038/ncb1201-1101

Matanis T, Akhmanova A, Wulf P, Nery ED, Weide T, Stepanova T, Galjart N, Grosveld F, Goud B, Zeeuw CID, Barnekow A, Hoogenraad CC. 2002. Bicaudal-D regulates COPI-independent Golgi-ER transport by recruiting the dynein-dynactin motor complex. Nat Cell Biol 4:986992. doi:10.1038/ncb891

Mattera R, Williamson CD, Ren X, Bonifacino JS. 2020. The FTS-HookFHIP (FHF) complex interacts with AP-4 to mediate perinuclear distribution of AP-4 and its cargo ATG9A. Molecular Biology of the Cell 31:17.

McKenney RJ, Huynh W, Tanenbaum ME, Bhabha G, Vale RD. 2014. Activation of cytoplasmic dynein motility by dynactin-cargo adapter complexes. Science 345:337-341. doi:10.1126/science.1254198

Miki H, Okada Y, Hirokawa N. 2005. Analysis of the kinesin superfamily: insights into structure and function. Trends in Cell Biology 15:467476. doi:10.1016/j.tcb.2005.07.006

Olenick MA, Dominguez R, Holzbaur ELF. 2019. Dynein activator Hook1 is required for trafficking of BDNF-signaling endosomes in neurons. Journal of Cell Biology 218:220-233. doi:10.1083/jcb.201805016

Presley JF, Cole NB, Schroer TA, Hirschberg K, Zaal KJM, LippincottSchwartz J. 1997. ER-to-Golgi transport visualized in living cells. Nature 389:81-85. doi:10.1038/38001

Pylypenko O, Hammich H, Yu I-M, Houdusse A. 2018. Rab GTPases and their interacting protein partners: Structural insights into Rab functional diversity. Small GTPases 9:22-48. doi:10.1080/21541248.2017.1336191

Reck-Peterson SL, Redwine WB, Vale RD, Carter AP. 2018. The cytoplasmic dynein transport machinery and its many cargoes. Nature reviews Molecular cell biology 19:382-398.

Redwine WB, DeSantis ME, Hollyer I, Htet ZM, Tran PT, Swanson SK Florens L, Washburn MP, Reck-Peterson SL. 2017. The human cytoplasmic dynein interactome reveals novel activators of motility. eLife 6:e28257. doi:10.7554/eLife.28257

Roux KJ, Kim DI, Raida M, Burke B. 2012. A promiscuous biotin ligase fusion protein identifies proximal and interacting proteins in mammalian cells. $J$ Cell Biol 196:801-810. doi:10.1083/jcb.201112098

Rowland AA, Chitwood PJ, Phillips MJ, Voeltz GK. 2014. ER contact sites define the position and timing of endosome fission. Cell 159:10271041. doi:10.1016/j.cell.2014.10.023

Rzomp KA, Scholtes LD, Briggs BJ, Whittaker GR, Scidmore MA. 2003. Rab GTPases are recruited to chlamydial inclusions in both a species-dependent and species-independent manner. Infect Immun 71:5855-5870. doi:10.1128/IAI.71.10.5855-5870.2003

Sannerud R, Marie M, Nizak C, Dale HA, Pernet-Gallay K, Perez F, Goud B, Saraste J. 2006a. Rab1 defines a novel pathway connecting the pre-Golgi intermediate compartment with the cell periphery. Mol Biol Cell 17:1514-1526. doi:10.1091/mbc.e05-08-0792

Sannerud R, Marie M, Nizak C, Dale HA, Pernet-Gallay K, Perez F, Goud B, Saraste J. 2006b. Rab1 defines a novel pathway connecting the pre-Golgi intermediate compartment with the cell periphery. Mol Biol Cell 17:1514-1526. doi:10.1091/mbc.e05-08-0792 
bioRxiv preprint doi: https://doi.org/10.1101/2021.10.07.463551; this version posted October 8, 2021. The copyright holder for this preprint (which was not certified by peer review) is the author/funder, who has granted bioRxiv a license to display the preprint in perpetuity. It is made available under aCC-BY-NC-ND 4.0 International license.

Christensen, Kendrick et al., 10/06/2021

Saraste J, Lahtinen U, Goud B. 1995. Localization of the small GTPbinding protein rab1p to early compartments of the secretory pathway. J Cell Sci 108 ( Pt 4):1541-1552.

Schindelin J, Arganda-Carreras I, Frise E, Kaynig V, Longair M, Pietzsch T, Preibisch S, Rueden C, Saalfeld S, Schmid B, Tinevez J-Y, White DJ, Hartenstein V, Eliceiri K, Tomancak P, Cardona A. 2012. Fiji: an open-source platform for biological-image analysis. Nat Methods 9:676-682. doi:10.1038/nmeth.2019

Schlager MA, Hoang HT, Urnavicius L, Bullock SL, Carter AP. 2014a. In vitro reconstitution of a highly processive recombinant human dynein complex. EMBO J 33:1855-1868. doi:10.15252/embj.201488792

Schlager MA, Hoang HT, Urnavicius L, Bullock SL, Carter AP. 2014b. In vitro reconstitution of a highly processive recombinant human dynein complex. The EMBO Journal 33:1855-1868. doi:10.15252/embj.201488792

Schlager MA, Kapitein LC, Grigoriev I, Burzynski GM, Wulf PS, Keijzer N, de Graaff E, Fukuda M, Shepherd IT, Akhmanova A, Hoogenraad CC. 2010. Pericentrosomal targeting of Rab6 secretory vesicles by Bicaudal-D-related protein 1 (BICDR-1) regulates neuritogenesis. EMBO J 29:1637-1651. doi:10.1038/emboj.2010.51

Schwaninger R, Plutner H, Bokoch GM, Balch WE. 1992. Multiple GTPbinding proteins regulate vesicular transport from the ER to Golgi membranes. Journal of Cell Biology 119:1077-1096. doi:10.1083/jcb.119.5.1077

Shannon P, Markiel A, Ozier O, Baliga NS, Wang JT, Ramage D, Amin N, Schwikowski B, Ideker T. 2003. Cytoscape: A Software Environment for Integrated Models of Biomolecular Interaction Networks. Genome Res 13:2498-2504. doi:10.1101/gr.1239303

Shin JJH, Gillingham AK, Begum F, Chadwick J, Munro S. 2017. TBC1D23 is a bridging factor for endosomal vesicle capture by golgins at the trans-Golgi. Nature cell biology 19:1424-1432.

Sowa ME, Bennett EJ, Gygi SP, Harper JW. 2009. Defining the human deubiquitinating enzyme interaction landscape. Cell 138:389-403.

Suda Y, Kurokawa K, Nakano A. 2018. Regulation of ER-Golgi Transport Dynamics by GTPases in Budding Yeast. Front Cell Dev Biol 5. doi:10.3389/fcell.2017.00122

Thul PJ, Åkesson L, Wiking M, Mahdessian D, Geladaki A, Ait Blal H, Alm T, Asplund A, Björk L, Breckels LM, Bäckström A, Danielsson F, Fagerberg L, Fall J, Gatto L, Gnann C, Hober S, Hjelmare M, Johansson F, Lee S, Lindskog C, Mulder J, Mulvey CM, Nilsson P, Oksvold P, Rockberg J, Schutten R, Schwenk JM, Sivertsson A, Sjöstedt E, Skogs M, Stadler C, Sullivan DP, Tegel H, Winsnes C, Zhang C, Zwahlen M, Mardinoglu A, Pontén F, von Feilitzen K, Lilley
KS, Uhlén M, Lundberg E. 2017. A subcellular map of the human proteome. Science 356:eaal3321. doi:10.1126/science.aal3321

Tisdale EJ, Bourne JR, Khosravi-Far R, Der CJ, Balch WE. 1992. GTPbinding mutants of rab1 and rab2 are potent inhibitors of vesicular transport from the endoplasmic reticulum to the Golgi complex. Journal of Cell Biology 119:749-761. doi:10.1083/jcb.119.4.749

Wang Y, Huynh W, Skokan TD, Lu W, Weiss A, Vale RD. 2019. CRACR2a is a calcium-activated dynein adaptor protein that regulates endocytic traffic. The Journal of Cell Biology 218:1619-1633. doi:10.1083/jcb.201806097

Weigel AV, Chang C-L, Shtengel G, Xu CS, Hoffman DP, Freeman M, lyer N, Aaron J, Khuon S, Bogovic J, Qiu W, Hess HF, Lippincott-Schwartz J. 2021. ER-to-Golgi protein delivery through an interwoven, tubular network extending from ER. Cell 184:2412-2429.e16. doi:10.1016/j.cell.2021.03.035

Welburn JPI. 2013. The Molecular Basis for Kinesin Functional Specificity During Mitosis. Cytoskeleton (Hoboken) 70:476-493. doi: $10.1002 / \mathrm{cm} .21135$

Westrate LM, Hoyer MJ, Nash MJ, Voeltz GK. 2020. Vesicular and uncoated Rab1-dependent cargo carriers facilitate ER to Golgi transport. J Cell Sci 133. doi:10.1242/jcs.239814

Xu L, Sowa ME, Chen J, Li X, Gygi SP, Harper JW. 2008. An FTS/Hook/p107(FHIP) complex interacts with and promotes endosomal clustering by the homotypic vacuolar protein sorting complex. Molecular biology of the cell 19:5059-5071.

Yan R, Chen K, Xu K. 2021. Tubular ERGIC (t-ERGIC): a SURF4mediated expressway for ER-to-Golgi transport (preprint). Cell Biology. doi:10.1101/2021.04.06.438517

Yao X, Wang X, Xiang X. 2014. FHIP and FTS proteins are critical for dynein-mediated transport of early endosomes in Aspergillus. Molecular biology of the cell 25:2181-2189.

Zhang J, Qiu R, Arst HN, Peñalva MA, Xiang X. 2014. HookA is a novel dynein-early endosome linker critical for cargo movement in vivo. The Journal of cell biology 204:1009-1026.

Zhang K, Foster HE, Rondelet A, Lacey SE, Bahi-Buisson N, Bird AW, Carter AP. 2017. Cryo-EM Reveals How Human Cytoplasmic Dynein Is Auto-inhibited and Activated. Cell 169:1303-1314.e18. doi:10.1016/j.cell.2017.05.025

Zhang Y, Wen Z, Washburn MP, Florens L. 2010. Refinements to Label Free Proteome Quantitation: How to Deal with Peptides Shared by Multiple Proteins. Anal Chem 82:2272-2281. doi:10.1021/ac9023999 
bioRxiv preprint doi: https://doi.org/10.1101/2021.10.07.463551; this version posted October 8, 2021. The copyright holder for this preprint (which was not certified by peer review) is the author/funder, who has granted bioRxiv a license to display the preprint in perpetuity. It is made available under aCC-BY-NC-ND 4.0 International license.

Christensen, Kendrick et al., 10/06/2021

Table 1: Plasmids used in this study

\begin{tabular}{|c|c|c|}
\hline Plasmid & Source or reference & Addgene \# (if applicable) \\
\hline GFP-HA & This study & N/A \\
\hline sfGFP-3XFLAG & Redwine et al., 2019 & N/A \\
\hline pMX-GFP & Cell Biolabs, Cat. \#RTV-050 & $\mathrm{N} / \mathrm{A}$ \\
\hline 3XHA-Rab5A & This study & $\mathrm{N} / \mathrm{A}$ \\
\hline 3XHA-Rab5A (Q79L) & This study & N/A \\
\hline 3XHA-Rab5A (N113I) & This study & $\mathrm{N} / \mathrm{A}$ \\
\hline 3XHA-Rab5B & This study & $\mathrm{N} / \mathrm{A}$ \\
\hline 3XHA-Rab5B (Q79L) & This study & N/A \\
\hline 3XHA-Rab5B (S34N) & This study & $\mathrm{N} / \mathrm{A}$ \\
\hline 3XHA-Rab5C & This study & $\mathrm{N} / \mathrm{A}$ \\
\hline 3XHA-Rab5C (Q80L) & This study & $\mathrm{N} / \mathrm{A}$ \\
\hline 3XHA-Rab5C (S35N) & This study & $\mathrm{N} / \mathrm{A}$ \\
\hline EGFP-Rab1A & Marci Scidmore (Rzomp et al., 2003) & https://www.addgene.org/49467/ \\
\hline EGFP-Rab1A(Q70L) & Marci Scidmore (Huang et al., 2010) & https://www.addgene.org/49537/ \\
\hline EGFP-Rab1A(S25N) & Marci Scidmore (Huang et al., 2010) & https://www.addgene.org/49539/ \\
\hline EGFP-Rab2 & Marci Scidmore (Huang et al., 2010) & https://www.addgene.org/49541/ \\
\hline EGFP-Rab3A & Marci Scidmore (Huang et al., 2010) & https://www.addgene.org/49542/ \\
\hline EGFP-Rab4A & Marci Scidmore (Rzomp et al., 2003) & https://www.addgene.org/49434/ \\
\hline GFP-Rab5B & Gia Voeltz (Rowland et al., 2014) & https://www.addgene.org/61802/ \\
\hline EGFP-Rab6A & Marci Scidmore (Rzomp et al., 2003) & https://www.addgene.org/49469/ \\
\hline EGFP-Rab7 & Richard Pagano (Choudhury et al., 2002) & https://www.addgene.org/12605/ \\
\hline EGFP-Rab8 & Marci Scidmore (Huang et al., 2010) & https://www.addgene.org/49543/ \\
\hline EGFP-Rab9 & Richard Pagano (Choudhury et al., 2002) & https://www.addgene.org/12663/ \\
\hline EGFP-Rab10 & Marci Scidmore (Rzomp et al., 2003) & https://www.addgene.org/49472/ \\
\hline EGFP-Rab11 & Richard Pagano (Choudhury et al., 2002) & https://www.addgene.org/12674/ \\
\hline EGFP-Rab14 & Marci Scidmore (Huang et al., 2010) & https://www.addgene.org/49549/ \\
\hline EGFP-Rab18 & Marci Scidmore (Huang et al., 2010) & https://www.addgene.org/49550/ \\
\hline EGFP-Rab30 & Marci Scidmore & https://www.addgene.org/49607/ \\
\hline Arf1-GFP & Paul Melancon (Chun et al., 2008) & https://www.addgene.org/39554/ \\
\hline pDEST47-Sar1-GFP & Richard Kahn & https://www.addgene.org/67409/ \\
\hline pcDNA5-HaloTag-3xFLAG & Kendrick et al., 2019 & N/A \\
\hline pcDNA5-HaloTag-Hook1-3xFLAG & This study & N/A \\
\hline pcDNA5-HaloTag-Hook2-3xFLAG & This study & N/A \\
\hline pcDNA5-HaloTag-Hook3-3xFLAG & Kendrick et al., 2019 & N/A \\
\hline $\mathrm{m}$ Emerald-Tubulin-6 & $\begin{array}{l}\text { Michael Davidson (Day and Davidson, } \\
\text { 2009) }\end{array}$ & \begin{tabular}{|l} 
https://www.addgene.org/54291/ \\
\end{tabular} \\
\hline pEGFP-VSVG & $\begin{array}{l}\text { Jennifer Lippincott-Schwartz (Presley et al., } \\
\text { 1997) }\end{array}$ & https://www.addgene.org/11912/ \\
\hline BiolD G2 & Kyle Roux (Kim et al., 2014) & N/A \\
\hline $\begin{array}{l}\text { pLenti_CMVRO3_FHIP1B_ } \\
\text { TagRFPT-V5 }\end{array}$ & This study & \begin{tabular}{|l|l}
$N / A$ \\
\end{tabular} \\
\hline $\begin{array}{l}\text { pLenti_CMVRO3_FHIP2A__ } \\
\text { TagRFPT-V5 }\end{array}$ & This study & $\mathrm{N} / \mathrm{A}$ \\
\hline TBC1D23-GFP & This study & N/A \\
\hline EGFP-GOLGA4 & This study & $\mathrm{N} / \mathrm{A}$ \\
\hline GMAP210-HA-GFP & This study & N/A \\
\hline BET1-GFP & This study & N/A \\
\hline SCFD1-HA-GFP & This study & N/A \\
\hline
\end{tabular}


bioRxiv preprint doi: https://doi.org/10.1101/2021.10.07.463551; this version posted October 8, 2021. The copyright holder for this preprint (which was not certified by peer review) is the author/funder, who has granted bioRxiv a license to display the preprint in perpetuity. It is made available under aCC-BY-NC-ND 4.0 International license.

Christensen, Kendrick et al., 10/06/2021

\begin{tabular}{|l|l|l|}
\hline $\begin{array}{l}\text { pSpCas9(BB)-2A-Puro (PX459) } \\
\text { V2.0 }\end{array}$ & Feng Zhang & https://www.addgene.org/62988/ \\
\hline His-Rab5B(A15-G191) & Cheryl Arrowsmith & https://www.addgene.org/25251/ \\
\hline 6xHis-SNAP-Rab5B(A2-G191) & This study & N/A \\
\hline pDyn3 & Schlager et al., 2014 & N/A \\
\hline pcDNA5-p62-HaloTag-3xFLAG & Redwine et al., 2017 & N/A \\
\hline pFastBac-Hook2-HaloTag-TEV-ZZ & This study & N/A \\
\hline pFastBac-Hook3-HaloTag-TEV-ZZ & This study & N/A \\
\hline $\begin{array}{l}\text { pBIG-ZZ-TEV-HaloTag-FHIP2A- } \\
\text { 3xFLAG-FTS }\end{array}$ & This study & N/A \\
\hline pFastBac-FHIP1B-HaloTag-TEV-ZZ & This study & N/A \\
\hline pLIB-3xFLAG-SNAP-FTS & This study & N/A \\
\hline pFastBac-ZZ-TEV-Lis1 & Baumbach et al., 2017 & https://www.addgene.org/49172/ \\
\hline pOPINE GFP-nanobody-6xHis & Brett Collins &
\end{tabular}


bioRxiv preprint doi: https://doi.org/10.1101/2021.10.07.463551; this version posted October 8, 2021. The copyright holder for this preprint (which was not certified by peer review) is the author/funder, who has granted bioRxiv a license to display the preprint in perpetuity. It is made available under aCC-BY-NC-ND 4.0 International license.

Christensen, Kendrick et al., 10/06/2021

\section{Supplemental Figures}
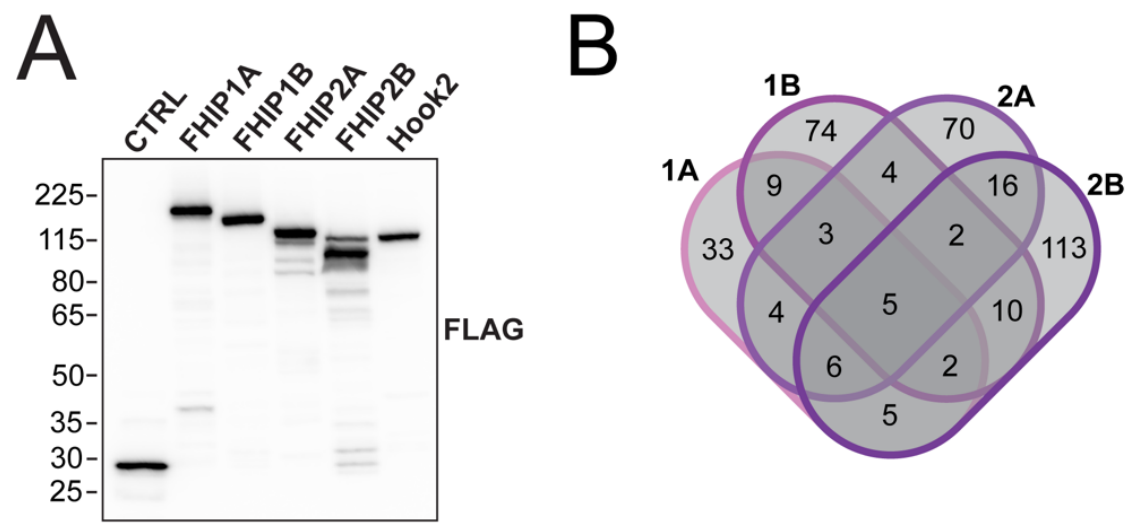

\section{$\mathrm{C}$}

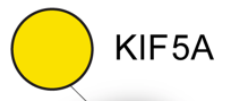

Kinesins<smiles>C1CCCCCCCCCCCC1</smiles>

KLC1

$\mathrm{KLC2}$

KLC4

$\mathrm{KINH}$

$\mathrm{KIF} 5 \mathrm{C}$
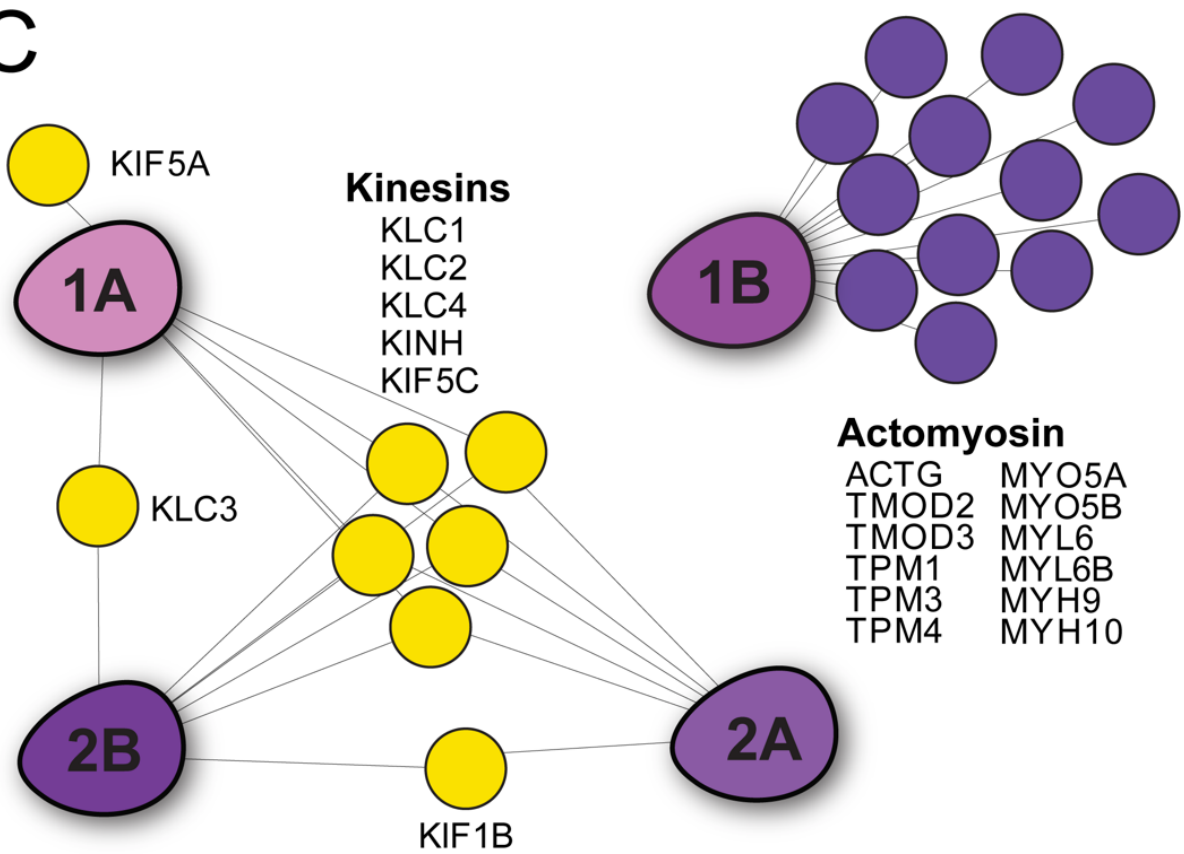

Actomyosin

ACTG MYO5A

TMOD2 MYO5B

TMOD3 MYL6

TPM1 MYL6B

TPM3 MYH9

TPM4 MYH10

Figure 1 - figure supplement 1.

(A) Human FHIP1A, FHIP1B, FHIP2A, FHIP2B, and human Hook2 tagged at the carboxy termini with 3XFLAG-BiolD2 were immunoprecipitated with FLAG affinity resin (FLAG-IP) from stable 293T cell lines. Immunoblots were probed with anti-FLAG antibody. Protein molecular weight markers are shown in kilo-Daltons to the left of the immunoblot. BiolD-3xFLAG provided a control (CTRL). (B) Venn diagram showing the overlap between all significant hits in all FHIP BiolD datasets. Significant hits displayed in the diagram showed $a \geq 3$-fold enrichment over cytoplasmic BiolD control, significance of $p<0.05$ by Student's two-tailed t-test, and presence in 3 out of 4 technical replicates. (C) Interaction diagram for FHIP carboxy-terminal BioID2 datasets. Oblong purple shapes represent FHIP1A ('1A'), FHIP1B ('1B'), FHIP2A ('2A'), and FHIP2B ('2B') datasets. Significant kinesin or actomyosin hits present in a FHIP BiolD dataset (based on gene ontology analysis) are indicated by colored circles connected by lines. Significant hits displayed in diagram showed $a \geq 3$-fold enrichment over cytoplasmic BiolD control, significance of $p<0.05$ by Student's two-tailed t-test, and presence in 3 out of 4 technical replicates. 
bioRxiv preprint doi: https://doi.org/10.1101/2021.10.07.463551; this version posted October 8, 2021. The copyright holder for this preprint (which was not certified by peer review) is the author/funder, who has granted bioRxiv a license to display the preprint in perpetuity. It is made available under aCC-BY-NC-ND 4.0 International license.

Christensen, Kendrick et al., 10/06/2021

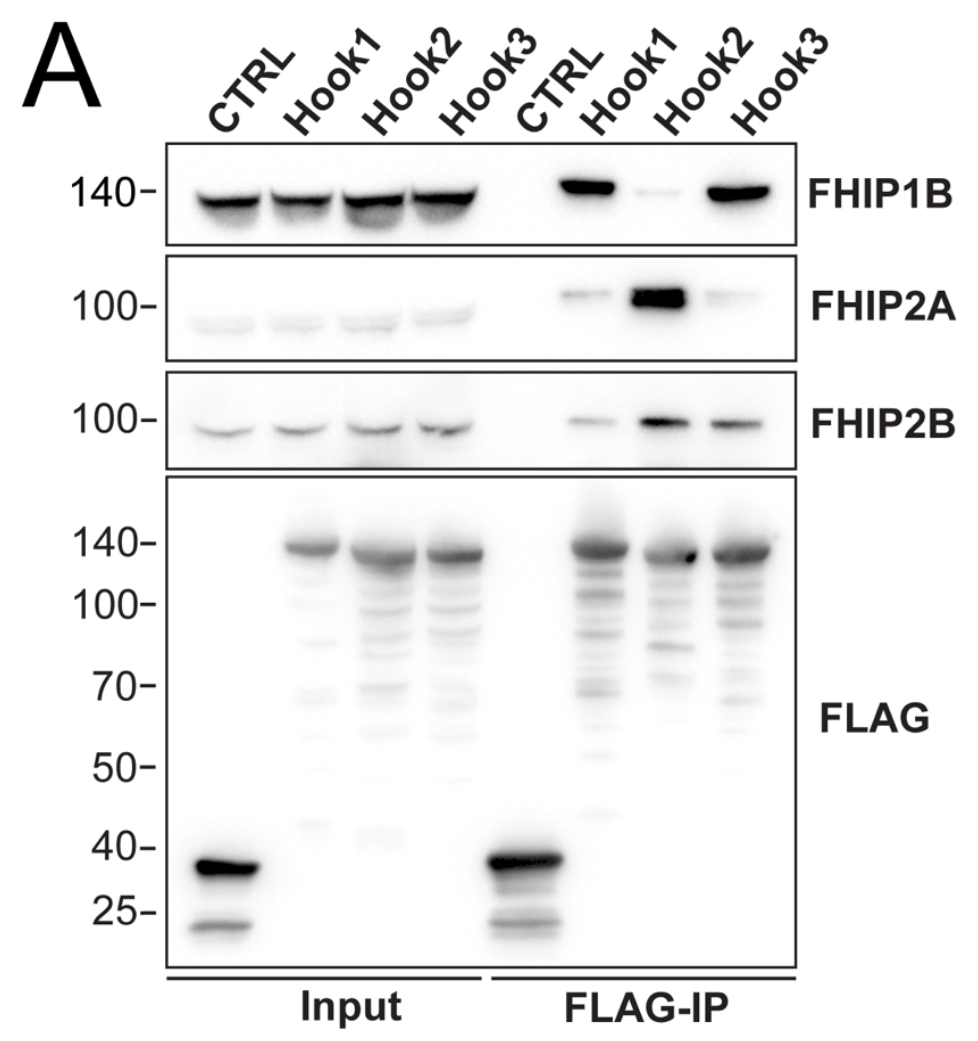

Figure 2 - figure supplement 1.

(A) Human Hook1, Hook2, and Hook3 tagged at the amino termini with HaloTag and the carboxy termini with 3xFLAG were immunoprecipitated with FLAG affinity resin (FLAG-IP) from 293T cell lines transiently transfected with these constructs. Immunoblots were probed with anti-FHIP1B, anti-FHIP2A, anti-FHIP2B, and anti-FLAG antibodies. Protein molecular weight markers are shown in kilo-Daltons to the left of each immunoblot. sfGFP-3xFLAG provided a control (CTRL). 
bioRxiv preprint doi: https://doi.org/10.1101/2021.10.07.463551; this version posted October 8, 2021. The copyright holder for this preprint (which was not certified by peer review) is the author/funder, who has granted bioRxiv a license to display the preprint in perpetuity. It is made available under aCC-BY-NC-ND 4.0 International license.

Christensen, Kendrick et al., 10/06/2021
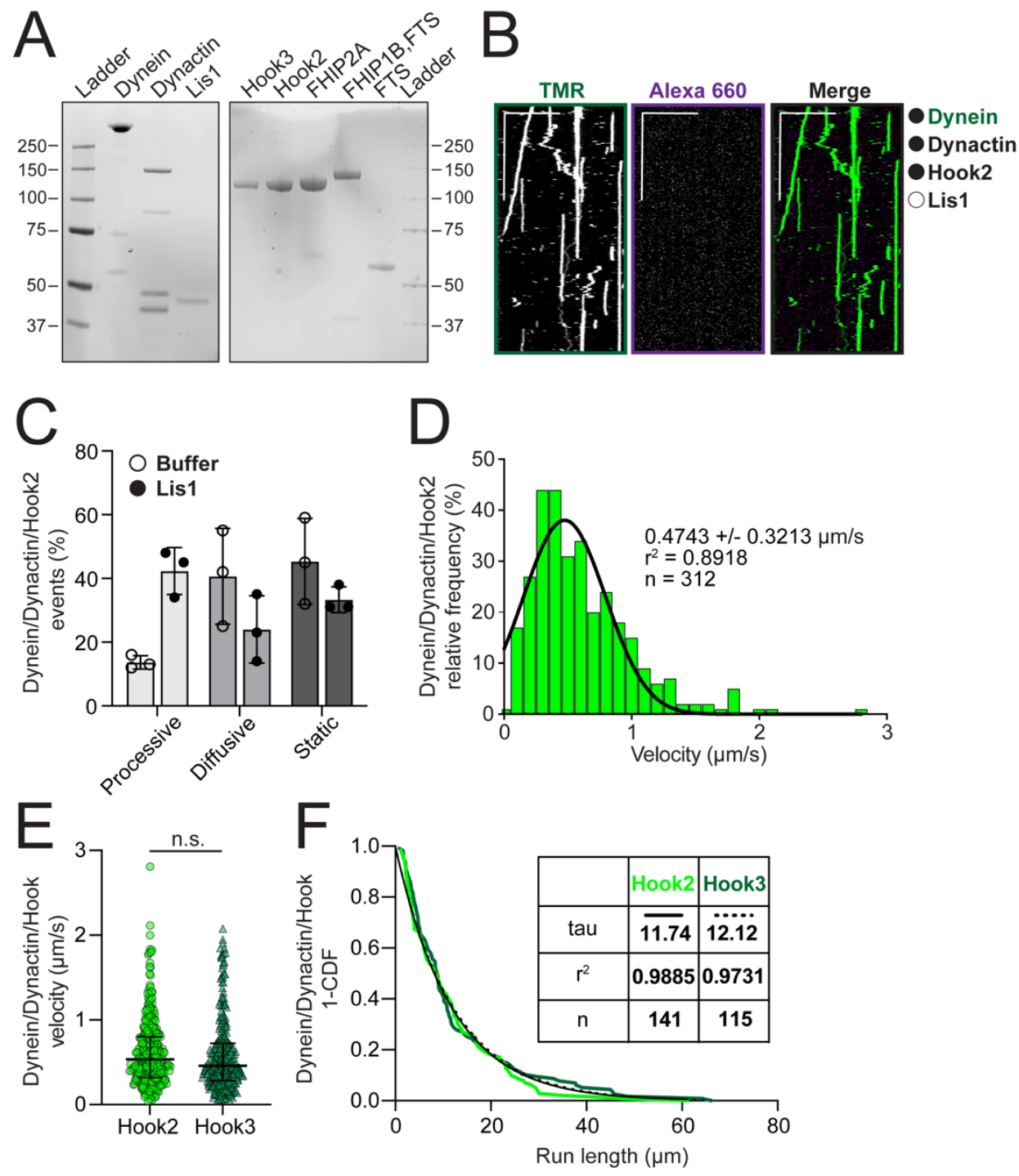

Figure 3 - figure supplement 1.

(A) SDS-PAGE of purified proteins used for motility assays. (B) Representative kymographs from single-molecule motility assays with purified (black circles) TMR-labeled dynein (green), unlabeled dynactin and unlabeled full-length Hook2 in the absence of Lis1 (white circle). Scale bars, $10 \mu \mathrm{m}(\mathrm{x})$ and $40 \mathrm{~s}(\mathrm{y})$. (C) Comparison of percent processive, diffusive and static events \pm SEM from singlemolecule TMR-dynein/dynactin/Hook2 performed in the absence (white circle, $n=18$ ) or presence (black circle, $n=36$ ) of Lis1. (D) A histogram of dynein/dynactin/Hook2 velocity fit to a Gaussian (black line, $0.4743 \pm 0.3213 \mu \mathrm{m} / \mathrm{s}$, mean $\pm S D, r^{2}=0.8918, n=312$ ). (E) Single-molecule velocity (median \pm interquartile range) of TMR-dynein/dynactin activated by full-length unlabeled Hook2 (light green circles, $0.4743 \pm 0.3213 \mu \mathrm{m} / \mathrm{s}$, mean $\pm \mathrm{SD}, \mathrm{n}=312$ ) or Hook3 (dark green triangles, $0.3901 \pm 0.2525 \mu \mathrm{m} / \mathrm{s}, \mathrm{mean} \pm \mathrm{SD}, \mathrm{n}=$ 283 ) in the presence of Lis1. n.s., no significance, $P=0.2854$, t-test with Welch's correction. $(F)$ Run length analysis of dynein/dynactin activated by full-length unlabeled Hook2 (light green, $n=141$ ) or Hook3 (dark green, $n=115$ ) in the presence of Lis1. The 1-cumulative frequency distribution (1-CDF) was fit to a one phase exponential decay (black line - Hook2, dotted black line - Hook3). The representative mean decay constants (tau) are listed in the table. 
bioRxiv preprint doi: https://doi.org/10.1101/2021.10.07.463551; this version posted October 8, 2021. The copyright holder for this preprint (which was not certified by peer review) is the author/funder, who has granted bioRxiv a license to display the preprint in perpetuity. It is made available under aCC-BY-NC-ND 4.0 International license.

Christensen, Kendrick et al., 10/06/2021
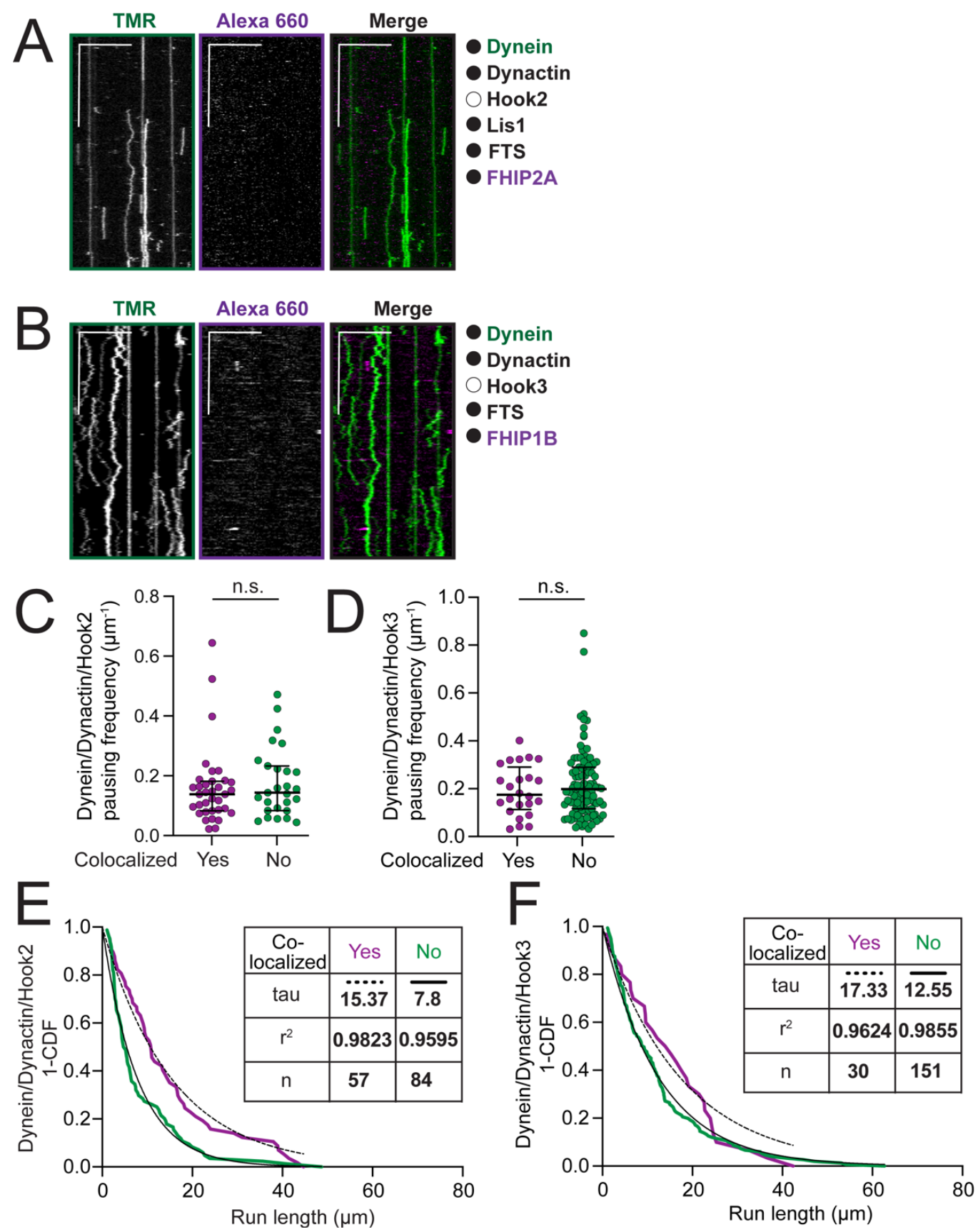

Figure 3 - figure supplement 2.

(A) Representative kymographs from single-molecule motility assays with purified (black circle) TMR-dynein (green), unlabeled dynactin, unlabeled Lis1, unlabeled FTS and FHIP2A-Alexa-660 (magenta) in the absence (white circle) of Hook2. Scale bars, $10 \mu \mathrm{m}$ $(\mathrm{x})$ and $40 \mathrm{~s}(\mathrm{y})$. (B) Representative kymographs from single-molecule motility assays with purified (black circle) TMR-dynein (green), unlabeled dynactin, unlabeled FTS and FHIP1B-Alexa 660 (magenta) in the absence (white circle) of Hook3. Scale bars, $10 \mu \mathrm{m}$ (x) and $40 \mathrm{~s}(\mathrm{y})$. (C) Pausing frequency of motile events (median \pm interquartile range) from TMR-dynein/dynactin/Hook2 experiments performed in the absence (white circle, $\mathrm{n}=71$ ) or in the presence of FHIP2A-Alexa 660 and FTS (black circle, $n=62$ ). $n . S$., no significance, $P=0.4872$, Mann-Whitney test. (D) Pausing frequency analysis of TMR-dynein/dynactin/Hook3 runs in the presence of FHIP1B-Alexa-660 and FTS, either colocalized with FHIP1B-Alexa-660 (yes, $n=24$ ) or not (no, $n=103$ ). n.s., no significance, $p=$ 0.3947, Mann-Whitney test. (E) Run length analysis of TMR-dynein/dynactin/Hook2 runs in the presence of FHIP2A-Alexa-660 and FTS, either colocalized with FHIP2A-Alexa-660 (yes - magenta) or not (no - green). The 1-cumulative frequency distributions (1CDF) were fit to a one phase exponential decay. The representative mean decay constants (tau) are listed in the table. $P=0.003$, Kolmogorov-Smirnov test. (F) Run length analysis of TMR-dynein/dynactin/Hook3 runs in the presence of FHIP1B-Alexa-660 and FTS, either colocalized with FHIP1B-Alexa-660 (yes - magenta) or not (no - green). The 1-cumulative frequency distributions (1- 
bioRxiv preprint doi: https://doi.org/10.1101/2021.10.07.463551; this version posted October 8, 2021. The copyright holder for this preprint (which was not certified by peer review) is the author/funder, who has granted bioRxiv a license to display the preprint in perpetuity. It is made available under aCC-BY-NC-ND 4.0 International license.

Christensen, Kendrick et al., 10/06/2021

CDF) were fit to a one phase exponential decay. The representative mean decay constants (tau) are listed in the table. $\mathrm{P}=0.0768$, Kolmogorov-Smirnov test.
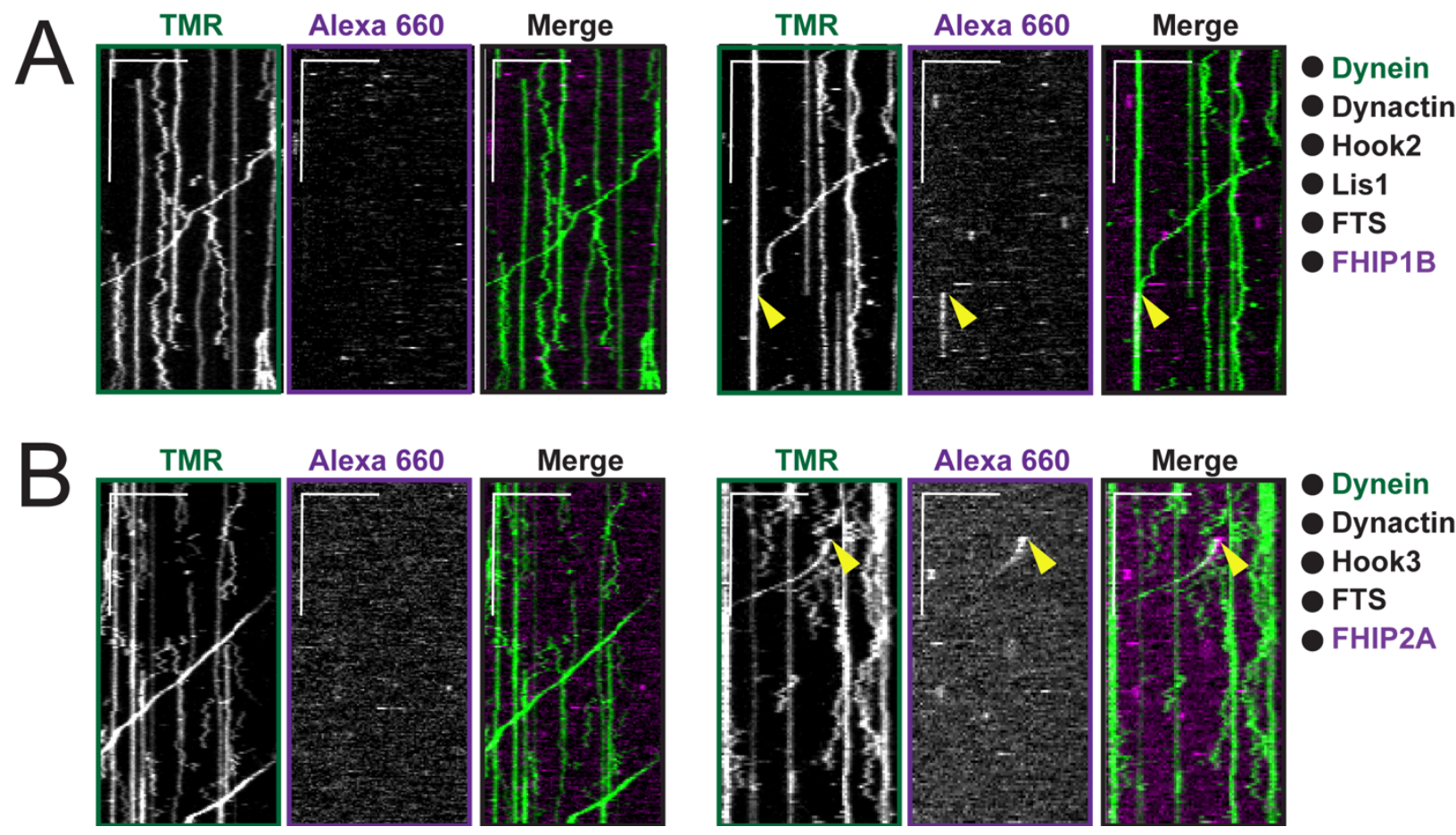

Figure 3 - figure supplement 3.

(A) Representative kymographs from single-molecule motility assays with purified (black circles) TMR-dynein (green), unlabeled dynactin, unlabeled full-length Hook2, unlabeled Lis1, unlabeled FTS and FHIP1B-Alexa-660. Two examples are shown. A two-color colocalized static event is marked with yellow arrows on each single-channel image and in the merge. Scale bars, $10 \mu \mathrm{m}(\mathrm{x})$ and 40 s (y). (B) Representative kymographs from single-molecule motility assays with purified (black circles) TMR-dynein (green), unlabeled dynactin, unlabeled full-length Hook3, unlabeled FTS and FHIP2A-Alexa-660. Two examples are shown. A two-color colocalized run is marked with yellow arrows on each single-channel image and in the merge. Scale bars, $10 \mu \mathrm{m} \mathrm{(x)}$ and $40 \mathrm{~s}(\mathrm{y})$. 

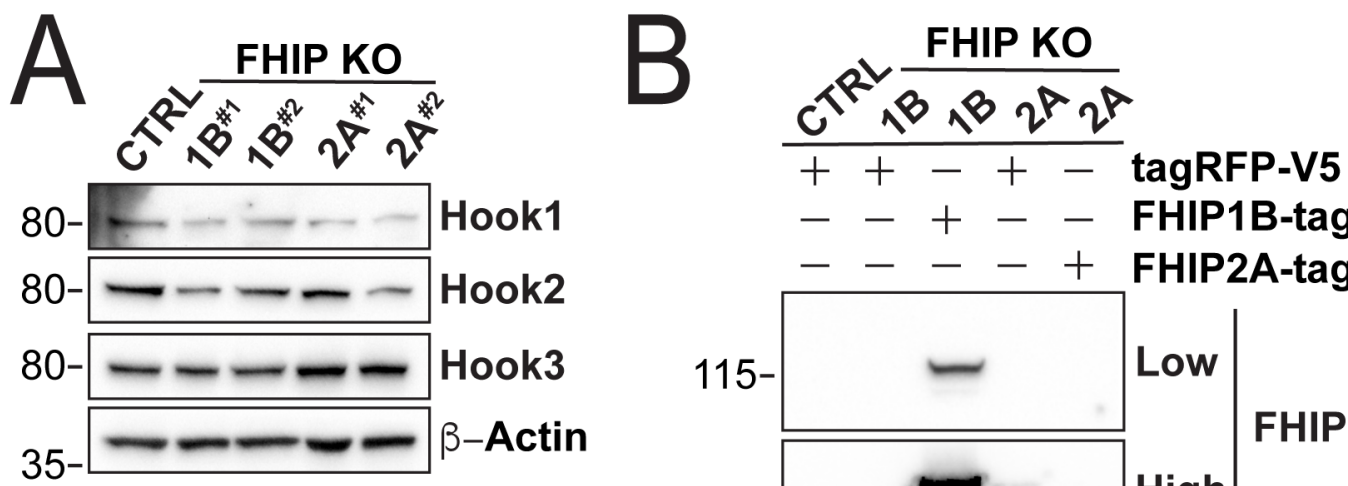$$
--+-- \text { FHIP1B-tagRFP-V5 }
$$
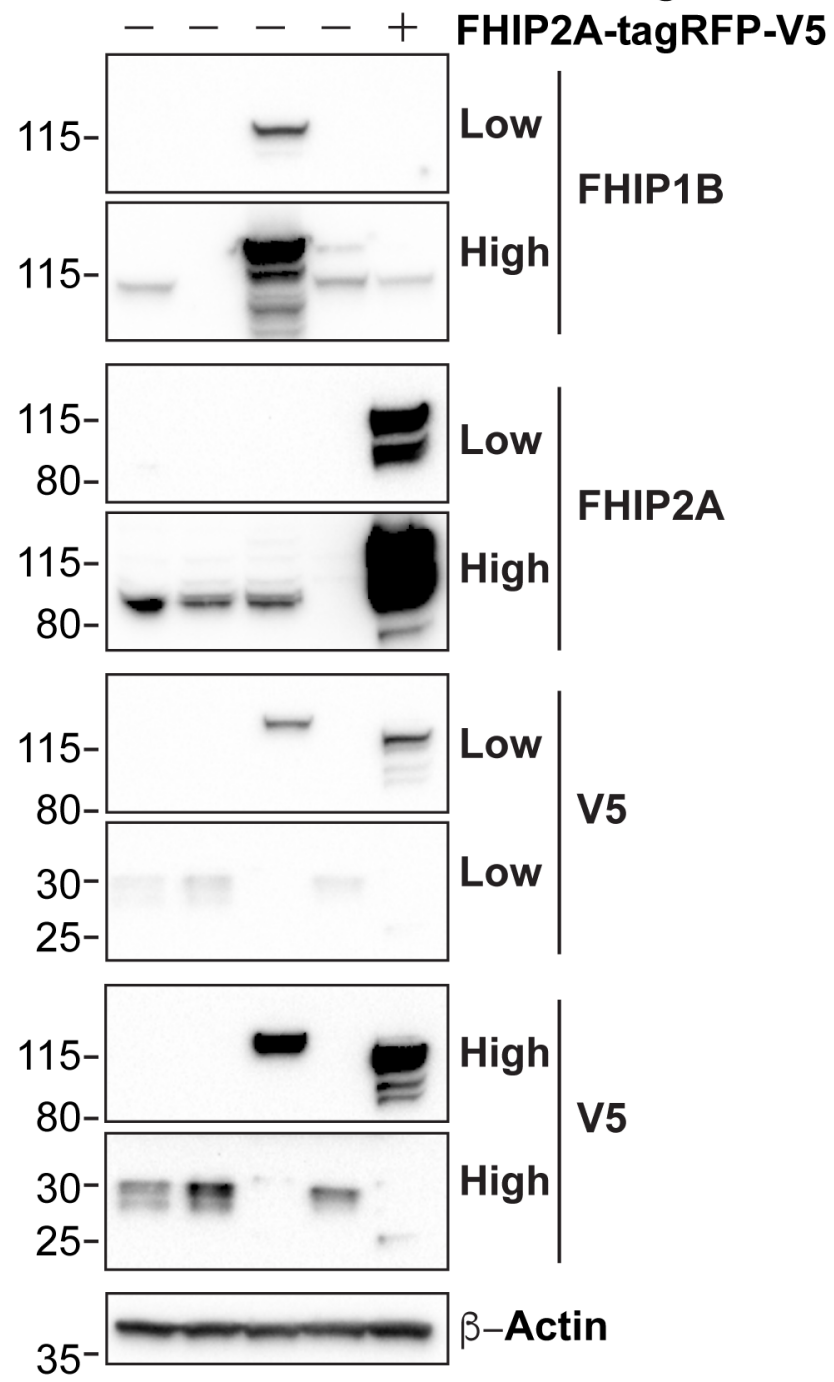

Figure 4 - figure supplement 1.

(A) Whole cell lysates from stable U2OS FHIP1B, FHIP2A knockout cells and Cas9 control cells (CTRL) immunoblotted with antiHook1, anti-Hook2, anti-Hook3, and $\beta$-actin antibodies. $\beta$-actin provided a loading control. Protein molecular weight markers are shown in kilo-Daltons to the left of each immunoblot. (B) Stable U2OS Cas9 control (CTRL) and FHIP1B and FHIP2A knockout (KO) cell lines transfected with the indicated plasmids. Immunoblots were probed with anti-FHIP1B, anti-FHIP2A, anti-V5 and anti- $\beta$-actin antibodies. High and low exposures are shown. $\beta$-actin provided a loading control. Protein molecular weight markers are shown in kilo-Daltons to the left of each immunoblot. 
bioRxiv preprint doi: https://doi.org/10.1101/2021.10.07.463551; this version posted October 8, 2021. The copyright holder for this preprint (which was not certified by peer review) is the author/funder, who has granted bioRxiv a license to display the preprint in perpetuity. It is made available under aCC-BY-NC-ND 4.0 International license.

Christensen, Kendrick et al., 10/06/2021
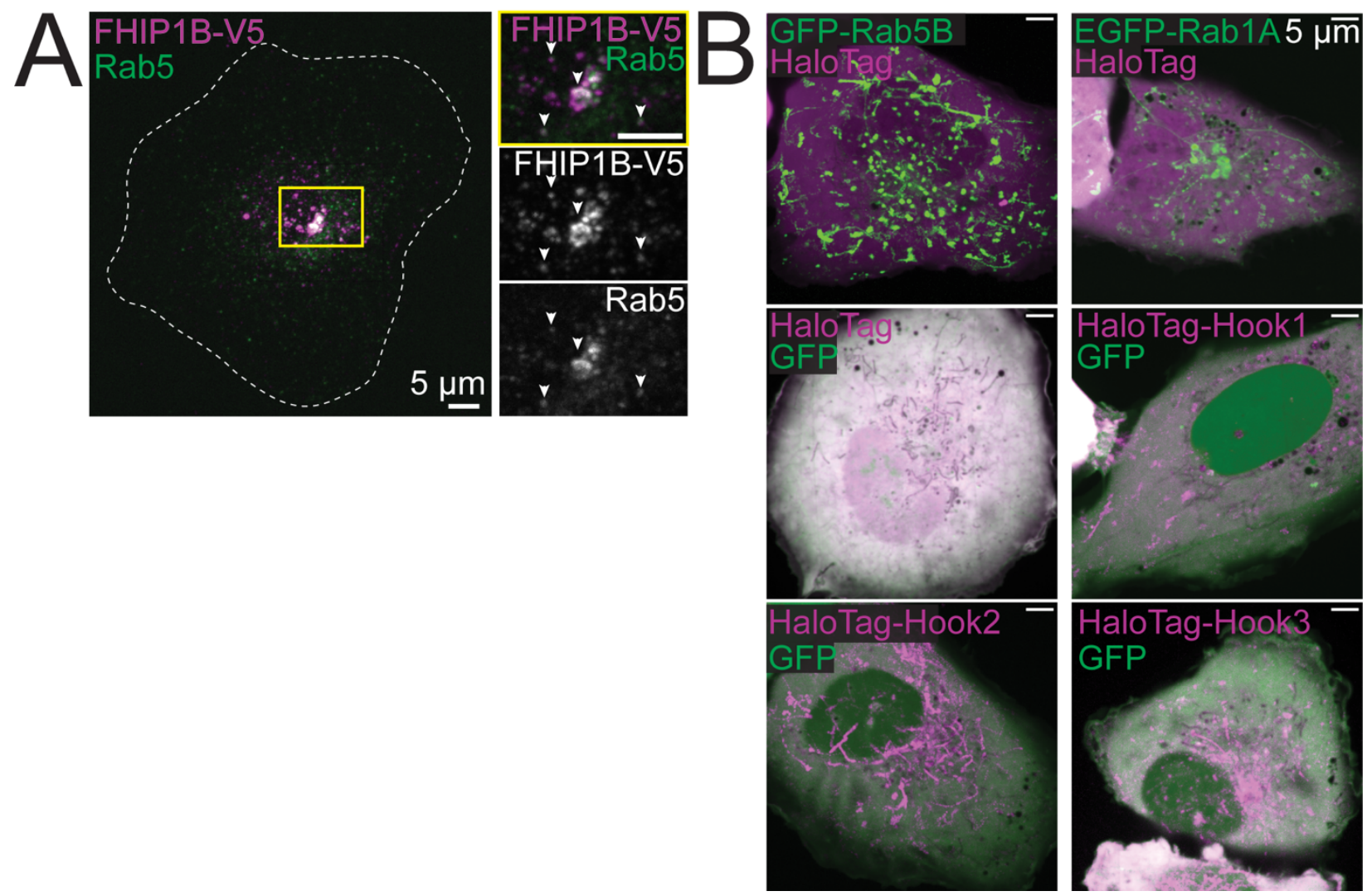

Figure 5 - figure supplement 1.

(A) Z-projection of FHIP1B KO cells expressing FHIP1B-TagRFP-T-V5 and stained with V5 and Rab5-specific antibodies. Yellow rectangle denotes cropped region. (B) Single-plane time-lapse projections of U2OS cells expressing EGFP-Rab5B or EGFP-Rab1A and HaloTag-3XFLAG (control) tagged with Janelia Fluor (JF) 646 (top), or U2OS cells expressing cytoplasmic GFP and HaloTag3XFLAG, HaloTag(JF646)-Hook1, HaloTag(JF646)-Hook2, or HaloTag(JF646)-Hook3. 
bioRxiv preprint doi: https://doi.org/10.1101/2021.10.07.463551; this version posted October 8, 2021. The copyright holder for this preprint (which was not certified by peer review) is the author/funder, who has granted bioRxiv a license to display the preprint in perpetuity. It is made available under aCC-BY-NC-ND 4.0 International license.

Christensen, Kendrick et al., 10/06/2021

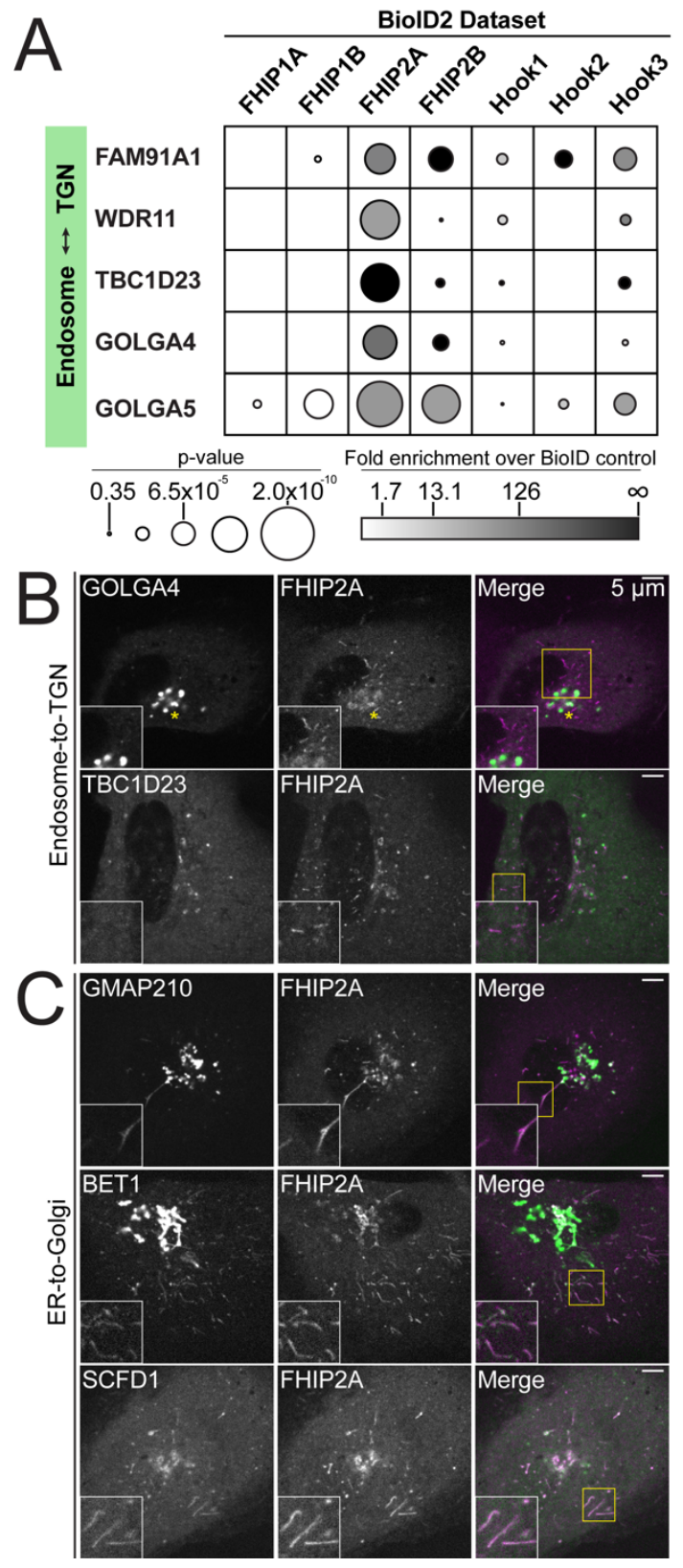

Figure 6 - figure supplement 1.

(A) Fold-enrichment over cytoplasmic BiolD2 control (grayscale intensity) and p-value (circle size) for selected known endosome-totrans-Golgi-network (TGN) transport-associated proteins identified in the indicated carboxy-terminal FHIP BioID2 datasets. (B) Single plane confocal micrographs of FHIP2A KO U2OS cells expressing FHIP2A-TagRFP-T-V5 (FHIP2A) and TBC1D23-GFP or EGFPGOLGA4, two proteins important for endosome-to-Golgi transport identified in FHIP2A BiolD dataset. Yellow rectangle denotes region of cropped inset shown. (C) Single-plane time-lapse projections of FHIP2A KO U2OS cells expressing FHIP2A-TagRFP-T-V5 (FHIP2A) and GFP-GMAP210, GFP-BET1, or GFP-SCFD1, proteins important for ER-to-Golgi transport identified in FHIP2A BiolD dataset. Yellow rectangle denotes region of cropped inset shown. 
bioRxiv preprint doi: https://doi.org/10.1101/2021.10.07.463551; this version posted October 8, 2021. The copyright holder for this preprint (which was not certified by peer review) is the author/funder, who has granted bioRxiv a license to display the preprint in perpetuity. It is made available under aCC-BY-NC-ND 4.0 International license.

Christensen, Kendrick et al., 10/06/2021

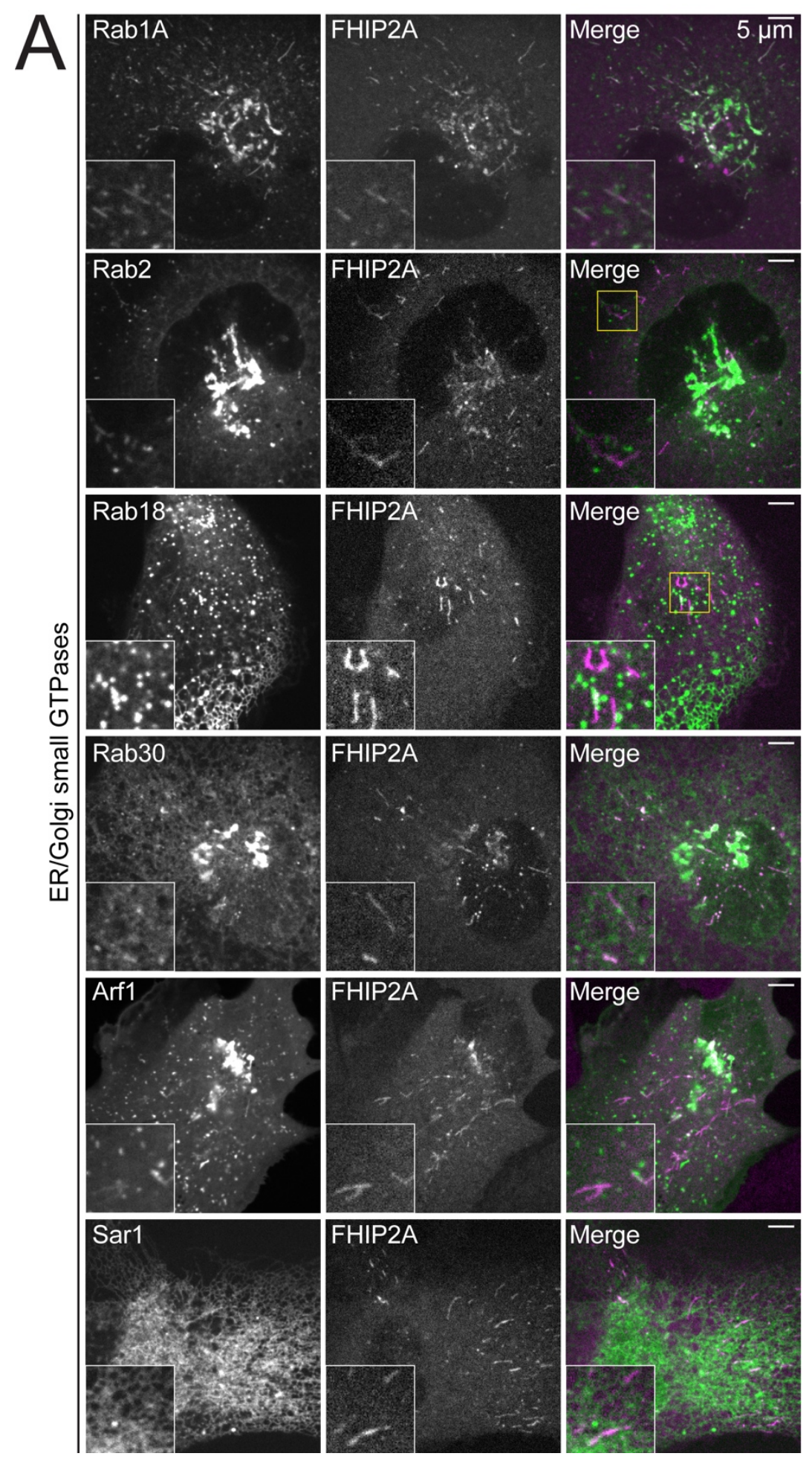

Figure 6 - figure supplement 2.

(A) Single-plane confocal micrographs of FHIP2A KO U2OS cells expressing FHIP2A-TagRFP-T-V5 (FHIP2A) and EGFP-Rab1A, EGFP-Rab2, EGFP-Rab18, GFP-Rab30, Sar1-GFP, or Arf1-GFP, known or putative small GTPases associated with the ER or Golgi. Yellow rectangle denotes region of cropped inset shown. 
bioRxiv preprint doi: https://doi.org/10.1101/2021.10.07.463551; this version posted October 8, 2021. The copyright holder for this preprint (which was not certified by peer review) is the author/funder, who has granted bioRxiv a license to display the preprint in perpetuity. It is made available under aCC-BY-NC-ND 4.0 International license.

Christensen, Kendrick et al., 10/06/2021
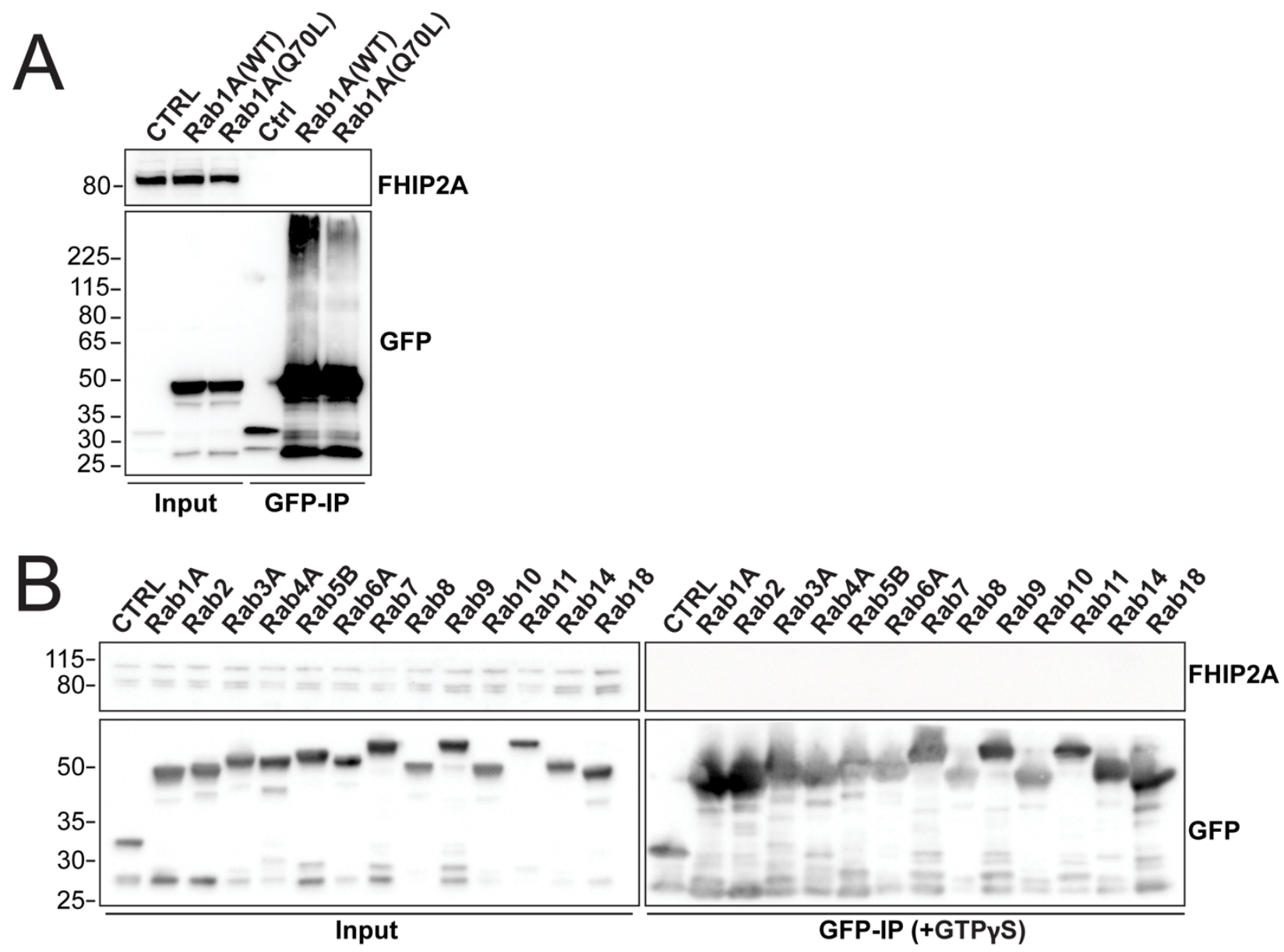

Figure 6 - figure supplement 3.

(A) Human Rab1A proteins (wild type - WT or GTP-locked mutant Q80L) tagged at the amino termini with EGFP were transiently expressed in 293T cells and immunoprecipitated with GFP nanobody affinity resin (GFP-IP). Immunoblots were probed with antiFHIP2A and anti-GFP antibodies. Protein molecular weight markers are shown in kilo-Daltons to the left of each immunoblot. 3xHAsfGFP provided a control (CTRL). (B) Indicated human Rab proteins tagged at the amino termini with EGFP were transiently expressed in 293T cells and immunoprecipitated with GFP nanobody affinity resin (GFP-IP) in the presence of GTPyS. Immunoblots were probed with anti-FHIP2A and anti-GFP antibodies. Protein molecular weight markers are shown in kilo-Daltons to the left of each immunoblot. 3xHA-sfGFP provided a control (CTRL). 
bioRxiv preprint doi: https://doi.org/10.1101/2021.10.07.463551; this version posted October 8, 2021. The copyright holder for this preprint (which was not certified by peer review) is the author/funder, who has granted bioRxiv a license to display the preprint in perpetuity. It is made available under aCC-BY-NC-ND 4.0 International license.

Christensen, Kendrick et al., 10/06/2021

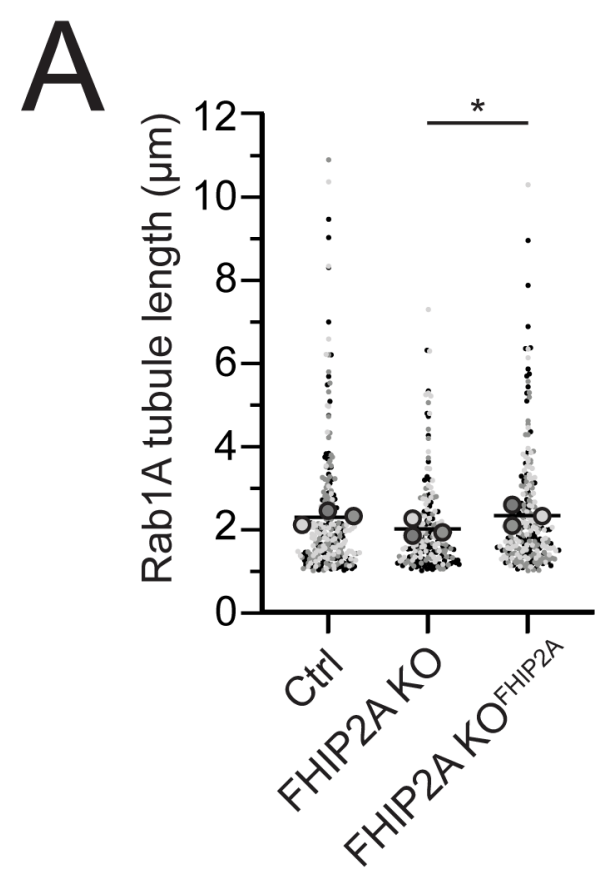

Figure 7 - figure supplement 1.

(A) Quantification of tubule length of motile Rab1A tubules in Cas9 control cells expressing cytoplasmic TagRFP-T (Ctrl), FHIP2A KO cells expressing cytoplasmic TagRFP-T (FHIP2A KO), or FHIP2A KO cells expressing FHIP2A-TagRFP-T-V5 (FHIP2A KOFHIP2A). Line denotes mean. Bolded circles denote means for each biological replicate. Differently shaded circles correspond to individual datapoints for cells from different biological replicates. $\mathrm{N}=55 \mathrm{Cas} 9$ control cells (258 motile tubules), 59 FHIP2A KO cells (219 motile tubules), and 54 FHIP2A KOFHIP2A cells (251 motile tubules) from 3 biological replicates. ${ }^{*} P=0.02$, Kruskal-Wallis with Dunn's post hoc test for multiple comparisons. 
bioRxiv preprint doi: https://doi.org/10.1101/2021.10.07.463551; this version posted October 8, 2021. The copyright holder for this preprint (which was not certified by peer review) is the author/funder, who has granted bioRxiv a license to display the preprint in perpetuity. It is made available under aCC-BY-NC-ND 4.0 International license.

Christensen, Kendrick et al., 10/06/2021

\section{Video legends}

Video 1. FHIP1B and FHIP2A localize to motile cargos with different morphologies.

Live-cell spinning-disk confocal microscopy of FHIP1B KO U2OS cells expressing FHIP1B-TagRFP-T-V5 (FHIP1B) or FHIP2A KO U2OS cells expressing FHIP2A-TagRFP-T-V5 (FHIP2A). Dotted lines denote cell outline.

Video 2. FHIP1B and FHIP2A move along microtubules.

Live-cell sequential acquisition spinning-disk confocal microscopy of FHIP1B KO U2OS cells expressing FHIP1B-TagRFP-T-V5 (FHIP1B-RFP, magenta) and mEmerald-Tubulin (green) or FHIP2A KO U2OS cells expressing FHIP2A-TagRFP-T-V5 (FHIP2A-RFP, magenta) and mEmerald-Tubulin (green).

Video 3. FHIP1B colocalizes with early endosomes.

Live-cell simultaneous acquisition spinning-disk confocal microscopy of FHIP1B KO U2OS cells expressing FHIP1B-TagRFP-T-V5 (FHIP1B, left panel, magenta in merge) and GFP-Rab5B (Rab5B, middle panel, green in merge).

Video 4. Hook1 colocalizes with Rab5B early endosomes.

Live-cell triggered acquisition spinning-disk confocal microscopy of U2OS cells expressing GFP-Rab5B (Rab5B, left panel, green in merge) and HaloTag-Hook1(JF646) (Hook1, middle panel, magenta in merge).

Video 5. Hook2 does not colocalize with Rab5B early endosomes.

Live-cell triggered acquisition spinning-disk confocal microscopy of U2OS cells expressing GFP-Rab5B (Rab5B, left panel, green in merge) and HaloTag-Hook2(JF646) (Hook2, middle panel, magenta in merge).

Video 6. Hook3 colocalizes with Rab5B early endosomes.

Live-cell triggered acquisition spinning-disk confocal microscopy of U2OS cells expressing GFP-Rab5B (Rab5B, left panel, green in merge) and HaloTag-Hook3(JF646) (Hook3, middle panel, magenta in merge).

Video 7. FHIP2A colocalizes with a subset of VSV-G cargo.

Live-cell sequential acquisition spinning-disk confocal microscopy of FHIP2A KO U2OS cell expressing FHIP2A-TagRFP-T-V5 (FHIP2A) and temperature-sensitive EGFP-VSV-G (VSV-G) following temperature shift from $40^{\circ} \mathrm{C}$ to $32^{\circ} \mathrm{C}$. In each of the two crops on righthand side, the top panel shows the VSV-G channel, the middle panel shows the FHIP2A channel, and the bottom panel shows the merge. The yellow rectangle and top crop series denote an EGFP-VSV-G tubule moving from the ER to the Golgi. The white rectangle and bottom crop series denote an EGFP-VSV-G tubule moving from the Golgi to the plasma membrane.

Video 8. Hook1 does not colocalize with Rab1A tubules.

Live-cell triggered acquisition spinning-disk confocal microscopy of U2OS cells expressing EGFP-Rab1A (Rab1A, left panel, green in merge) and HaloTag-Hook1(JF646) (Hook1, middle panel, magenta in merge).

Video 9. Hook2 colocalizes with Rab1A tubules.

Live-cell triggered acquisition spinning-disk confocal microscopy of U2OS cells expressing EGFP-Rab1A (Rab1A, left panel, green in merge) and HaloTag-Hook2(JF646) (Hook2, middle panel, magenta in merge).

Video 10. Hook3 partially colocalizes with Rab1A tubules.

Live-cell triggered acquisition spinning-disk confocal microscopy of U2OS cells expressing EGFP-Rab1A (Rab1A, left panel, green in merge) and HaloTag-Hook3(JF646) (Hook3, middle panel, magenta in merge).

Video 11. FHIP2A has a functional relationship with Rab1A.

Live-cell triggered acquisition spinning-disk confocal microscopy of FHIP2A KO U2OS cells expressing FHIP2A-TagRFP-T-V5 (FHIP2A-TagRFPT, middle panels, magenta in merge) and EGFP-Rab1A (WT) (top), EGFP-Rab1A (Q70L) (middle), or EGFP-Rab1A (S25N) (bottom, left panels, green in merge).

Video 12. FHIP2A affects Rab1A tubule motility.

Live-cell spinning-disk confocal microscopy of EGFP-Rab1A(WT) in Cas9 control cells expressing cytoplasmic TagRFP-T (EGFPRab1A, Cas9 ctrl, left), FHIP2A KO cells expressing cytoplasmic TagRFP-T (EGFP-Rab1A, FHIP2A KO, middle), or FHIP2A KO cells expressing FHIP2A-TagRFP-T-V5 (EGFP-Rab1A, FHIP2A KOFIP2A, right). TagRFP-T channels not shown.

\section{Additional Supplementary Files}

Supplementary File 1. BiolD2 mass spectrometry datasets.

All BiolD2 mass spectrometry data referenced in the manuscript in Figure 1C, Figure 1 - figure supplement 1B-C, Figure 2A, Figure $5 \mathrm{~A}$, Figure $6 \mathrm{~A}$, and Figure 6 - figure supplement 1A. The first five tabs correspond to the FHIP1A, FHIP1B, FHIP2A, FHIP2B, and Hook2 carboxy-terminal BiolD2 datasets from this study. The sixth and seventh tabs are the Hook1 and Hook3 carboxy-terminal datasets from Redwine et al., 2017 for comparison.

Supplementary File 2. Gene ontology (GO) analysis for FHIP BiolD2 datasets.

The results of gene ontology searches using GOrilla (Eden et al. 2009, 2007). Enriched GO terms were identified by using the Homo sapiens database and by comparing two unranked lists of genes, using any significant hits in each dataset as the "Target set" and any non-significant hits in the same dataset as the "Background set" and searching for GO terms for process, function, and component. Standard search parameters ( $p$-value threshold of $10^{-3}$ ) were used. Each tab corresponds to the component, function, or process search results for one FHIP carboxy-terminal dataset. 